\title{
Beyond solvents and electrolytes: ionic liquids- based advanced functional materials
}

Shiguo Zhang, , ,a,b Qinghua Zhang, ${ }^{\mathrm{a}}$ Yan Zhang, ${ }^{\mathrm{a}}$ Zhengjian Chen, ${ }^{\mathrm{a}, \mathrm{b}}$ Masayoshi

Watanabe*, $^{*, \mathrm{~b}}$ and Youquan Deng*,a

${ }^{a}$ Center for Green Chemistry and Catalysis, State Key Laboratory of Solid

Lubrication, Lanzhou Institute of Chemical Physics, Chinese Academy of Sciences,

No.18, Tianshui Middle Road, 730000, Lanzhou, China

E-mail: sgzhang1981@,gmail.com; ydeng@licp.cas.cn

${ }^{\mathrm{b}}$ Department of Chemistry and Biotechnology, Yokohama National University, 79-5

Tokiwadai, Hodogaya-ku, Yokohama 240-8501, Japan

E-mail: $\underline{\text { mwatanab@ynu.ac.jp }}$ 
Abstract: Instead of being seen as alternative solvents and electrolytes for organic reactions, catalysis, separation, electrochemistry, and so on, ionic liquids (ILs) consisting of discrete cations and anions have recently emerged as versatile building blocks for advanced functional materials. A number of functional ILs and IL-containing composite materials have been realized by either chemical modification (covalent functionalization or ion-exchange metathesis) or physical integration of ILs and traditional materials. The unique structure and behavior of ILs as a platform not only provides additional opportunities to adjust the physicochemical properties of these ionic materials for task-specific applications, but also offers other attractive features such as intrinsic ionic conductivity and high thermal, chemical, and electrochemical stability. These soft materials combine the favorable features of ILs and the original chemistries of the functional groups or materials; some even possess unexpected functions resulting from synergetic interaction between these two components. Materialization of ILs is truly a novel, promising research direction for both IL chemistry and materials science. In this article, we review recent advances in IL-based functional materials, focusing on smart and sensitive materials, optical materials, energetic materials, and IL/carbon hybrid materials.

Keywords: Ionic liquids; functional materials; sensitive; optical; energetic; hybrid materials 


\section{Contents}

1. Introduction

2. Smart (responsive) and sensitive materials

2.1. Photoresponsive materials

2.2. $\mathrm{pH}-\mathrm{Responsive} \mathrm{materials}$

2.3. Temperature-Sensitive materials

2.4. Gas sensing materials

2.5. Ion-responsive materials

2.6. Moisture-sensitive materials

2.7. Magnetic-responsive materials

2.8. Electrochromic materials

2.9. Ionic liquids with switchable polarity

3. Optical Materials

3.1. Luminescent Materials

3.1.1. Intrinsic fluorescence of common ionic liquids

3.1.2. Luminescent ionic liquids

3.1.3. Luminescent ionic liquid crystals

3.1.4. Ionic liquids composite/hybrid luminescent materials 
3.2. Nonlinear optical materials

3.3. Photonic ionic liquids

3.4. Ionic liquids-based structural colour materials

4. Energetic materials

4.1. Energetic ionic liquids

4.2. Hydrogen-storage materials

5. Ionic Liquids/Carbon Hybrid Materials

5.1. Non-covalent grafting of ionic liquids on carbon nanoforms

5.2. Covalent grafting of ionic liquids on carbon nanoforms

6. Conclusions 


\section{Introduction}

Ionic liquids (ILs) have been a source of fascination for scientists and engineers for many decades. Since the discovery of air- and water-stable ILs by Wilkes in 1992,[1] research and development (R\&D) of ILs has attracted overwhelming interest, and the number of publications concerning ILs has increased substantially. Owing to their peculiar and tunable properties compared to molecular compounds, including a wide liquid range, high ionic conductivity, negligible vapor pressure, and high electrochemical and thermal stability, as well as a significant ability to solubilize organic, inorganic, and polymeric materials, ILs have caused a green revolution in chemistry, physics, and materials science in the past two decades, in terms of both conceptual innovation and technological breakthroughs. In particular, ILs have been intensively studied (1) as alternative green, designable solvents and media to replace traditional volatile organic solvents for a host of processes linked to green chemistry and clean technology such as organic reactions, catalysis, extraction, and separation, and (2) as safe electrolytes for electrochemistry and a number of energy-related applications, especially in batteries, fuel cells, supercapacitors, and dye-sensitized solar cells. Many and reviews focused on these topics are available (see selected references[2-8]).

Actually, replacing traditional solvents or electrolytes is only one part of the story of ILs. In a new trend, ILs are now evolving from solvents and electrolytes to novel functional media, fluids, and materials.[9-13] In particular, the conjunction between ILs and materials has greatly expanded the use of ILs in 
various areas related to materials science (Figure 1). In these applications, ILs are always discussed as versatile and high-potential building blocks for novel advanced functional materials. The resulting materials are expected to offer many advantages over traditional molecular materials. (1) Through chemical functionalization or ion-exchange metathesis of the ionic constituents, specific functional groups can be easily incorporated into the IL skeleton to form new ionic materials. (2) These functional materials not only retain the key features of the original materials but also possess the characteristics of ILs. It is thought that the ionic nature of ILs, which the molecular materials lack, can provide these materials with intrinsic ion conductivity as well as a substantial ionic scaffold for producing advanced materials. (3) The virtually unmeasurable vapor pressure, combined with a wide temperature window for the liquid phase and excellent thermal, mechanical, chemical, and electrochemical stability, enable operation of IL-based materials under extreme conditions such as high or low temperature and high vacuum or pressure. (4) The infinite combination of chemical structures of their constitutive ions and functional groups, as well as the variable length of the alkyl chain, could allow designing or tailoring of IL-based materials with appropriate properties, for example, melting point, viscosity, density, polarity, solubility, hydrophobicity/hydrophilicity, and conductivity. The concept of ILbased advanced functional materials has already been established and attracted considerable attention in recent years.

This review, which is based on an exhaustive analysis of the previous literature updated with the most recent articles, attempts to outline advances in 
IL-based functional materials as well as their multiple applications. In this review, IL-based functional materials are classified into several typical classes, with an emphasis on smart and sensitive materials, optical materials, energetic materials, IL/carbon hybrid materials, and so on. Some of them may be further divided into subclasses for more detailed discussion. Finally, we provide a conclusion and perspective. Note that the field of IL materials is developing rapidly, and the research directions are diverse; thus, it is almost impossible to comprehensively review the literature in a single article. For example, the topic of synthesis and preparation of inorganic or organic materials in which ILs serve only as templates, solvents, or media is not discussed here.

\section{Smart (responsive) and sensitive materials}

\subsection{Photoresponsive materials}

Smart (responsive) materials are a family of materials the original properties of which can be changed by applying external stimuli such as light, temperature, moisture, $\mathrm{pH}$, or an electric or a magnetic field. Of the external triggers, light represents the most advantageous stimulus as it is ubiquitous and offers very high spatial and temporal resolution, allowing for rapid, noninvasive, and truly remote control.[14] Incorporating ILs with photoresponsive functionality will yield socalled photoresponsive ILs, which exploit the light response together with the

properties peculiar to ILs. Many intrinsically photoresponsive ILs have been 
developed by direct incorporation of photochromic moieties into either cations or anions of ILs, as shown in Figure 2.[15-24]

The first photochromic IL was reported by Pina et al. and realized through a simple combination of methyl orange (MO) anions and appropriate organic cations.[15] Photochromic ILs maintain the binary features of light-responsive materials and ILs, and their photochromic response can be tuned by simply changing the cation of these ILs. However, because the MO anion is an aminoazobenzene type, in which $1\left(n-p^{*}\right)$ and $1\left(p-p^{*}\right)$ are at comparable energies, and its thermal cis-to-trans isomerization occurs too rapidly at ambient temperature,[25] the cis-isomers of these photoresponsive ILs were short-lived in both organic solvents and liquid films. ILs with stable and reversible interconversion between two distinct isomeric forms were obtained by incorporating diarylethene or spiropyran moieties into the cations, although the synthetic procedures for such photochromic moieties involves a relatively long, complex, and tedious procedure.[16, 19, 24] In contrast, azobenzene, one of the most frequently used photochromic moieties, can be easily incorporated into the IL skeleton.[20] It is noteworthy that although covalent or ionic integration facilitates the sensitization process, the photochromic moieties always exhibit a large molecular volume and strong $\pi-\pi$ stacking interaction, which inevitably complicates the structure of ILs and increases their melting points. Most of the reported photochromic ILs are likely solid.[15, 19] Generally, room temperature ILs (RTILs) have to be designed by incorporating bulky anions, e.g., bis(trifluoromethanesulfonyl)imide $\left(\left[\mathrm{NTf}_{2}\right]\right)$, and long spacers to depress the melting point.[15, 19, 20] 
Incorporation of photoresponsive groups into ILs can cause photoinduced changes in their physicochemical properties. The melting points[17] and conductivities[20] of these ILs can reportedly be modulated under alternating ultraviolet (UV) and visible light irradiation. For example, Deng et al. designed a series of photoresponsive ILs with an azobenzene ending group.[20] All these ILs exhibit slight but distinct and reversible photoresponsive conductivity in specific solvents such as dichloromethane, ethyl acetate, and tetrahydrofuran (THF), whereas this phenomenon was absent in other solvents such as methanol, ethanol, and acetonitrile. This solvent-dependent photoresponsive conductivity is likely attributable to a photoinduced reversible change in the aggregation state of ion clusters. On the basis of the same idea, the conductivity modulation was further improved to $130 \%$ by directly using cinnamate as the anion.[23] Instead of covalent bonding or ion pairing between a photoresponsive group and IL moieties, composite materials could also be obtained by directly mixing common ILs with photoresponsive molecules.[26, 27] For example, ion-conductive gels were obtained by soaking a photoresponsive polymer gel with an imidazolium IL, 1,3-dibutylimidazolium bromide ([BBIm][Br]), which shows obvious photoirradiation-controlled ionic conductivity under alternating UV and visible light irradiation caused by local shrinkage or expansion of the obtained ion gels.[26] In addition, alternating irradiation of equimolar magnetic IL 1-butyl-3methylimidazolium tetrachloroferrate $\left([\mathrm{BMIm}]\left[\mathrm{FeCl}_{4}\right]\right)$ and azobenzene by UV and visible light at $25^{\circ} \mathrm{C}$ resulted in a monotonous increase in the magnetic moment despite the reversible photoisomerism of azobenzene, probably owing to the formation of short-range order in the supramolecular system through 
irreversible aggregation of paramagnetic iron (III) complexes under irradiation.[27] This photoresponsive capacity of IL-based composite materials could be further expanded by forming more ordered organizing structures such as ionic liquid crystals (ILCs),[28, 29] IL-containing micelles,[30] and IL/blockcopolymer-based self-assembly.[31-33] For example, doping the ILC 1-dodecyl3-methylimidazolium tetrafluoroborate $\left(\left[\mathrm{C}_{12} \mathrm{MIm}\right]\left[\mathrm{BF}_{4}\right]\right)$ with very small amounts of 4-methoxy-4'-methylazobenzene $(<5 \mathrm{wt} \%)$ can give rise to a reversible isothermal phase transition between the smectic A mesophase and isotropic liquid phase.[34]

\section{$2.2 \mathrm{pH}$-sensitive materials}

Traditional dyes such as methyl red (MR) and MO are widely used in the chemistry laboratory as $\mathrm{pH}$ indicators, although their availabilities are strongly hampered by the limited solubility; e.g., MO can be applied only in aqueous solutions, whereas MR is soluble only in some nonaqueous systems. Recently, many efforts have been made to modify the indicator dyes using an IL-based strategy, which is generally realized by metathesis between common ILs and dye salts. The resulting sensitive materials not only possess improved solubility in a wide range of solvents, but also exhibit more sensitivity toward $\mathrm{pH}$ changes.[3541] For example, a series of IL-modified dyes obtained by anion exchange between imidazolium/pyridinium salts and $\mathrm{MR} / \mathrm{MO}$ salts exhibit lower melting points and enhanced solubility than the original dye salts. MR-based ILs, e.g., [BMIm]MR, exhibited an obvious response with well-differentiated color 
changes over a wide range of $\mathrm{pH}(1-7)$ in aqueous solutions, whereas MR itself, owing to its limited solubility, is sensitive only in aqueous solutions of $\mathrm{pH}=1$. In contrast to MR-based ILs, MO-based ILs displayed good sensitivity in nonaqueous systems. For example, [BMIm] MO can work well when $\mathrm{CF}_{3} \mathrm{SO}_{3} \mathrm{H}$ is diluted in typical organic solvents from $10^{-1} \mathrm{M}$ to $10^{-5} \mathrm{M}$.[36] Similarly, pHsensitive colorimetric ILs were also designed by simply pairing the trihexyltetradecylphosphonium cation $\left(\left[\mathrm{P}_{666,14}\right]\right)$ with dianionic and monoanionic fluorescein $\left([\mathrm{FL}]^{2-}\right.$ and $\left.[\mathrm{FL}]^{-}\right)$. The hydrophobic cation enables the ILs to form nanoparticles (NPs) with obvious $\mathrm{pH}$-dependent changes in both the absorption and fluorescence spectra. Interestingly, the dianionic IL $\left[\mathrm{P}_{666,14}\right]_{2}[\mathrm{FL}]$ exhibits more significant sensitivity than $\left[\mathrm{P}_{666,14}\right][\mathrm{FL}]$, probably because the presence of two cations favors well-established J-aggregation compared to that of one cation.[37] By combination and immobilization of a number of [ $\left.\mathrm{P}_{666,14}\right]$-based IL dyes on specialized matrices or substrates such as glass filter papers, cotton threads, and silica and alumina plates, $\mathrm{pH}$-dependent hydrophobic colorimetric sensor arrays were fabricated that can stably detect and identify closely related complex materials such as cigarette smoke. These results also suggested that IL indicators can not only detect the $\mathrm{pH}$ value of the condensed phase, but also sense acidic or basic vapors such as hydrochloric acid and ammonia.[39]

Despite the improved $\mathrm{pH}$ response of IL dyes, this solution-based colorimetric method is difficult to use in practical applications. To address this issue, IL-based monomer dyes were covalently copolymerized with acrylonitrile to form plastic strips[38] or physically incorporated into polymer matrices to 
obtain proton-responsive ionogels.[41] Therefore, $\mathrm{pH}$ indication in this case can be easily implemented by simply dipping the as-prepared films into an acidic or a basic solution. Moreover, these films can be repeatedly used with a stable and reversible response. The $\mathrm{pH}$ response of IL dyes may also induce additional morphological transitions if there are strong noncovalent interactions between ILs themselves, such as J-aggregation assisted by $\pi-\pi$ stacking[37] or hydrophobic interactions of long alkyl chains.[40] For example, it was reported that potassium-phthalic-acid-based $\quad$ IL $\quad\left(\left[\mathrm{C}_{14} \mathrm{MIm}\right]\left[\mathrm{C}_{6} \mathrm{H}_{4} \mathrm{COOKCOO}\right]\right)$ likely aggregates to form self-assembled vesicles without any additives in aqueous solution. When the solution's $\mathrm{pH}$ value changed, a reversible transition between spherical micelles and vesicles was observed, which can be visualized by transmission electron microscopy (TEM) (Figure 3).[40]

\subsection{Temperature-sensitive materials}

Because of their non-toxicity, wide liquidus range, and negligible volatility and volume change with temperature, ILs are potential thermometric fluids in liquidin-glass (LIG) thermometers to replace traditional volatile liquids such as ethanol and toxic mercury. A proof of concept was provided by Rogers and coworkers.[42] Colorless ILs tris(2-hydroxyethyl)methylammonium methylsulfate ([TEMA $\left.]\left[\mathrm{MeSO}_{4}\right]\right)$ and $\left[\mathrm{P}_{666,14}\right]\left[\mathrm{NTf}_{2}\right]$ were colored with trace amounts of ILmodified Direct Red 81 (62 and $952 \mathrm{ppm}$ for [TEMA][MeSO 4$]$ and $\left[\mathrm{P}_{666,14}\right]\left[\mathrm{NTf}_{2}\right]$, respectively) for visualization and then introduced into customized glass holders with a spherical reservoir and a capillary tube (Figure 
4a). The obtained thermometers based on the two ILs exhibit obvious temperature-dependent volume changes between $100{ }^{\circ} \mathrm{C}$ and $0{ }^{\circ} \mathrm{C}$ (Figure $4 \mathrm{~b}$ ). These results demonstrate the opportunities for using ILs to create customized temperature measurement devices, although the IL-based thermometers were kinetically slower than equivalent commercial LIG thermometers as a result of the high viscosity of the ILs.[42] The response may be further improved by using more temperature-sensitive ILs such as 1-allyl-3-alkylimidazolium dicyanamide ILs ([AC $\left.\left.\mathrm{Am}_{\mathrm{n}}\right]\left[\mathrm{N}(\mathrm{CN})_{2}\right]\right)$, which were found to possess high coefficients of volume thermal expansion $\left(5.80-6.75 \times 10^{-4} \mathrm{~K}^{-1}\right)$ that are much higher than that of mercury $\left(1.8 \times 10^{-4} \mathrm{~K}^{-1}\right)$.[43]

Unlike thermometers operated by the temperature-dependent molar volume (or density) of ILs, optical IL-based thermometers could be realized by virtue of thermochromism or temperature-dependent emission.[44, 45] For example, ILs can be employed as viscoelastic media for developing high-operating-range optical thermometers based on viscosity-dependent intramolecular excimer formation of 1,3-bis(1-pyrenyl)propane. Under an increase in temperature, and hence a decrease in the IL's bulk viscosity, the excimer-to-monomer fluorescence intensity ratio $\left(I_{\mathrm{E}} / I_{\mathrm{M}}\right)$ for the probe was significantly enhanced because of temperature-dependent monomer-excimer interconversion. The process is reversible over expanded heating and cooling cycles and displayed no hysteresis in an operational range spanning 25 to $140{ }^{\circ} \mathrm{C}$. Moreover, the luminescent thermometer exhibited high precision; the average uncertainty in temperature estimation was less than $0.35{ }^{\circ} \mathrm{C}$ in the $25-100{ }^{\circ} \mathrm{C}$ range.[44] Physically entrapping gold and silver nanorods within a polymeric IL can also produce an 
IL-based thermochromic system, which, however, exhibits an irreversible thermochromic transition from green to orange-red because of temperatureinduced variation in the aspect ratio of the nanorods.[45] As an alternative to physical encapsulation, intrinsically thermochromic ILs can be obtained by incorporation of ILs with metal (nickel or uranyl)-containing complexes as anions. The temperature-induced local environment of the nickel or uranyl ion, including the coordination number and cation-anion interactions, result in a color change.[46-48] For example, reversible and stable thermochromic ILs were realized by dissolving $[\mathrm{BMIm}]_{2} \mathrm{NiCl}_{4}$ in 1-hydroxyalkyl-3-methylimidazolium ([C $\left.\left.\mathrm{C}_{\mathrm{n}} \mathrm{OHMIm}\right]\right)$-based ILs. Upon heating from $\mathrm{RT}$ to $80{ }^{\circ} \mathrm{C}$, the solution changes color from yellow or green to blue owing to the temperature-induced coordination reaction involving the hydroxyl group of the ILs. Compared to reported systems based on conventional solvents, the new ILs exhibit more sensitive and energyeffective responses to temperature changes, a much wider range of working temperatures, and greater stability in repeated heating-cooling cycle operations.[46] This nickel system could be further combined with polymers to fabricate thermochromic composite films.[47]

\subsection{Gas-sensing materials}

Gas sensors are of increasing importance owing to their potential applications in ambient air monitoring, industrial process control, biomedical diagnostics, occupational health and safety, and military and civilian counterterrorism. 
Extensive efforts have been made to develop new materials and transducers for gas sensing at both RT and high temperatures. ILs should be promising candidates for robust sensing materials simply because of their structural diversity, high thermal stability, high solubility of gas molecules, and negligible volatility. In particular, ILs' lack of vapor pressure eliminates the possibility of loss of these liquids by vaporization during measurements, making them highly attractive for stable gas sensing. For example, common ILs can be directly used for detection of polar and nonpolar organic vapors in quartz crystal microbalance (QCM) techniques.[49-58] The working principle of the QCM is based on the measured change in frequency between a reference state and the state when the quartz crystal is exposed to a sample vapor. The first IL-based QCM sensor was developed by Dai and coworkers, who spin-coated ILs on the surfaces of QCM devices as a transducing layer. The as-prepared QCM sensors can rapidly and reversibly respond to vapors of different types and concentrations, as manifested by significant frequency shifts of the corresponding quartz crystal.[49] The low volatility and remarkable thermal stability make IL-based QCM sensors suitable for gas sensing in more extreme conditions, especially high temperatures, where conventional solvents would evaporate or decompose.[50, 52] The sensing mechanism of IL-based QCM sensors is likely temperature-dependent: both the mass loading and the viscosity change of the IL film upon absorption of vapors caused the frequency change at RT,[49] and at high temperatures, the frequency changes were due mainly to mass loading in the IL film.[50] In addition to remarkable stability at both RT and high temperatures, the tunable affinity, sensitivity, and selectivity of ILs toward certain organic vapor analytes through 
the modification of cations or anions highlight the superior properties of ILs for sensor applications.[49, 52, 54] Entrapping ILs within matrices such as nanoporous alumina,[51] polymers,[58] and graphene[54] can not only overcome the problems related to the liquid's softness and the possibility of dewetting and flow, but also significantly enhance the sensitivity, specificity, and stability of ILbased gas sensors. In comparison with common ILs without any functional groups, QCMs involving functionalized ILs such as switchable ILs (SILs) 1 and 2 (Figure 5) showed high potential for chemoselective gas detection of aldehyde/ketone and amine gases, respectively, using specific chemical reactions. SIL 1 readily reacts with aldehyde/ketone gas samples to form covalent imine adducts and thus can chemoselectively detect aldehyde/ketone gases, as expected, while remaining totally insensitive to common organic vapors such as hexane, ethanol, ethyl acetate, and, most significantly, moisture. SIL 2 exhibited a significant response to amine gases based on the transimination reaction in the presence of a Lewis acid catalyst $\left[\mathrm{Sc}(\mathrm{OTf})_{3}\right]$. In contrast, the control IL, [b-3C$\mathrm{im}]\left[\mathrm{NTf}_{2}\right]$ (Figure 5), was nearly inert to the amine gas. The only disadvantage of functional IL-based QCMs is that the response is irreversible, and the QCM chip has to be regenerated by washing away the used SIL and replacing it with a new one.[56]

Because most of the investigated ILs do not exhibit optical or redox properties, the signal transducers of most IL-based sensors reported so far are mainly limited to QCMs.[49-58] To solve this problem, Mochida et al. designed a series of vapor- and gas-responsive ILs comprising cationic metal $\left(\mathrm{Cu}^{\mathrm{II}}\right.$ and $\left.\mathrm{Ni}^{\mathrm{II}}\right)$ chelate complexes and a bulky anion $\left[\mathrm{NTf}_{2}\right]$ (Figure 6a).[59] When exposed to 
organic vapors and gases, these ILs exhibit reversible changes in color, thermal properties, and magnetic properties (for $\mathrm{Ni}^{\mathrm{II}}$ ) because of coordination changes (Figure 6b). As shown in Figure 6c, the $\mathrm{Ni}^{\mathrm{II}}$-containing IL $[\mathbf{2 a}]\left[\mathrm{NTf}_{2}\right]$ is a dark reddish liquid that turned green after absorbing organic vapors having a high donor number (DN), such as N,N-dimethylformamide (DMF), dimethyl sulfoxide (DMSO), and pyridine, whereas the color did not change when it was exposed to organic vapors with low DN values, such as acetonitrile, acetone, and methanol. Exposure of $[\mathbf{1 a}]\left[\mathrm{NTf}_{2}\right]$ to ammonia gas at $1 \mathrm{~atm}$ caused a color change from dark purple to green within a few seconds. The original color was restored when the IL was left in air or purged with nitrogen gas, accompanied by a corresponding absorption shift (Figure 6d). In addition, vapor absorption also caused changes in the melting point and viscosity.

Instead of intrinsically gas-sensing materials, ILs could also be employed as suitable matrices for the preparation of composite materials with a gas response. One such attractive application is the incorporation of $\mathrm{pH}$ indicators into ILs and monitoring of the carbon dioxide $\left(\mathrm{CO}_{2}\right)$-induced absorbance or fluorescence changes to produce optical $\mathrm{CO}_{2}$ sensors relying on the high solubility of $\mathrm{CO}_{2}$ in water-miscible ILs (approximately 10 to 20 times that in conventional solvents).[60-62] For example, Borisov et al. fabricated optical $\mathrm{CO}_{2}$ sensors based on emulsion of RTILs in a silicone matrix. Semi-quantitative determination of $\mathrm{CO}_{2}$ was achieved by dissolving an absorption-based $\mathrm{pH}$ indicator such as bromothymol blue in $[\mathrm{BMIm}]\left[\mathrm{BF}_{4}\right]$, which displays a distinctive response to $\mathrm{CO}_{2}$ in the dynamic range from $0 \%$ to $100 \%$, with a color change from dark blue to yellowish-green. Further quantitative determination based on ratiometric 
measurement was realized by co-dissolving a fluorescence-based $\mathrm{pH}$ indicator (8hydroxypyrene-1,3,6-trisulfonate) and an inert fluorescent dye \{4dicyanomethylene-2-methyl-6-[4-(dimethylamino)styryl]-4H-pyrane $\}$ in an IL. The former responds linearly to the $\mathrm{CO}_{2}$ concentration, and the latter serves as a fluorescent reference.[62] In addition, IL-based $\mathrm{CO}_{2}$ sensors could be obtained by exploring switchable IL-induced electrochemiluminescence (ECL),[63] which will be discussed in detail in the section on switchable ILs.

\subsection{Ion-responsive materials}

ILs consist entirely of cations and anions. One of their most attractive features is that simply varying the ions can readily tune their physicochemical properties. Therefore, ILs themselves are a potential platform for ion-responsive materials, especially anion-responsive materials, because of their easy realization by anion

exchange. Lee et al. fabricated an anion-responsive surface by self-assembly of a monolayer of thiol-functionalized imidazolium ILs with a long alkyl chain spacer between the terminated ionic core and thiol moiety. The water contact angle was found to gradually increase from $23^{\circ}$ for $[\mathrm{Br}]$ to $65^{\circ}$ for $\left[\mathrm{NTf}_{2}\right]$, thus successfully quantifying the hydrophobicity of the anions in the following order: $\left[\mathrm{NTf}_{2}\right]>$ $\left[\mathrm{PF}_{6}\right]>\left[\mathrm{CF}_{3} \mathrm{SO}_{3}\right]>\left[\mathrm{ClO}_{4}\right]>\left[\mathrm{NO}_{3}\right]>\left[\mathrm{BF}_{4}\right]>[\mathrm{Br}] .[64]$ Simply exchanging the hydrophilic anion $[\mathrm{Br}]$ with the hydrophobic $\left[\mathrm{PF}_{6}\right]$ in an IL surfactant causes destruction of the micelles.[65] The observed anion response could be enhanced for polymeric ILs that combine the peculiar properties of ILs and polymers.[6670] For example, double-hydrophilic block copolymers (DHBCs) bearing one 
polymeric IL block tend to form self-assembled structure in water, and the presence of IL units endows DHBCs with a reversibly anion-sensitive selfassembled morphology. When the anion $[\mathrm{Br}]$ was exchanged for $\left[\mathrm{NTf}_{2}\right]$ in the polymeric IL block, the polymeric IL block switched from hydrophilic to hydrophobic, causing a transition from unimers to micellar[66] or vesicle aggregates[67] depending on the specific structure of the DHBCs. Interestingly, by combining the unique properties of both polymeric ILs and photonic structures, Li et al. fabricated novel photonic IL (PIL)-based anion sensory systems that provided successful "naked-eye" anion detection.[68-70] PILs possess a highly ordered and interconnected three-dimensional (3D) macroporous structure, wherein anion exchange among polymeric ILs grafted on the walls of the macropores results in a volume change and thus a shift in the stop band of photonic crystals. Therefore, the anion exchange events can be transformed into readable optical signals (color changes). When PIL films were soaked in aqueous solutions with diverse anions such as $\left[\mathrm{NTf}_{2}\right],\left[\mathrm{PF}_{6}\right],\left[\mathrm{ClO}_{4}\right],\left[\mathrm{BF}_{4}\right],\left[\mathrm{NO}_{3}\right]$, and [Br], the color changed from red to blue, depending strongly on the size of the anions. $[68,70]$ To overcome the problem associated with a single PIL film that can selectively detect anions only under the same concentration, a cross-reactive sensor PIL array based on three different ILs was fabricated by the same group. All the analyses performed in this case showed excellent discrimination not only for different anions but also for their binary or tertiary mixtures, providing a handy, rapid, and sensitive method of anion detection.[69] 
ILs could also be designed for the detection of metal ions instead of anions.[71, 72] Marchand et al. synthesized a task-specific fluorogenic IL containing 8-hydroxyquinoline benzoate as a ligand (Figure 7a). This IL shows very weak fluorescence with a low quantum yield in its original state $(0.002$ in acetonitrile); however, metal binding with the ligand yields a maximum fluorescence enhancement factor of 94 and a quantum yield of 0.41 with high sensitivity toward mercury versus other heavy metals such as copper, lead, and cadmium (Figure $7 \mathrm{~b}$ and $7 \mathrm{c}$ ). In combination with a microsystem prototype, this IL allows real-time detection of mercury in water with very high sensitivity, reaching a detection limit of 50 parts-per-billion (ppb).[71] An ionic complex of polymeric ILs, charged fluorescent molecules, and hydrophobic anions yields fluorescent NPs by virtue of hydrophobic balance between the three components; the NPs showed high sensitivity and selectivity for fluorescent sensing of copper ions.[72]

\subsection{Moisture-sensitive materials}

Self-reporting humidity sensors are constructed using the above-mentioned strategy of PILs, wherein a poly IL containing a hydrophilic anion ([Br]) was used as the platform for sensing moisture.[73] As the relative humidity (RH) increased from $20 \%$ to $80 \%$, a large shift of $148 \mathrm{~nm}$, from 498 to $646 \mathrm{~nm}$, was observed in the reflectance spectra of the PILs, and RH sensing was accompanied by distinct color changes of the PIL film from blue to green, orange, and red, covering the entire visible range. The interesting color change was ascribed to the 
fact that the moisture swells the volume of the PIL film and, as a consequence, induces a continual shift of its diffraction peak, depending on the amount of water adsorbed. Remarkably, this PIL sensor exhibited high stability and reversibility over a large $\mathrm{RH}$ range in a multicycle experiment.[73] In addition, on the basis of the close correlation between the water uptake of an IL and its conductivity increase, an IL-based humidity sensor has also been fabricated and even commercialized. This type of IL sensor reportedly showed significantly faster response times (up to a factor of 2.5) and less sensitivity to cross-contamination than existing sensors based on polymer membranes.[74]

\subsection{Magnetic-responsive materials}

Magnetic ILs are a subclass of ILs containing magnetic components responsive to an external magnetic field, which are attractive candidates for preparing a new and better class of ferrofluids and magnetorheological fluids. The first magnetic IL, [BMIm] $\left[\mathrm{FeCl}_{4}\right]$, was reported by Hamaguchi et al. in 2004 and showed a strong response to an external magnetic field (Figure 8). [75] Since then, a series of magnetic ILs containing various transition metal cores, such as $\mathrm{Fe}^{\mathrm{III}},[76-79]$ $\mathrm{Co}^{\mathrm{II}},[80,81] \mathrm{Mn}^{\mathrm{II}},[82] \mathrm{Gd}^{\mathrm{III}},[82] \mathrm{Dy}^{\mathrm{III}} ;[83,84]$ different ligands including halides $(\mathrm{Cl}, \mathrm{Br}),[82]$ pseudohalogens $\quad\left[\mathrm{NCS}, \quad \mathrm{SCN}, \quad \mathrm{N}(\mathrm{CN})_{2}\right],[81, \quad 83] \quad$ and ethylenediaminotetraacetic acid (EDTA);[85] different cationic or anionic moieties; [76, 78, 86, 87] and different alkyl chain lengths in the cation[88] have been prepared. The magnetic core can be located on either an anion[75] or a 
cation $[89,90]$ in magnetic ILs. The IL structure was found to influence their magnetic properties, whereas changing the metal ions was the most efficient method of improving the effective magnetic moment, as expected. For example, magnetic ILs containing $\mathrm{Dy}^{3+}$ anions, as reported by Mudring and coworkers,[83] exhibited a high effective magnetic moment $\left(\mu_{\mathrm{eff}}=10.4 \mu_{\mathrm{B}}\right)$, nearly twice that of $\mathrm{Fe}^{3+}$-based magnetic ILs $\left(5.80-5.85 \mu_{\mathrm{B}}\right)$.[88] In contrast, although the structure of the cation (imidazolium to ammonium, phosphonium, pyrrolidinium, and even amino-acid-based cations) as well as the alkyl chain length slightly affects the magnetic susceptibility, modification of these nonmagnetic structures is likely to easily tune relevant properties such as the density, viscosity, ion conductivity, and water solubility for extended applications.[76, 86-88] For example, a series of monocationic, dicationic, or tricationic magnetic ILs containing the $\left[\mathrm{FeCl}_{3} \mathrm{Br}\right]$ anion have been designed by incorporating long hydrocarbon chains and/or bulky aromatic moieties into the imidazolium cation;[87] they show great promise for liquid-liquid extraction over traditional hydrophilic magnetic ILs owing to their strong hydrophobicity.[91] Notably, tricationic ILs paired with three $\left[\mathrm{FeCl}_{3} \mathrm{Br}\right]$ anions exhibited a high $\mu_{\text {eff }}$ of $11.76 \mu_{\mathrm{B}}$, which is the highest value ever reported for magnetic ILs.[87] In addition to the most frequently investigated inorganic magnetic ILs, paramagnetic nitroxide radicals such as the 2,2,6,6-tetramethyl-1piperidinyloxyl (TEMPO) moiety have also been incorporated into ILs to form metal-free magnetic ILs.[92, 93] However, the $\mu_{\text {eff }}$ values $\left(<2.0 \mu_{\mathrm{B}}\right)$ of these ILs are much lower than that of metallic magnetic ILs.[88, 94] A novel bimagnetic IL with both TEMPO and $\left[\mathrm{FeCl}_{4}\right]$ was further developed by $\mathrm{He}$ et al. and exhibits a 
high $\mu_{\text {eff }}$ of $6.66 \mu_{\mathrm{B}}$, probably because of the cooperative contribution from the metallic and nonmetallic magnetic moieties.[95]

Interestingly, the magnetic properties of magnetic ILs can be controlled by external stimuli. $[27,59,85]$ The magnetic susceptibility of a $\left[\mathrm{BMIm}^{-}\left[\mathrm{FeCl}_{4}\right]\right.$ and azobenzene mixture was reported to increase continuously under alternative UV and visible light irradiation,[27] whereas EDTA metal complex ([Co(EDTA)])based magnetic ILs can switch reversibly from diamagnetic to paramagnetic upon reduction/oxidation.[85] In addition, an external magnetic field seems to affect the local structures of intrinsically magnetic ILs and hence the behavior and reaction of nonmagnetic materials in these systems.[89, 96-98] For example, in situ polymerization of $\mathrm{N}$-methylpyrrole in $[\mathrm{BMIm}]\left[\mathrm{FeCl}_{4}\right]$ produces either rod- or bead-shaped nanostructures, depending strongly on the presence or absence of an external magnetic field.[96] Moreover, a paramagnetic ferrocenium-based IL ([butyloctamethylferrocenium] $\left[\mathrm{NTf}_{2}\right]$ ) with magnetic anisotropy was found to exhibit a magnetically responsive solidification process. In the absence of magnetic fields, it formed microscopic domains during solidification, whereas under a magnetic field of $0.6 \mathrm{~T}$, this liquid crystallized into needles arranged perpendicular to the magnetic field.[89]

To address the disadvantages associated with liquid magnetic ILs, many efforts have focused on immobilizing magnetic ILs via chemical polymerization[99, 100] or physical incorporation within specific matrices to form composite materials such as magnetic fibers[101] and ionogels.[102] These materials combine the mechanical properties of the matrix with the function of the magnetic ILs, such as magnetism, and may find potential applications as 
reusable catalysts or adsorbents for extraction and separation. Furthermore, magnetic ILs can be combined with other functional moieties to develop bi- or multifunctional materials such as magnetic ILCs,[84] electrochromic and magnetic ILs,[85] and magnetic and luminescent ILs.[83]

Although common magnetic ILs are demonstrated to respond strongly to a magnet, they are nearly paramagnetic with no strong interactions among the spins, and they do not provide any possibility of magnetorheological behavior. Alternatively, magnetic fluids, which consist of ferromagnetic NPs dispersed in carrier liquids, are neither paramagnetic nor ferromagnetic because spin ordering exists only locally within the particles. Unlike conventional carriers for magnetic fluids, ILs possess high dielectric constants, high polarities, ionic charges, and supramolecular structures that may help to disperse NPs. In addition, the properties of ILs can be tuned by varying the composition of the ions. Thus, the use of ILs as carrier media to replace conventional organic carrier media in magnetic fluids has attracted considerable interest,[103-109] which may expand or improve the application of magnetic fluids in various areas of science and engineering. Several types of micrometer- or nanometer-sized magnetic particles such as hematite $\left(\mathrm{Fe}_{2} \mathrm{O}_{3}\right),[103,105,108]$ magnetite $\left(\mathrm{Fe}_{3} \mathrm{O}_{4}\right),[104] \mathrm{Co},[106]$ and $\mathrm{CoFe}_{2} \mathrm{O}_{4}[105]$ have been explored in intrinsically nonmagnetic ILs, with surface modification of the NPs or without any stabilizing additives. For example, IL ferrofluids prepared by dispersing superparamagnetic iron oxide NPs in protic and aprotic ILs were found to be stable for several months.[109] A recent study demonstrated that suspensions of a low content of hematite NPs in an IL exhibit Newtonian behavior similar to that shown by pure ILs, whereas concentrated 
suspensions show non-Newtonian characteristics including shear thinning and shear thickening.[103] Schubert et al. further investigated the magnetorheological behavior of a series of magnetorheological fluids by using ILs as carriers in dispersions of magnetite particles.[104] The use of ILs has endowed the obtained magnetorheological fluids with outstanding stability and low rates of sedimentation without any stabilizing additives. Moreover, a magnetorheological effect, i.e., instantaneous and quasireversible modification of the rheological properties of these fluids under a magnetic field due to the formation of large chains of magnetic particle aggregates, was also observed.

\subsection{Electrochromic materials}

Electrochromism is a reversible color change displayed by some materials when they are oxidized or reduced electrochemically; it has been explored for academic and industrial applications such as information displays, antiglare rear view mirrors in automobiles, and smart windows. Conventional electrochromic devices have been realized by dipping organic redox-active materials in electrolyte solutions or combining them with solid electrolytes.[110] The fabrication of useful electrochromic devices depends on both the electrochromic compounds and the electrolytes. ILs, owing to their good thermal stability, high conductivity, and wide electrochemical window, have been shown to be potential electrolytes for electrochromism.[111] Furthermore, incorporating functional electrochromes into the skeleton of ILs will yield intrinsically electrochromic ILs having two- 
fold functions, i.e., for electrochromism and as electrolytes. Electrochromic ILs as well as ILCs based on EDTA metal complexes ([Cation][Co(EDTA)]),[85] vanadate oxide ([Cation][ $\left.\left.\mathrm{VO}_{3}\right]\right),[112]$ bipyridinium cations (viologen),[113-116] and $\pi$-conjugated moieties such as terthiophene[117, 118] and thienoviologen[119] have been intensively studied in recent years. Arguably the most popular choice of organic electrochromes is the viologens because of their durable electrochromic properties. As shown in Figure 9, disubstituted bipyridinium dications generally undergo two successive electron transfer processes and thus exhibit three redox states: the dication (transparent), radical cation (blue-violet), and neutral compound. Normally, the dication species are more stable, whereas the radical cation is intensely colored, exhibiting a high molar absorption coefficient associated with intense intramolecular optical charge transfer. A series of electrochromic ILs based on the viologen platform, including RTILs and ILCs, have been synthesized; the substituents (type and length) on the nitrogen atoms were found to affect the colors of the radical cations, whereas both the substituents and counteranions strongly affect the phase transition behavior and solution ability.[113-116] Figure 9c confirms reversible electrochromism for a typical electrochromic IL, $\left[\mathrm{C}_{2} \mathrm{C}_{6} \mathrm{bpy}\right]\left[\mathrm{NTf}_{2}\right]$ (for the structure, see Figure 9b), which can switch between being a transparent or pale yellow solution and being a blue solution under an applied potential.[113] Viologen-based electrochromic ILs could be further designed by introducing oxygen on the side chains of the bipyridinium cations with alternative anions to lower the melting points[114] or attaching two trioctyloxybenzyl alcohol groups to the viologen moiety to form columnar ILCs.[116] In particular, when a 
phosphonium core was tethered to the viologen moiety as a separate electrolyte and then encapsulated within a hybrid sol-gel, the switching kinetics of the electrochromic platform were approximately 2 orders of magnitude faster $(221 \mathrm{~s}$ to reach 95\% absorbance) than those of [Cation][Co(EDTA)]-based electrochromic ILs $(18,000 \mathrm{~s})$.[85] Note that intrinsically electrochemical RTILs may also find potential application in redox flow batteries, in which more energy is likely to be stored in liquid electrolytes than in conventional redox flow batteries.[120]

Other $\pi$-conjugated moieties such as terthiophene[117, 118] and thienoviologen[119] have also been explored as electroactive species for synthesis of electrochromic ILCs. For example, electrochromic ILC 1 combining ionic and electronic functions was produced using terthiophene-based mesogens and terminal imidazolium groups (Figure 10a).[117, 118] Distinct reversible electrochromic responses were observed in the bulk liquid crystalline state (smectic A) without additional electrolyte solution (Figure 10c and 10d). In contrast, reference compound 2 does not exhibit such electrochromism in the bulk liquid crystal state despite its comparable oxidation potential compared to compound 1. The electrochromism in the $\pi$-conjugated ILC is ascribed to coupling of two-dimensional (2D) electronic (hole) and ionic transportation in the nanosegregated structure of ILCs (Figure 10b). This idea was further employed by Beneduci et al. to develop novel thienoviologen-based ILCs, which exhibited not only electrochromism in both the smectic and columnar phases, but also electrofluorochromism in bulk liquid crystals.[119] 


\subsection{Ionic liquids with switchable polarity}

Solvents are highly important for chemical reactions because they may strongly affect the conversion and selectivity. ILs, owing to their high polarity and strong solubility toward most organic compounds, have been extensively studied as designable solvents for green chemistry and clean technology. However, their negligible volatility inevitably complicates the subsequent separation and cycling processes. The novel switchable ILs demonstrated by Jessop et al. may effectively address these problems. A smart system can easily convert from a non-IL (a two-component molecular system consisting of an alcohol and an amine base) to an IL (a salt in liquid form) upon exposure to a $\mathrm{CO}_{2}$ atmosphere and then revert back to its non-ionic form when exposed to nitrogen or argon gas, as shown in Figure 11a. Correspondingly, the polarity of this smart system was greatly changed from nonpolar (as chloroform) to polar (as DMF or propanoic acid). This difference in polarity can be seen by examining the miscibility of decane with the mixture: under nitrogen it is miscible, whereas under $\mathrm{CO}_{2}$ it forms a separate phase (Figure $11 \mathrm{~b}$ and 11c).[121] The detailed physicochemical properties such as the melting point, reversibility, polarity, viscosity, basicity, conductivity, and solvation ability could also be tuned by selecting suitable components such as organic bases and alcohols,[122-127] or even using other triggers such as $\mathrm{SO}_{2}[128]$ or $\mathrm{CS}_{2}$ instead of $\mathrm{CO}_{2}$.[129] In addition to the twocomponent system, simple one-component switchable ILs could be derived from 
a single organic base (Figure 12).[130, 131] On the basis of this concept, even reversible zwitterionic ILs can be obtained.[128, 132]

Switchable polarity can help to dissolve and then precipitate a solute or to dissolve reagents for a chemical synthesis and then precipitate the product, thus facilitating organic syntheses and separations conducted in switchable ILs. These smart ILs have practical applications for separation of aliphatic and aromatic amines,[133] treatment and transformation of cellulose,[134, 135] and $\mathrm{CO}_{2}$ capture.[136] More importantly, these ILs with switchable properties including the conductivity, viscosity, and polarity may provide a new on-off platform for design of novel advanced materials such as $\mathrm{CO}_{2}$ gas sensors[137, 138] and responsive microemulsions.[139] The most significant advantages of advanced materials based on this system over previously mentioned photo-, electrochemical-, and magnetic-responsive materials are that switchable ILs can be easily prepared without any complicated functional groups and tedious synthetic procedures, and the triggers are just a $\mathrm{CO}_{2}$ or nitrogen atmosphere at RT. For example, this strategy has been used to prepare switchable surfactants by replacing commonly used organic bases with long-chain alkyl amidine compounds; the switchable surfactants can be transformed into charged surfactants by exposure to a $\mathrm{CO}_{2}$ atmosphere and thus stabilize water/alkane emulsions.[137] In addition, the switchable conductivity of smart ILs was used to construct $\mathrm{CO}_{2}$ gas sensors based on IL-induced ECL. As shown in Figure 13, this sensor contains electrochemiluminescent luminol- $\mathrm{O}_{2}$ in an electrolyte-free DMF-dipropylamine (DPA) cosolution. In the absence of $\mathrm{CO}_{2}$, no current or ECL emission was observed in such a sensing solution containing luminol, DPA, 
and DMF, as no conductive ion exists in the solution. However, the injection of $\mathrm{CO}_{2}$ into the sensor causes $\mathrm{CO}_{2}$ and DPA to react to form a conductive carbamate IL, which induces strong ECL reactions of the luminol- $\mathrm{O}_{2}$ system. The ECL intensity is proportional to the concentration of $\mathrm{CO}_{2}$ and is free of interference from other gases such as $\mathrm{SO}_{2}, \mathrm{NO}_{2}$, and $\mathrm{CO} .[63]$

\section{Optical materials}

\subsection{Luminescent materials}

3.1.1 Intrinsic fluorescence of common ionic liquids. ILs are often based on aromatic moieties such as imidazolium or pyridinium and therefore exhibit intrinsic luminescence thanks to low-lying $\pi-\pi^{*}$ transitions.[140] Unfortunately, the luminescence of these common ILs is weak, inefficient, and unexploitable. Previous work by Samanta et al. revealed that common ILs such as $[\mathrm{BMIm}]\left[\mathrm{BF}_{4}\right]$ and $[\mathrm{BMIm}]\left[\mathrm{PF}_{6}\right]$ typically display very low emission intensities in the visible region $\left(\Phi_{\mathrm{f}}<0.05\right)$. $[140,141]$ Pyrrolidinium ILs with extremely high purity are even nonfluorescent.[142] An exception is that a symmetrical hydrophilic IL, $[\mathrm{BBIm}][\mathrm{Cl}]$, was found to be highly fluorescent with emission at $388 \mathrm{~nm}$ when excited below $340 \mathrm{~nm}$. The symmetrical plane-conjugated structure resulted in a very high quantum yield of 0.523 in an aqueous medium.[143] The luminescence efficiency of ILs could be greatly improved by nanoconfinement of ILs, as proven by the result for dicyanamide-based ILs within mesoporous silica

gels.[144] Regarding the intrinsically weak luminescence of common ILs, 
alternative approaches to enhance the luminescence efficiency are in great demand. Essentially there are two basic strategies for obtaining IL-based luminescent materials: incorporation of organic or inorganic luminescent functionalities into the IL skeleton and formation of IL-based composite/hybrid materials by physical entrapment of luminescent compounds within the IL matrix.

3.1.2 Luminescent ionic liquids. Luminescent ILs differ from common types of fluorescent organic molecules. On one hand, the chromophores endow ILs with luminescence by the incorporation of functionalities into one or both ions. On the other hand, the IL-based modification strategy may in turn help to tune the physicochemical properties of the emissive salts, such as their thermal stability, phase behavior, water-solubility or insolubility, and polarity, and their photophysical properties such as their fluorescence emission wavelength, quantum yield, and photostability.[145-149] Various organic fluorophores such as benzobis(imidazolium) (BBI),[146, 150] quinolizinium,[151] anthracene,[152, 153] squaraine,[154] dansyl,[155, 156] salicylate,[157] and carbazole,[158] have been embedded in either cations ( $\mathrm{a}-\mathrm{f}$ in Figure 14) or anions ( $\mathrm{g}$ in Figure 14) via covalent functionalization or ion-exchange metathesis to form luminescent ILs.

Among the investigated chromophores, BBI (Figure 14a) provides a versatile platform for designing fluorescent ILs because the charged moieties that are embodied within the chromophore are highly tunable.[146, 150] Appropriate selection of the four $\mathrm{N}$-substituents, two C1-substituents, two counterions, and 
even regioisomers on the imidazolium moieties yields salts that not only exhibit tunable electronic and physical characteristics, including solution-based and solid-state fluorescence, but also offer other advantages ascribed specifically to their charged nature. The glass transitions of BBI-based ILs can ultimately be reduced to less than $0{ }^{\circ} \mathrm{C}$ by depressing the molecular symmetry and noncoordinating counterions. As expected, all of the BBI ILs with structural variation exhibited emission ranging between 329 and $561 \mathrm{~nm}$ while displaying high quantum efficiencies of up to 0.91. Depending on the nature of the fluorogenic core, solvent-dependent emission characteristics were also observed in conjunction with large Stokes shifts ranging from 4570 to $13,793 \mathrm{~cm}^{-1}$. More importantly, the BBI chromophore was found to avoid self-quenching mechanisms and maintain intense emission in condensed phases such as a liquid or mesomorphic film. The anions that have been shown to play a key role in controlling the physical properties of BBI salts, however, have less effect on their photoluminescence, except for red-edge effects.

Unlike the case for BBI ILs, the anions were found to strongly affect the fluorescence emission intensity in acetonitrile for anthracene-based imidazolium ILs (Figure 14b) with various anions including $[\mathrm{Cl}],\left[\mathrm{BF}_{4}\right],\left[\mathrm{PF}_{6}\right],\left[\mathrm{SO}_{3} \mathrm{CF}_{3}\right]$, $\left[\mathrm{N}(\mathrm{CN})_{2}\right],\left[\mathrm{NTf}_{2}\right]$, and $\left[\mathrm{PhBF}_{3}\right]$, although their emission wavelengths are anionindependent.[152] Therefore, in addition to affecting the solubility, melting point, and thermal stability, anions may strongly affect the quantum efficiency of luminescent ILs in some cases. Bulky anions whose negative charge is highly delocalized are likely to have high quantum efficiencies.[151, 158] For example, unbranched quinolizinium ILs with $\left[\mathrm{NTf}_{2}\right]$ were reported to have an unexpectedly 
high quantum yield of up to $>99 \%$ in solution.[151] Such an anion-dependent luminescence is generally correlated with the extent of cation-anion pairing present in solution.[151, 152] On the basis of the possible interionic interactions in ILs, the structure of nonfunctional cations such as imidazolium, phosphonium, quaternary ammonium, and pyridinium was found to affect the emission shifts of salicylate-bearing ILs. In particular, when the pyridinium cation was replaced by others, the emission maximum showed a remarkable hypsochromic shift from greater than $570 \mathrm{~nm}$ to ca. $400 \mathrm{~nm}$.[157] In contrast, incorporating a luminescent dansyl unit into either the cations[155] or anions[156] resulted in strong luminescence both in solution and in neat phases but was less affected by the IL structure, whereas the structural (anion/cation) composition of ILs affects the photostability in the bulk phase. Moreover, nearly all these ionic-liquidized dansyl materials showed a remarkable hypsochromic shift in the peak emission wavelength when dissolved in solvents of decreasing polarity.[155, 156] A response of the fluorescence to the solvent polarity was also achieved by decorating anthracene-based imidazolium ILs with long alkyl tails for aggregation-induced emission.[153] The concept of ionic-liquidized materials has also been used to develop near-infrared fluorescent ionic materials with uniform, stable luminescence suitable for in vivo imaging.[159] Very interestingly, in the absence of conventional fluorophores, a hydrophobic Brønsted-acidic colorless IL based on a polyamidoamine dendrimer exhibits unexpectedly strong blue photoluminescence near $436 \mathrm{~nm}$, whereas its neutral precursor and hydrophilic analogue exhibit relatively weak fluorescent signals.[145] 
Despite the attractive features of luminescent ILs bearing organic chromophores, the functionalized materials are generally accessible only via more complicated synthetic routes, and the organic chromophores often result in higher melting points and viscosities. Alternatively, introduction of transition metal ions, especially lanthanide ions, can yield highly luminescent ILs with narrow emission bands, high color purity, high quantum efficiency and photostability, and long decay times.[83, 160-163] The europium ion $\left(\mathrm{Eu}^{3+}\right)$ appears to be the most intensively investigated metal ion. For example, lowmelting europium ILs $\left([\mathrm{R}]_{\mathrm{x}}\left[\mathrm{Eu}\left(\mathrm{NTf}_{2}\right)_{3+\mathrm{x}}\right], \quad x=1\right.$ for $\mathrm{R}=1$-propyl-3methylimidazolium and 1-butyl-3-methylimidazolium; $x=2$ for $\mathrm{R}=1$-butyl-1methylpyrrolidinium) were obtained by coordinating europium ions solely with a weakly coordinating anion $\left[\mathrm{NTf}_{2}\right]$. These three ILs require no neutral co-ligand such as water and consequently can be regarded as the first true f-element ILs; they show a strong tendency to form supercooled liquids and have a strong red luminescence typical of $\mathrm{Eu}^{3+} \cdot[160]$ An interesting point regarding luminescent ILs containing lanthanide ions is that some of them may serve as bifunctional materials with additional magnetic properties. For example, dysprosium ILs $\left[\mathrm{C}_{6} \mathrm{MIm}\right]_{5-\mathrm{x}}\left[\mathrm{Dy}(\mathrm{SCN})_{8-\mathrm{x}}\left(\mathrm{H}_{2} \mathrm{O}\right)_{\mathrm{x}}\right] \quad\left(x=0-2, \quad \mathrm{C}_{6} \mathrm{MIm} \quad=\quad\right.$-hexyl-3methylimidazolium) simultaneously exhibit intense yellow emission and a strong response to external magnetic fields.[83]

Unlike simple inorganic lanthanide ions, lanthanide complexes such as lanthanide (III) $\beta$-diketonate complexes attracted consideration attention for synthesis of luminescent ILs because lanthanide complexes show greatly enhanced photoluminescence assisted by the so-called antenna effect, an energy 
transfer from the ligand to the lanthanide.[164-169] Unfortunately, the application of lanthanide (III) $\beta$-diketonate complexes has been limited because of easy photodegradation under long-term UV light irradiation. Binnemans et al. designed a novel ionic-liquidized material based on a europium $\beta$-diketonate complex, $\quad$ i.e., $\quad$ 1-hexyl-3-methylimidazolium tetrakis(2thenoyltrifluoroacetonato)europate(III) complex $\quad\left(\left[\mathrm{C}_{6} \mathrm{MIM}\right]\left[\mathrm{Eu}(\mathrm{tta})_{4}\right]\right)$. Interestingly, $\left[\mathrm{C}_{6} \mathrm{MIM}\right]\left[\mathrm{Eu}(\mathrm{tta})_{4}\right]$ readily dissolves in the $\mathrm{IL}\left[\mathrm{C}_{6} \mathrm{MIM}\right]\left[\mathrm{NTf}_{2}\right]$, and the resulting soution possess unexpected photochemical stability without any significant decrease in the quantum yield after 10 days of exposure to daylight.[164] The observed IL-induced photostability also holds true for luminescent anionic samarium (III) diketonate and dipicolinate complexes with both visible and near-infrared luminescence.[165] By virtue of the antenna effect, novel luminescent ILs were developed by reaction of $\mathrm{Eu}^{3+}$-coordinated carboxylfunctionalized ILs with terpyridine-functionalized imidazolium salts by Li et al. Depending on the anions of the carboxyl-functionalized ILs, these materials can be tuned to be viscous and transparent RTILs with bright red emission under UV light (Figure 15).[167]

These luminescent ILs have found potential applications including sensing of biomacromolecules,[143] detection of metal ions,[71] enantiomeric recognition,[170] and biomedical imaging.[154, 159] In particular, a fluorescent amino-acid-based chiral RTIL, L-phenylalanine ethyl ester bis(trifluoromethane) sulfonamide, despite its very low quantum yield (0.06) in ethanol, shows analytedependent fluorescence emission and can be employed for enantiomeric recognition.[170] 
3.1.3 Luminescent ionic liquid crystals. Obtaining luminescent ILs with liquid crystal behavior through rational construction of a mesomorphic moiety leads to new ionic, soft, ordered luminescent ILCs. Such luminescent materials are usually obtained by incorporating conjugated units into luminescent ILs or lengthening the attached alkyl chain to form a mesogen, mainly by modification of the cations.[84, 146, 171-183] Luminescence was usually realized by using inorganic lanthanide anions $[84,171,172,180]$ or organic chromophores with intense fluorescence.[146, 175-183] For example, BBI and 5,5bibenz(imidazolium) (BiBz) salts bearing long alkyl $N$-substituents from $\mathrm{C}_{8} \mathrm{H}_{17}$ to $\mathrm{C}_{18} \mathrm{H}_{37}$ and $\mathrm{C}_{15} \mathrm{H}_{31}$ can form either smectic or cubic thermotropic liquidcrystalline mesophases that persisted from 27.5 up to $216.2{ }^{\circ} \mathrm{C}$. BBI salts with $n$ $\mathrm{C}_{16} \mathrm{H}_{33} N$-substituents were emissive $\left(\lambda_{\mathrm{em}}=330 \mathrm{~nm}\right)$ with quantum yields ranging from 0.39 for salts containing $\left[\mathrm{MeSO}_{4}\right]$ anions to 0.99 for analogues containing bromides. A BiBz salt with the same $N$-substituents and bromide counteranions exhibited a slightly lower quantum yield (0.88) but a higher $\lambda_{\mathrm{em}}(346 \mathrm{~nm})$.[178] Organic-chromophore-containing ILCs, however, generally require tedious synthetic modifications. A simple way to easily produce luminescent ILCs is to use the ionic self-assembly process, a technique in which multiple charged organic species are organized by their association with oppositely charged amphiphilic counterions. For example, anions that contain $\pi$-conjugated chromophores such as anthracene[176] or 4,4-difluoro-4-bora-3a,4a-diazasindacene (F-BODIPY) 2,6-disulfonate[177] can be easily incorporated to yield highly luminescent ILCs (Figure 16). In particular, when a rigid dianionic 
BODIPY core associated with two imidazolium cations was functionalized by 1,2,3-trialkoxybenzyl units, columnar mesophases were formed from RT to about $130{ }^{\circ} \mathrm{C}$ for ILCs with alkyl chains containing 8,12 , and 16 carbon atoms, and the obtained ILCs showed strong emission at $532 \mathrm{~nm}$ with high quantum yields $0.54 \%-0.62$ and narrow emission profiles. The strong luminescence of the BODIPY unit was maintained in the mesophase, and fluorescence measurements confirmed the presence of $J$ aggregates in all cases.[177] In most cases, the optical properties of luminescent ILCs may be modulated depending on the physical state of the ILCs.[171, 174] In addition to the commonly used lanthanide anions and organic chromophores, ILCs containing $\left[\mathrm{M}(\mathrm{CN})_{2}\right](\mathrm{M}=\mathrm{Au}, \mathrm{Ag})$ reportedly displayed blue phosphorescent emission in their smectic A or columnar phase. The luminescence originates mostly from $\mathrm{M}-\mathrm{M}$ interactions, because no emission is observed for analogues containing the $[\mathrm{Cl}]$ anion.[173, 174]

\subsubsection{Ionic-liquid-based composite/hybrid luminescent materials. As}

mentioned above, most luminescent ILs were realized by incorporation of organic or inorganic chromophores within cations or anions to overcome the intrinsically weak fluorescence of nonfunctional ILs. Instead of this complicated strategy, ILbased composite/hybrid luminescent materials can be easily obtained by physical entrapment of luminescent compounds within ILs. These luminescent soft materials show obvious advantages in fabricating soft optical devices. Because most common ILs are transparent to absorption through almost the entire visible and near-infrared spectral regions[141] and have tunable polarity and 
noncoordinating ability, excellent stability, selective solubility, and nearly blank fluorescence,[140-142] they show promise as optical media or matrices for luminescent compounds. For example, ILs are good media for emissive lanthanide ions. ILs in this system can be thoroughly dried so that water molecules in the neighborhood of the lanthanide ion that quench the excited states (in particular for near-infrared luminescence[184]) can be dramatically removed.[184-188] ILs may also participate in the sensitization of lanthanide ions, and nonradiative deactivation processes are minimized compared to the solid state or organic solutions. Therefore, the optical transition is far less quenched than in conventional solvents. The resulting liquid luminescent materials possess many favorable properties including improved luminescence performance and enhanced photochemical stability.[163, 186] In addition, conventional organic fluorophores such as Rhodamine $6 \mathrm{G}[147]$ or merocyanine[148] or inorganic quantum dots[189, 190] in ILs showed greatly improved emission compared to that in molecular solvents.

ILs with weakly coordinating anions usually possess poor solubility toward luminescent lanthanide compounds, making it difficult to prepare soft luminescent materials. Pairing common nonluminescent ILs with strongly coordinating anions[191] or decorating lanthanide (III) $\beta$-diketonate complexes with imidazolium cations[164] is likely to solve this problem. Another approach is to attach functional groups such as carboxyl to the cationic core of ILs.[192194] Such task-specific ILs have recently been demonstrated to solubilize lanthanide oxides.[195-199] For example, highly luminescent lanthanide complex/IL composite materials were facilely obtained by directly dissolving 
$\mathrm{Eu}_{2} \mathrm{O}_{3}$ and organic ligands (2-thenoyltrifluoroacetone and 1,10-phenanthroline) into carboxyl-functionalized ILs without any solvents. The presence of organic ligands is necessary because irradiating only an IL-Eu mixture with UV light $(365 \mathrm{~nm})$ results in no obvious emission. $[195,196]$

ILs can also be combined with luminescent carbon dots[200] and semiconductor nanocrystals such as CdSe,[201] CdTe,[189, 190, 202, 203] and $\mathrm{ZnO}[204,205]$ to fabricate luminescent composite materials. In particular, when CdTe nanocrystals were extracted from water to a hydrophobic IL, the photoluminescence quantum yield increased noticeably from 0.16 in water to 0.27 in ILs, despite the identical absorption spectra of the nanocrystals in these two media. CdTe nanocrystals exhibit longer-term photostability under light irradiation in ILs than in aqueous solution.[189] More interestingly, the CdTe/IL hybrid displays temperature-dependent photoluminescence. As shown in Figure 17a, as the temperature decreases from 250 to $50 \mathrm{~K}$, the photoluminescence intensity of CdTe nanocrystals in $[\mathrm{BMIm}]\left[\mathrm{NTf}_{2}\right]$ increases considerably, and an obvious hypsochromic shift appears. The emission quantum yield reaches almost 0.95 below $100 \mathrm{~K}$. This point was confirmed by the significantly enhanced photoluminescence emission of CdTe in $[\mathrm{BMIm}]\left[\mathrm{NTf}_{2}\right]$ at $77 \mathrm{~K}$ compared to that at RT, whereas the emission of CdTe in water at RT was almost completely quenched after chilling in liquid $\mathrm{N}_{2}$ (Figure 17b).[202] Luminescent ionogels with superior mechanical properties and better processability have been obtained by encapsulating ILs and luminescent compounds, especially lanthanide complexes, into silica networks[197, 206-208] or polymers.[92, 209-213] For example, the europium (III) $\beta$-diketonate complex has been incorporated into 
inorganic-organic hybrid materials containing large quantities of IL $\left[\mathrm{C}_{6} \mathrm{MIm}\right]\left[\mathrm{NTf}_{2}\right]$, producing a crack-free, fully transparent, and colorless monolith. The resulting ionogel is ion-conductive and shows intense and high-purity red photoluminescence, caused mainly by the very intense ${ }^{5} \mathrm{D}_{0}-{ }^{7} \mathrm{~F}_{2}$ line at $611.5 \mathrm{~nm}$, when irradiated with UV light.[206] Analogously, luminescent hybrid materials were prepared by doping europium (III) complexes in a matrix consisting of a blend of poly(methyl methacrylate) (PMMA) and the IL $\left[\mathrm{C}_{6} \mathrm{MIm}\right]\left[\mathrm{NTf}_{2}\right]$, wherein the IL not only acts as a plasticizer but also enhances the solubility of the europium (III) complexes in the polymer matrix. The obtained flexible PMMA films showed bright red photoluminescence upon irradiation with UV light. The luminescence color can be tuned by a suitable choice of the lanthanide ion, ranging from blue for $\mathrm{Tm}^{3+}$ to green for $\mathrm{Tb}^{3+}$ and near-infrared emission for ions such as $\mathrm{Nd}^{3+}, \mathrm{Er}^{3+}$, and $\mathrm{Yb}^{3+} \cdot$ [209] It is noteworthy that IL-based soft materials possessing white luminescence have been successfully fabricated by integrating lanthanide $\beta$-diketonates with another (either organic or inorganic) chromophore such as polyoxometalates,[214] $\mathrm{ZnO},[205] \mathrm{ZnS},[215]$ or $\mathrm{Ag} / \mathrm{Ag}_{2} \mathrm{~S}[216] \mathrm{NPs}$.

\subsection{Nonlinear optical materials}

Nonlinear optics (NLO) is a branch of optics that describes the behavior of light in nonlinear media, that is, media in which the dielectric polarization responds nonlinearly to the electric field of light with very high intensities. Organic NLO materials have attracted considerable attention because of their potential applications in optical communication, data manipulation, and information 
processing. They have advantages over inorganic ones, including a shorter response time, lower dielectric constant, and better synthetic flexibility.[217-219] However, organic NLO materials still suffer from low thermal stability and poor processability.[220, 221] In this context, ILs appears to be one of these potential NLO materials that may overcome these disadvantages. First, the third-order NLO properties of common ILs were measured on the basis of two coefficients, the nonlinear index coefficient $\left(n_{2}\right)$ and linear absorption coefficient $\left(\alpha_{2}\right)$. [222225] Sesto et al. investigated the nonlinear optical properties in 2003. Several $\left[\mathrm{P}_{666,14}\right]$-based ILs paired with various anions including nitrodithioacetate (Ksalt), dithiomaleonitrile (DTMN), methyl xanthate, and diethyldithiacarbamate (DDTC) have been proven to show significant third-order NLO behavior. Although no trend has been discerned from the experimental data, using higherrow-element anions likely increases the nonlinear optical response. For example, $\left[\mathrm{P}_{666,14}\right][\mathrm{DTMN}]$, which possesses a dianion with more sulfur atoms, exhibits the largest $n_{2}$ of $-6.1 \times 10^{-14} \mathrm{~m}^{2} / \mathrm{W}$, approximately 20,000 times greater than that of $\mathrm{CS}_{2}$ and 10 times greater than that of $\left[\mathrm{P}_{666,14}\right][\mathrm{DDTC}] .[222]$ Common imidazolium ILs having a variable alkyl chain length and various anions such as $\left[\mathrm{BF}_{4}\right],\left[\mathrm{PF}_{6}\right],\left[\mathrm{NTf}_{2}\right]$, and $\left[\mathrm{CF}_{3} \mathrm{COO}\right]$ were further explored by the $Z$-scan technique.[223-225] All of these ILs showed a large anion-dependent $n_{2}$ but low values of $\alpha_{2} \cdot$ [223] [EMIm] $\left[\mathrm{CF}_{3} \mathrm{COO}\right]$ presents the highest $n_{2}$ of $-2.764 \times 10^{-11}$ $\mathrm{m}^{2} / \mathrm{W}$ under a continuous-wave argon laser at $514 \mathrm{~nm} .[224]$

In addition to the third-order NLO properties, the second-order NLO properties of ILs have also been studied. Considering that compounds with 
second-order NLO activity must be noncentrosymmetric at both the molecular and material levels, Xiao et al.[226] synthesized a series of ILs containing imidazolium cations bearing a conjugated aromatic core with donor-acceptor substituents and variable anions (Figure 18). They found that both the substituents and anions have certain effects on the second-order NLO properties. More specifically, for a given substituent on the phenyl ring, changing the anion from $\left[\mathrm{PF}_{6}\right]^{-}$to $\left[\mathrm{NTf}_{2}\right]^{-}$decreases the first hyperpolarizability $(\beta)$, whereas varying the substituents from hydrogen to a more electron-donating substitute such as hydroxyl or methoxyl increases the value of $\beta$. These results indicated that ionic salts with a specific second-order NLO response could possess larger hyperpolarizabilities with stronger electron-donating ability of the substituent on the phenyl ring.

\subsection{Photonic ionic liquids}

Photonic crystals, including self-assembled arrays of colloids (colloidal crystals) and their inverted structures (inverse opals), are periodic nanostructures that affect the motion of photons in much the same way that ionic lattices affect electrons in solids. Owing to their unique band-gap optical (photonic) properties, photonic crystals are attractive optical materials for controlling and manipulating the flow of light.[227] Direct infiltration of ILs into gel-immobilized colloidal crystals produces novel photonic crystals with high stability and a highly tunable optical stop band. The stop-band wavelength can be nearly linearly tuned from the visible $(560 \mathrm{~nm})$ to the near-infrared region $(956 \mathrm{~nm})$ depending on the 
mixing ratio of hydrophilic and hydrophobic ILs. In combination with the good ionic conductivity and favorable solvating properties offered by ILs, these ILcontaining photonic materials have potential for use in many new applications such as electro-optic conversion materials.[228]

Instead of being used as a solvent for composite photonic crystals, ILs can also be incorporated into the skeleton of photonic crystals to form PILs by a fourstep approach: fabrication of a silica colloidal crystal template, infiltration of the template with a mixed solution of IL monomer, polymerization, and selective dissolution of the template. The obtained PILs have inverted versions (inverse opals) of the template structure (silica colloidal crystal arrays) that can directly generate optical signals by Bragg diffraction.[68, 70, 73] As shown in Figure 19a, the PILs formed from 1-(2-acryloyloxyhexyl)-3-methylimidazolium bromide possess interconnected, highly ordered porous structure; this structure is favorable for rapid counteranion exchange within IL films. The PIL films displayed substantial color changes from pink to blue when the anions were varied from $[\mathrm{Br}]$ to $\left[\mathrm{NTf}_{2}\right]$ with a corresponding shift of the stop bands in the visible light range (Figure 19b and 19c). The principle behind the controlled optical response of such nanostructured PILs is as follows: capture of the targeted species within the PIL porous lattice changes the lattice constant of the PILs through swelling or shrinkage and consequently induces a shift in the spectral position of the colored Bragg reflections.[68] In addition to optical anion recognition and sensing, the constructed PIL also shows promise for the detection of humidity as well as solvents with different polarities.[68, 70, 73] More 
interestingly, the photonic band structure of PILs is very sensitive to an external electric field. For a PIL film with an oxidization-stable counteranion $\left[\mathrm{BF}_{4}\right]$, the reflection peak shifts toward shorter wavelengths with an increase in the voltage, saturating at a shift of about $30 \mathrm{~nm}$ for a field of ca. $5 \mathrm{~V}$. The reflection spectrum is recovered to the initial state after the removal of the applied voltage. Stable pulsed optical signals on the order of seconds can be obtained when a pulsed square-wave voltage is applied.[70] The PILs can be further designed as inverse opal spheres with tunable optical properties to more precisely discriminate anions, anion mixtures, and organic solvents. In addition, these materials can serve as a platform to prepare new functional photonic spheres with magnetic, catalytic, electrochemically active, redox-active, oxidative, or plasmonic function by a simple anion exchange reaction.[69]

\subsection{Ionic-liquid-based structural color materials}

Inspired by the nanostructures found in biological systems, Watanabe et al. reported that highly concentrated suspensions of polymer-grafted silica NPs in ILs formed soft glassy colloidal arrays (SGCAs). Unlike typical photonic-bandgap materials such as photonic materials with long-range ordered nanostructure,

IL-based SGCAs have short-range ordered structure and exhibit a soft-solid character and homogeneous and angle-independent structural colors.[229-232]

Figure 20a shows a photograph of the colloidal arrays formed by dispersing PMMA-grafted silica NPs in $[\mathrm{EMIm}]\left[\mathrm{NTf}_{2}\right]$ with different particle concentrations 
$(\mathrm{A}=33.3, \mathrm{~B}=25.0, \mathrm{C}=14.3)$. The color of the colloidal array changed from red to green to blue as the particle concentration increased, with a corresponding blue-shift of the reflection peak (Figure 20b). This color change over the entire visible range was precisely controlled by adjusting the particle size of the silica core and the chain length of the grafted polymer. Because the colloidal systems do not contain any chromophores capable of absorbing visible light, the colors were identified as structural colors on the basis of the scattering of coherent light from short-range ordered glassy colloidal arrays. The negligible vapor pressure and high chemical stability of ILs favors the direct evaluation of the particle arrangement of the colloidal array in an IL using TEM. As seen in Figure 20c, the spatial periodicity exhibits short-range order, and the mean interparticle distance decreases with increasing particle concentration. The ring-shaped 2D Fourier power spectra derived from the TEM images clearly indicate that the particles are not fully randomly distributed but are substantially nanostructured with respect to visible wavelengths at intermediate spatial frequencies. The circular rings further indicate that the colloidal arrays are equivalently nanostructured in all directions, which explains the angle-independent optical properties. It is noteworthy that the present systems are highly stable. For at least 20 months, neither crystallization nor a change in color was observed in the colloidal arrays. The only disadvantage is that the structural color of these short-range ordered structures is not as intense as that of conventional crystalline arrays (i.e., it is non-brilliant).[229] Replacing the PMMA polymer with poly(benzyl methacrylate) (PBnMA), which exhibits lower-critical-solution-temperature phase behavior in ILs, produces thermosensitive SGCAs.[230] Although both PBnMA- and PMMA-SGCAs 
display similar structural colors at low temperatures, the color of the PBnMA system disappears after heating to $100{ }^{\circ} \mathrm{C}$, and the solution becomes opaque because of the glass-to-gel transition. This color change is reversible, although it takes a relatively long time owing to the slow dynamics of PBnMA redissolution. In addition to the optical properties, these gel-like colloidal arrays have high ionic conductivity (greater than $10^{-3} \mathrm{~S} \mathrm{~cm}^{-1}$ at RT), suggesting potential use as solid electrolytes for electrochemical devices.[232]

\section{Energetic materials}

\subsection{Energetic ionic liquids}

Energetic materials represent a class of materials with large amounts of stored chemical energy that can be released.[233] Typical classes of energetic materials include explosives, pyrotechnics, and propellants, which are used in a wide range of military and civilian applications. [234] Recently, a new class of socalled energetic ionic liquids (EILs), sometimes also called energetic ionic salts, has emerged and become a hot topic in the fields of energetic materials and IL chemistry.[9, 235, 236] In general, EILs can be defined as energetic ionic compounds with a melting point of $<100{ }^{\circ} \mathrm{C}$ that have potential applications as explosives, propellants, pyrotechnics, and so on.[236] Essentially, EILs can be taken as a special class of IL-based materials, because their functional nature is to use the ultrahigh reactivity of the constituent ions or energetic/flammable frameworks in the EIL structures. Clearly, the advent of EIL materials is the 
result of interdisciplinary research between IL chemistry and energetic materials. According to the application, current EIL materials can be divided roughly into two main classes: high explosives and green propellant fuels. As an example of the former use, EILs are mainly used as a promising explosive melt phase to replace trinitrotoluene (TNT) in melt-pour explosives. For propellant uses, EILs can be rationally designed as green hypergolic fuels to replace toxic hydrazinederived fuels in the formulation of liquid bipropellants.[237] In this sense, there is no doubt that R\&D of EIL materials have opened a new door for developing more next-generation IL-based materials.

In fact, EIL materials are also not new things. For example, the first EIL, the hydrazinium azide salt (m. p. $=75^{\circ} \mathrm{C}$ ), was reported in 1890.[238] In the ensuing dozen years, some energetic organic nitrate salts were discovered, which also qualified as EILs according to the definition.[239] However, at that time the concept of EILs had not been presented, and the application potential of these energetic ionic materials had also not been realized. Until 2003, Drake et al. reported some energetic ionic salts with nitrate, perchlorate, and dinitramide anions and formally proposed the concept of EILs.[240] Since then, the enormous application potential of these energetic ionic materials has begun to be recognized, and more and more EIL materials have been discovered and used for military and civilian applications. In this field, several famous research groups, e.g., those of Thomas M. Klapötke from University of Munich, Jean'ne M. Shreeve from University of Idaho, Stefan Schneider and Gregory Drake from Edwards Air Force Base, Robin D. Rogers from University of Alabama, and some others, have made outstanding contributions. Considering that some very 
current reviews of IL-based energetic materials are available,[236, 241, 242] in this section we will focus only on some representative examples, especially of hypergolic ILs, and their design concepts and highly energetic nature in particular will be discussed.

In explosive use, an ideal EIL for TNT replacement should better meet several technical criteria such as a melting point of $80-100^{\circ} \mathrm{C}$, higher detonation performance than TNT, enhanced safety, and good compatibility with other energetic ingredients. Since 2001, considerable efforts have been devoted to synthesizing EILs as green alternatives to TNT in melt-pour explosives.[243-245] Some of the most representative examples are tetrazolium-based EILs (EILs 1-6), which were synthesized via protonation or quaternization of tetrazole frameworks (e.g., 5-amino-tetrazole, 1-amino-5-methyltetrazole, or 1,5-diamino-4-methyl1H-tetrazole) followed by a metathesis reaction with the silvers of nitrate, perchlorate, or dinitramide (Figure 21).[246-249] Among them, EIL-3, i.e., 1,5diamino-4-methyl-1H-tetrazolium dinitramide, exhibited excellent energetic properties as a potential TNT replacement, e.g., a melting point of $85^{\circ} \mathrm{C}$, high thermal stability of $>150{ }^{\circ} \mathrm{C}$, and high nitrogen content and oxygen content of up to $57.01 \mathrm{wt} \%$ and $28.94 \mathrm{wt} \%$, respectively. Similarly, three protonated tetrazolium-based dinitramide salts also displayed good energy density; e.g., the density of EIL-4 was $1.856 \mathrm{~g} \mathrm{~cm}^{-3}$, and its calculated detonation velocity and pressure were $9429 \mathrm{~m} \mathrm{~s}^{-1}$ and $38.4 \mathrm{GPa}$, respectively, which are much higher those that of TNT (e.g., $6881 \mathrm{~m} \mathrm{~s}^{-1}$ and $19.5 \mathrm{GPa}$, respectively). A true explosion test of EIL-4 also demonstrated its high explosive brisance using a Koenen test steel sleeve apparatus under confinement (Figure 21b). In this experiment, the 
explosion of EIL-4 was initiated via thermal ignition using four Bunsen burners. The entire explosion process was recorded and monitored by a high-speed camera (4000 frames $\mathrm{s}^{-1}$ ). It was estimated that its experimental detonation velocity was close to $9200 \pm 500 \mathrm{~m} \mathrm{~s}^{-1}$.

Exploring the applications of hypergolic ILs as green bipropellant fuels is an entirely new area in the field of IL-based functional materials.[236, 237] In contrast to their use as explosives, EILs are considered promising propellant fuels mainly because of their unique properties including low volatility, low melting point, low corrosivity, low fire hazard, low toxicity, ultrafast ignition delay, high specific impulse, and good thrust control. In the propellant field, the designable character of EILs, i.e., the modular design strategy of component ions, makes the construction of a desired hypergolic fuel possible, where the properties of EILs can be customized for specific tasks. In 2008, the hypergolic reactivity of some $\left[\mathrm{N}(\mathrm{CN})_{2}\right]$-containing ILs with white fuming nitric acid (WFNA) was first reported.[250, 251] This work encouraged researchers to search for new IL fuels and to explore their application feasibility in green propellant materials. The ignition delay (ID) time is an important parameter for practical applications of a hypergolic bipropellant fuel. In general, an ultrafast ID time, e.g., shorter than 5 $\mathrm{ms}$, is strongly preferred. To meet this requirement, highly reactive boronhydrogen bonds and a fuel-rich character were purposely designed into the structures of EILs, and three series of EILs with B-H bonds were obtained: dicyanoborate $\left(\left[\mathrm{BH}_{2}(\mathrm{CN})_{2}\right]^{-}\right)$-based ILs, $[252,253]$ tetrahydroborate $\left(\left[\mathrm{BH}_{4}\right]^{-}\right)$-

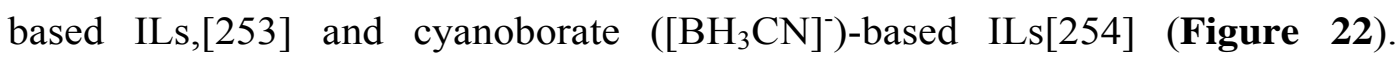


Among them, the dicyanoborate-based EILs are very stable to water and exhibit very short ID times; e.g., the ID time of $\mathrm{N}$-allyl-N,N-dimethylhydrazinium dicyanoborate (EIL-7) is as short as $4 \mathrm{~ms}$. In contrast, two other categories of EILs, i.e., $\left[\mathrm{BH}_{4}\right]^{-}$- and $\left[\mathrm{BH}_{3} \mathrm{CN}\right]^{-}$-based salts, were relatively reactive to atmospheric moisture, although they all exhibited comparable or even shorter ID times; e.g., the ID times of 1-allyl-3-methylimidazolium borohydride (EIL-8) and 1-ethyl-3-methylimidazolium cyanoborohydride (EIL-9) are 2 and $4 \mathrm{~ms}$, respectively (Figure 22). All of these hypergolic EILs displayed enormous potential as promising green replacements for toxic hydrazine-based fuels in liquid bipropellants.

In addition to WFNA and $\mathrm{N}_{2} \mathrm{O}_{4}, \mathrm{H}_{2} \mathrm{O}_{2}$ is also considered for use as the oxidizer in the propellant formulation. A new class of EILs that can be ignited with $\mathrm{H}_{2} \mathrm{O}_{2}$ was recently designed and synthesized.[255] In the structures, the hydrogen-rich $\left[\mathrm{Al}\left(\mathrm{BH}_{4}\right)_{4}\right]^{-}$anion was employed and paired with bulky phosphonium cations to form the desired EILs (Figure 22). When these ILs come into contact with $98 \% \mathrm{H}_{2} \mathrm{O}_{2}$, spontaneous ignition and combustion occurs in 30 ms. This work demonstrated the hypergolic feasibility of an EIL with a lowhazard $\mathrm{H}_{2} \mathrm{O}_{2}$ oxidizer. Moreover, the tetranitratoaluminate anion $\left(\left[\mathrm{Al}\left(\mathrm{NO}_{3}\right)_{4}\right]^{-}\right)$ was also used as a high oxygen carrier in the design and construction of oxygenbalanced EILs.[256] For example, when $\left[\mathrm{Al}\left(\mathrm{NO}_{3}\right)_{4}\right]^{-}$was paired with a nitrogenrich cation as an energetic counterion, i.e., 1-ethyl-4,5-dimethyltetrazolium, a colorless viscous liquid could be obtained. Interestingly, this EIL exhibited unique self-ignition and self-sustained burning behavior under thermal heating to about $200{ }^{\circ} \mathrm{C}$. It was estimated that its propulsion efficiency as a rocket 
monopropellant significantly exceeded those of state-of-the-art materials such as hydrazine.

Although significant progress has been made in the field of EILs, many challenges remain to be overcome. Future research should focus on a deeper understanding of IL-based energetic materials, such as the correlations between their structure and properties or performance (e.g., detonation velocity, specific impulse, and safety), which will be of great significance to promoting their practical engineering-oriented applications. Moreover, one may use technological aides such as computer-aided molecular design and combinatorial chemistry for structure screening and property optimization of a potentially desirable EIL molecule. We believe that EILs, as an emerging field for IL-based functional materials, are far from fully exploited.

\subsection{Hydrogen-storage materials}

Hydrogen is considered to be a clean alternative to fossil fuels. Efficient and safe methods of hydrogen storage are highly desirable for its large-scale application. Many efforts have been devoted to developing new materials and technologies for physical and chemical hydrogen storage, but they still suffer from drawbacks including low hydrogen capacities, slow release rates, and high release temperatures.[257] Certain ILs such as [BMIm]Cl were demonstrated to be an excellent medium for hydrogen storage, in which both the extent and rate of dehydrogenation of ammonia borane $\left(\mathrm{NH}_{3} \mathrm{BH}_{3}\right)$ increased significantly compared to the dehydrogenation of $\mathrm{NH}_{3} \mathrm{BH}_{3}$ in the solid state.[258] For example, in 
contrast to the solid-state reactions (no hydrogen production at $85^{\circ} \mathrm{C}$ within $3 \mathrm{~h}$ ), dehydrogenation of $\mathrm{NH}_{3} \mathrm{BH}_{3}$ in $[\mathrm{BMIm}] \mathrm{Cl}$ showed no induction period and evolved 0.95 equivalents of $\mathrm{H}_{2}$. Ultimately, the IL-based system gave a total of 1.6 equivalents of $\mathrm{H}_{2}$ after heating for $22 \mathrm{~h}$ at $95{ }^{\circ} \mathrm{C}$, much higher than that of $\mathrm{NH}_{3} \mathrm{BH}_{3}$ alone $\left(0.9\right.$ equivalents of $\mathrm{H}_{2}$ after heating for $48 \mathrm{~h}$ at $\left.95{ }^{\circ} \mathrm{C}\right)$. The remarkable hydrogen release was ascribed to the favorable formation and stabilization of the ionic intermediate (possibly diammoniate of diborane) for dehydrogenation of $\mathrm{NH}_{3} \mathrm{BH}_{3}$ in ILs.[259] In the presence of transition metal catalysts, the dehydrogenation selectivity and extent can be further improved.[260] The hydrogen release of ammonia boranes in ILs was also affected by the temperature,[258, 259] ammonia borane/IL weight ratio,[259] IL structure and properties,[260, 261] and type of ammonia boranes.[262, 263]

In addition to their use as promoting solvents for hydrogen release, the potential of ILs themselves as efficient chemical hydrogen-storage materials has also been explored by exploiting the unique features of ILs, such as low vapor pressure and structure tunability.[264-266] Rieger et al. synthesized two ILs, methylguanidinium borohydride $\left(\left[\left(\mathrm{N}_{3} \mathrm{H}_{8} \mathrm{C}\right) \mathrm{C}\right]\left[\mathrm{BH}_{4}\right]\right)$ and guanidinium borohydride $\left(\left[\left(\mathrm{N}_{3} \mathrm{H}_{6}\right) \mathrm{C}\right]\left[\mathrm{BH}_{4}\right]\right)$ by simple ion exchange (Figure 23a). $\left[\left(\mathrm{N}_{3} \mathrm{H}_{8} \mathrm{C}\right) \mathrm{C}\right]\left[\mathrm{BH}_{4}\right]$ is a yellow viscous liquid $\left(\mathrm{m} . \mathrm{p} .=-5^{\circ} \mathrm{C}\right)$ that releases $9.0 \mathrm{wt} \%$ $\mathrm{H}_{2}$ under both thermal and catalytic conditions, whereas $\left(\left[\left(\mathrm{N}_{3} \mathrm{H}_{6}\right) \mathrm{C}\right]\left[\mathrm{BH}_{4}\right]\right.$ is a white solid with a hydrogen storage capacity of $10.7 \mathrm{wt} \%$. Upon heating at $75{ }^{\circ} \mathrm{C}$ for $20 \mathrm{~min},\left[\left(\mathrm{~N}_{3} \mathrm{H}_{8} \mathrm{C}\right) \mathrm{C}\right]\left[\mathrm{BH}_{4}\right]$ evolved 2.9 equivalents of $\mathrm{H}_{2}$ in the presence of Wilkinson's catalyst $(1 \mathrm{~mol} \%)$, whereas $\left[\left(\mathrm{N}_{3} \mathrm{H}_{6}\right) \mathrm{C}\right]\left[\mathrm{BH}_{4}\right]$ in dry diglyme evolved 3.9 equivalents of $\mathrm{H}_{2}$ with $10.3 \mathrm{wt} \%$ loading of Wilkinson's catalyst. The high 
capacity to release pure $\mathrm{H}_{2}$ makes these compounds interesting targets for hydrogen-storage applications.[264] To avoid the volatility of the N-substituted amine-boranes, which reduces conversion during $\mathrm{H}_{2}$ release, the $\mathrm{N}$-substituted amine-borane was deliberately attached to the alkyl chain of the cationic cores to form hydrogen-storage ILs with different anions ([Cl], [OTf], $\left[\mathrm{NTf}_{2}\right]$ ) by an anhydrous anion exchange method (Figure 23b). Thermogravimetric evaluation revealed that the dehydrogenation temperature of these ILs was strongly influenced by the anions. Substituting $[\mathrm{Cl}]$ for either the $[\mathrm{OTf}]$ or $\left[\mathrm{NTf}_{2}\right]$ anion lowers the dehydrogenation temperature by ca. $50^{\circ} \mathrm{C}$, whereas switching among three cations (imidazolium, pyrrolidinium, and pyrazolium) causes only a ca. 10 ${ }^{\circ} \mathrm{C}$ variance. Interestingly, one such IL can be blended with at least two equivalents of $\mathrm{NH}_{3} \mathrm{BH}_{3}$ to increase the hydrogen-storage capacity while maintaining a fluid phase by forming oligomeric products. Therefore, this hydrogen-storing fuel can be readily loaded/unloaded from a vehicle.[265]

\section{Ionic liquid/carbon hybrid materials}

\subsection{Non-covalent grafting of ionic liquids on carbon nanoforms}

Most traditional ILs, owing to their aromatic cations, likely interact with graphitic carbon nanoforms such as carbon nanotubes (CNTs),[267] graphene,[268] and graphite structure[269] to form non-covalent IL/carbon hybrids.[270] These novel soft materials not only combine the properties of ILs and carbon nanoforms, but 
also present some peculiar properties due to synergistic effects between the two components. For example, provided that the carbons are electroconductive and the ILs are ion conductive, this type of hybrid material shows mixed conductivity with both ionic and electronic contributions.[271] Of particular interest is that CNTs can be readily dispersed in an imidazolium IL by mechanical milling.[267, 272-275] It is well known that CNTs, especially single-walled CNTs (SWCNTs), are good dopants even at a low loading level because of their greater aspect ratios and mechanical moduli as well as very high conductivities $\left(10^{2}-10^{3} \mathrm{~S} \mathrm{~cm}^{-1}\right)$. However, SWCNTs tend to form agglomerates, resulting in rather poor mechanical and electroconductive properties. Aida et al. found that simply grinding mixtures of imidazolium-ion-containing RTILs and SWCNTs in an agate mortar yielded a gel-like composite (bucky gel), which can be easily processed into any shape without disrupting the nanotube structures (Figure 24a). Owing to the negligible volatility of ILs, bucky gels, in sharp contrast with ordinary organogels and hydrogels, are highly stable and can retain their physical properties even under reduced pressure. Moreover, upon gelation, the heavily entangled SWCNT bundles are untangled to give highly dispersed, much finer bundles (Figure 24b and 24c).[267] The driving force for the dispersion and stabilization of SWCNTs in imidazolium ILs has been intensively investigated by both experiments and theoretical calculations.[276-279] Weak van der Waals interactions including cation $-\pi$ and $\pi-\pi$ interactions between the aromatic imidazolium cation and the nanotube surface most likely account for the absence of strong aggregation between SWCNTs. Furthermore, the use of polymerizable ILs causes dispersion of CNTs in polymer media.[280, 281] In this case, 
mechanically reinforced and electroconductive polymeric bucky gels (bucky plastics) were fabricated by in situ free-radical polymerization of an acrylateappended imidazolium IL gelled with SWCNTs. For example, a bucky plastic film containing $3.8 \mathrm{wt} \%$ of SWCNTs exhibits an enhancement of the dynamic hardness by a factor of four and an electrical conductivity of $0.56 \mathrm{~S} \mathrm{~cm}^{-1}$. Changing the cross-linking group from methacrylate to vinyl was found to dramatically reduce the tensile modulus and results in brittle films.[280] The bucky gels possess unique properties such as the combined nonvolatility and thermal stability of RTILs and high electronic conductivity of CNTs. As a result, they have found potential applications as electrodes for actuators,[282, 283] sensors,[284] supercapacitors,[285, 286] $\mathrm{Li}-\mathrm{O}_{2}$ and $\mathrm{Li}-$ air batteries,[287] and dye-sensitized solar cells,[288] and as sorbents for preconcentration of analytes.[289, 290] Interestingly, the use of bucky gels as reaction media can further facilitate covalent functionalization of SWCNTs.[291, 292] For example, extremely rapid and green chemical functionalization of SWCNTs in imidazolium ILs was realized, wherein SWCNTs are exfoliated and functionalized predominantly as individuals by grinding them for minutes at RT with aryldiazonium salts in the presence of ILs and $\mathrm{K}_{2} \mathrm{CO}_{3}$.[291]

Because graphene and SWCNTs share very similar physicochemical features, such as the conjugated electronic structure and surface properties, the approach that has been adopted to prepare solubilized CNTs is also extended to graphene.[268, 293-295] Stable dispersions of reduced graphene oxide (GO) in hydrophilic imidazolium or pyridinium ILs at relatively high concentrations (7.0 $\mathrm{mg} \mathrm{mL} \mathrm{mL}^{-1}$ ) were obtained without any surfactants or stabilizers.[293] The 
combination of the unique properties of ILs and graphene helps to open up new applications of graphene materials. It was reported that the use of graphene can significantly improve the low-temperature physical properties of energetic ILs through the manipulation of intermolecular interactions between ILs and graphene.[268] A specific interaction between ILs and CNTs or graphene is also observed when an IL is entrapped within highly graphitic nanocarbon, which is promising for the formation of a functional carbon layer on the surface of nanocarbon.[269]

\subsection{Covalent grafting of ionic liquids on carbon nanoforms}

The functionalization of carbon materials by ILs via a covalent method is another approach to producing IL/carbon hybrid materials. For example, chemical modification of carbon nanoforms, especially CNTs, by ILs can improve their compatibility and stability. The tunable properties of ILs could also be transferred to the solid surfaces of carbon nanoforms, providing control over the surface wettability.[296-303] Covalent modification of CNTs is usually performed using a standard method with the following steps: (a) chemical oxidation of CNTs under harsh conditions yielding carboxylic acid functional groups on their surface; (b) covalent modification of CNTs using an IL backbone (usually amineterminated ILs); (c) anionic exchange (Figure 25). By using this stepwise functionalization strategy, complementary double-covalent functionalized SWCNTs that involve both solubilizing ILs and electroactive moieties can be synthesized.[304] In comparison with the pristine CNTs, the modified CNTs 
showed greatly improved solubility and dispersibility in most solvents, which can be further tuned by varying the type of anions. For example, the solubility of imidazolium-IL-modified multi-walled CNTs (MWCNTs) in water is ordered as follows: $[\mathrm{Br}]>\left[\mathrm{BF}_{4}\right]>\left[\mathrm{PF}_{6}\right]>\left[\mathrm{NTf}_{2}\right] .[297]$ Furthermore, the solubility of the IL-functionalized MWCNTs in water and organic solvents could be reversibly switched by anion exchange.[298] The counterions in IL-modified carbon materials can be further extended to functional anions such as photoactive,[305] electrochemically active,[299, 304] and metal-containing anions, $[302,303]$ which may enable their potential applications in lubrication,[306] catalysis, $[302,307$, 308] electrochemistry,[299] and so on. For example, IL-modified MWCNTs were evaluated as lubricant additives in ILs with good friction reduction and antiwear properties.[306] In the case of IL/CNT hybrids containing $\mathrm{PtCl}_{4}{ }^{2-}$, further reduction resulted in small Pt NPs with a uniform dispersion and good size distribution $(3 \mathrm{~nm})$ that adhere to the surface of IL-functionalized CNTs. Owing to the combined high conductivity of CNTs and excellent activity of Pt NPs, the as-prepared hybrids can be directly explored as electrocatalysts for methanol oxidation reactions and exhibit higher electrocatalytic activity than the commercial C/Pt catalyst.[302]

This IL-based covalent grafting method could be applicable to other carbon nanoforms such as nanohorns,[309] fullerene,[310] and especially graphene.[305, 311-316] Note, however, that chemical modification of graphene by ILs generally starts from $\mathrm{GO}$, because $\mathrm{GO}$ contains more plentiful and reactive epoxy groups than inert graphene.[305, 311-314] For example, polydisperse graphene nanosheets were synthesized and stabilized by amine-terminated ILs via a 
nucleophilic ring-opening reaction between the epoxy groups of GO and the amine groups of ILs. Without any polymeric or surfactant stabilizers, the resulting graphene could be dispersed well in water, DMF, and DMSO.[311] Through one-step hydrothermal treatment of a mixture of GO and an amineterminated IL, three-dimensional (3D) macroassembly of graphene was obtained, wherein ILs were expected to play a two-fold role, i.e., in situ reduction of GO and promotion of the formation of 3D nanostructure.[314] Interestingly, a GObased fluid is successfully obtained by sulfonation of GO accompanied by ionic attachment of a bulky amine-terminated Jeffamine ${ }^{\circledR}$.[315] These IL-modified GOs could be used as precursors for direct pyrolysis to yield nitrogen-doped graphene.[316, 317]

\section{Conclusions}

In this review article, we have highlighted the recent development of IL-based advanced functional materials. The conjunction between ILs and materials has led to an explosion in diverse applications related to nearly all aspects of materials science. IL-based functional materials can be roughly classified into two categories: functional ILs (or ionic liquidized materials) and IL-containing composite materials, which are obtained by chemical modification (covalent functionalization or ion-exchange metathesis) and physical combination of ILs and traditional materials, respectively. A typical example is the soft materials obtained through either covalent or noncovalent functionalization of CNTs by ILs. The former, with covalently grafted ILs, possesses anion-dependent solubilities in aqueous and organic solvents, whereas the latter forms stable bucky 
gels assisted by the noncovalent interactions between the IL cation and the nanotube surfaces. This type of hybrid material shows mixed conductivity with both ionic and electronic contributions and opens a new way to use ILs and CNTs. Depending on the ionic constituents, alkyl chain length, and functional groups, the properties of these IL-based functional materials, such as the melting point, polarity, viscosity, density, hydrophilicity/hydrophobicity, solubility, acidity, and coordination ability, can be tailored, and the materials themselves can be easily designed as mono-, bi-, or multifunctional materials for given applications. For example, metal-containing ILs are regarded as new multifunctional materials that combine the properties of ILs with additional functions such as magnetic, luminescent, and/or catalytic properties depending on the enclosed metal ion used. No doubt the combination of IL chemistry with materials science in multiple crossed disciplines will produce more and new advanced materials with improved properties and unexpected performance compared to conventional materials.

The following key points need to be considered for future development of ILbased functional materials: (a) Unlike traditional molecular materials, various interactions such as covalent bonding, hydrogen bonding, van der Waals forces, cation $-\pi$ and $\pi-\pi$ interactions, and electrostatic interaction coexist in these ionic materials, making it possible to develop more advanced functional materials. However, finding a balance between exploiting these interactions and fundamental understanding of the correlations between the structure, properties, and performance of these novel materials is required to unlock their potential. For example, the introduction of additional functional groups, especially organic 
functional groups possessing large molecular volume and strong $\pi-\pi$ stacking interaction, not only complicates the entire synthetic procedure, but also greatly increases the melting point of the final ionic materials, sometimes far above 100 ${ }^{\circ} \mathrm{C}$, which is detrimental for favorable applications of liquid materials. Bulky anions or long alkyl chains are usually employed to depress the melting points, and the resulting materials are either supercooled liquids or highly viscous. (b) Even though excellent pioneering work demonstrated that ILs can be exploited as ideal materials for the liquid mirror of a space telescope with a silver coating,[318, 319] considerable room still remains for advanced applications of IL-based soft materials under extreme conditions, especially at very high or low temperature, very high pressure, or vacuum. For example, the negligible vapor pressure, high stability, and good friction reduction and antiwear properties of ILs make it possible to use ILs as potential lubricants for rocket motors and aerospace vehicles. (c) Another problem is that functionalization of ILs is usually performed on the cationic cores, whereas the counterions are generally varied to modulate the physical properties to some extent. It is therefore desirable to design and synthesize more functional anions like the metal-containing anions.

Despite the above challenges, the application of IL-based functional materials is full of opportunities, and significant progress in this area has been made in recent years. Materialization of ILs not only advances the development of conventional materials greatly, but also opens a new potential direction for intensive IL research. As a promising candidate, IL-based advanced functional materials are likely to bridge the gap between inorganic and organic materials, 
molecular and ionic materials, and solid and liquid materials. One can confidently predict intensified interest in this research field.

\begin{tabular}{|c|c|}
\hline \multicolumn{2}{|l|}{ Abbreviation index } \\
\hline \multicolumn{2}{|l|}{$2 \mathrm{D}$} \\
\hline $3 \mathrm{D}$ & three-dimensional \\
\hline$[\mathrm{ACnIm}]\left[\mathrm{N}(\mathrm{CN})_{2}\right]$ & 1-allyl-3-alkylimidazolium dicyanamide \\
\hline$\beta$ & hyperpolarizability \\
\hline BBI & benzobis(imidazolium) \\
\hline$[\mathrm{BBIm}][\mathrm{Br}]$ & 1,3-dibutylimidazolium bromide \\
\hline$\left[\mathrm{BH}_{4}\right]$ & tetrahydroborate \\
\hline$\left[\mathrm{BH}_{2}(\mathrm{CN})_{2}\right]$ & dicyanoborate \\
\hline$[\mathrm{BH} 3 \mathrm{CN}]$ & cyanoborate \\
\hline $\mathrm{BiBz}$ & 5,5-bibenz(imidazolium) \\
\hline$[\mathrm{BMIm}]\left[\mathrm{FeCl}_{4}\right]$ & 1-butyl-3-methylimidazolium tetrachloroferrate \\
\hline$\left[\mathrm{C}_{6} \mathrm{MIm}\right]$ & 1-hexyl-3-methylimidazolium \\
\hline$\left[\mathrm{C}_{12} \mathrm{MIm}\right]\left[\mathrm{BF}_{4}\right]$ & 1-dodecyl-3-methylimidazolium tetrafluoroborate \\
\hline$\left[\mathrm{C}_{\mathrm{n}} \mathrm{OHMIm}\right]$ & 1-hydroxyalkyl-3-methylimidazolium \\
\hline CNTs & carbon nanotubes \\
\hline DDTC & diethyldithiacarbamate \\
\hline DHBCs & double-hydrophilic block copolymers \\
\hline $\mathrm{DMF}$ & $\mathrm{N}, \mathrm{N}$-dimethylformamide \\
\hline DMSO & dimethyl sulfoxide \\
\hline
\end{tabular}




\begin{tabular}{|c|c|}
\hline $\mathrm{DN}$ & donor number \\
\hline DPA & dipropylamine \\
\hline DTMN & dithiomaleonitrile \\
\hline ECL & electrochemiluminescence \\
\hline EDTA & ethylenediaminotetraacetic acid \\
\hline EILs & energetic ionic liquids \\
\hline$[\mathrm{Eu}(\mathrm{tta}) 4]$ & tetrakis(2-thenoyltrifluoroacetonato)europate(III) \\
\hline F-BODIPY & 4,4-difluoro-4-bora-3a,4a-diazas-indacene \\
\hline$[\mathrm{FL}]$ & fluorescein \\
\hline $\mathrm{GO}$ & graphene oxide \\
\hline ID & ignition delay \\
\hline$I_{\mathrm{E}} / I_{\mathrm{M}}$ & the excimer-to-monomer fluorescence intensity ratio \\
\hline ILCs & ionic liquid crystals \\
\hline ILs & ionic liquids \\
\hline LIG & liquid-in-glass \\
\hline $\mathrm{MO}$ & methyl orange \\
\hline MR & methyl red \\
\hline MWCNTs & multi-walled carbon nanotubes \\
\hline NPs & nanoparticles \\
\hline NH3BH3 & ammonia borane \\
\hline$\left[\left(\mathrm{N}_{3} \mathrm{H}_{6}\right) \mathrm{C}\right]\left[\mathrm{BH}_{4}\right]$ & guanidinium borohydride \\
\hline$\left[\left(\mathrm{N}_{3} \mathrm{H}_{8} \mathrm{C}\right) \mathrm{C}\right]\left[\mathrm{BH}_{4}\right]$ & methylguanidinium borohydride \\
\hline NLO & nonlinear optics \\
\hline$\left[\mathrm{NTf}_{2}\right]$ & bis(trifluoromethanesulfonyl)imide \\
\hline
\end{tabular}




\begin{tabular}{|c|c|}
\hline$\left[\mathrm{P}_{666,14}\right]$ & trihexyltetradecylphosphonium \\
\hline PBnMA & poly(benzyl methacrylate) \\
\hline PIL & photonic IL \\
\hline PMMA & poly(methyl methacrylate \\
\hline $\mathrm{ppb}$ & parts-per-billion \\
\hline QCM & quartz crystal microbalance \\
\hline $\mathrm{R} \& \mathrm{D}$ & research and development \\
\hline RH & relative humidity \\
\hline RTILs & room temperature ionic liquids \\
\hline SGCAs & soft glassy colloidal arrays \\
\hline SILs & switchable ionic liquids \\
\hline SWCNTs & single-walled carbon nanotubes \\
\hline TEM & transmission electron microscopy \\
\hline$[\mathrm{TEMA}]\left[\mathrm{MeSO}_{4}\right]$ & tris(2-hydroxyethyl)methylammonium methylsulfate \\
\hline TEMPO & 2,2,6,6-tetramethyl-1-piperidinyloxyl \\
\hline THF & tetrahydrofuran \\
\hline TNT & trinitrotoluene \\
\hline UV & ultraviolet \\
\hline WFNA & white fuming nitric acid \\
\hline$\mu_{\text {eff }}$ & effective magnetic moment \\
\hline
\end{tabular}

\section{Acknowledgements}


This work was supported by the National Natural Science Foundation of China

(No. 21103208, 21203219 and 21173240) and the ALCA program of the Japan

Science and Technology Agency (JST).

\section{Notes and references}

[1] Wilkes JS, Zaworotko MJ. Air and water stable 1-ethyl-3-methylimidazolium based ionic liquids. J Chem Soc, Chem Commun. 1992:965-7.

[2] Hallett JP, Welton T. Room-temperature ionic liquids: solvents for synthesis and catalysis. 2. Chem Rev. 2011;111:3508-76.

[3] Sun X, Luo H, Dai S. Ionic liquids-based extraction: a promising strategy for the advanced nuclear fuel cycle. Chem Rev. 2011;112:2100-28.

[4] Pârvulescu VI, Hardacre C. Catalysis in ionic liquids. Chem Rev. 2007;107:2615-65.

[5] Hapiot P, Lagrost C. Electrochemical reactivity in room-temperature ionic liquids. Chem Rev. 2008;108:2238-64.

[6] MacFarlane DR, Tachikawa N, Forsyth M, Pringle JM, Howlett PC, Elliott GD, et al. Energy applications of ionic liquids. Energy Environ Sci. 2014;7:232-50.

[7] Armand M, Endres F, MacFarlane DR, Ohno H, Scrosati B. Ionic-liquid materials for the electrochemical challenges of the future. Nat Mater. 2009;8:621-9.

[8] Zhang S, Ueno K, Dokko K, Watanabe M. Recent Advances in Electrolytes for Lithium-Sulfur Batteries. Adv Energy Mater. 2015;5:1500117.

[9] Smiglak M, Metlen A, Rogers RD. The Second Evolution of lonic Liquids: From Solvents and Separations to Advanced Materials-Energetic Examples from the lonic Liquid Cookbook. Acc Chem Res. 2007;40:1182-92.

[10] Smiglak M, Pringle J, Lu X, Han L, Zhang S, Gao H, et al. Ionic liquids for energy, materials, and medicine. Chem Commun. 2014;50:9228-50.

[11] Torimoto T, Tsuda T, Okazaki Ki, Kuwabata S. New frontiers in materials science opened by ionic liquids. Adv Mater. 2010;22:1196-221.

[12] Zhang S, Dokko K, Watanabe M. Porous ionic liquids: synthesis and application. Chem Sci. 2015;6:3684-91.

[13] Zhang S, Dokko K, Watanabe M. Carbon materialization of ionic liquids: from solvents to materials. Mater Horiz. 2015;2:168-97.

[14] Lee H-Y, Diehn K, Sun K, Chen T, Raghavan S. Reversible Photorheological Fluids Based on SpiropyranDoped Reverse Micelles. J Am Chem Soc. 2011; 133:8461-3.

[15] Branco LC, Pina F. Intrinsically photochromic ionic liquids. Chem Commun. 2009:6204-6.

[16] Yam VWW, Lee JKW, Ko CC, Zhu NY. Photochromic Diarylethene-Containing lonic Liquids and NHeterocyclic Carbenes. J Am Chem Soc. 2009;131:912-3.

[17] Tamura H, Shinohara Y, Arai T. Synthesis and Photochemistry of Stilbene lonic Liquids. Chem Lett. 2010;39:240-1.

[18] Kawai A, Kawamori D, Monji T, Asaka T, Akai N, Shibuya K. Photochromic Reaction of a Novel Room Temperature Ionic Liquid: 2-Phenylazo-1-hexyl-3-methylimidazolium Bis(pentafluoroethylsulfonyl)amide. Chem Lett. 2010;39:230-1.

[19] Coleman S, Byrne R, Alhashimy N, Fraser KJ, MacFarlane DR, Diamond D. Photochromic imidazolium based ionic liquids based on spiropyran. Phys Chem Chem Phys. 2010;12:7009-17.

[20] Zhang S, Liu S, Zhang Q, Deng Y. Solvent-dependent photoresponsive conductivity of azobenzeneappended ionic liquids. Chem Commun. 2011;47:6641-3.

[21] Asaka T, Akai N, Kawai A, Shibuya K. Photochromism of 3-butyl-1-methyl-2-phenylazoimidazolium in room temperature ionic liquids. J Photoch Photobio A. 2010;209:12-8.

[22] Avó Jo, Cunha-Silva L, Lima JoC, Jorge Parola A. Design and Synthesis of Photoactive lonic Liquids. Org Lett. 2014;16:2582-5.

[23] Yang J, Wang H, Wang J, Zhang Y, Guo Z. Highly efficient conductivity modulation of cinnamate-based light-responsive ionic liquids in aqueous solutions. Chem Commun. 2014;50:14979-82. 
[24] Nakashima T, Miyamura K, Sakai T, Kawai T. Photo-, Solvent-, and Ion-Controlled Multichromism of Imidazolium-Substituted Diarylethenes. Chem Eur J. 2009;15:1977-84.

[25] Sekkat Z, Knoll W. Photoreactive Organic Thin Films. Academic Press; 2002.

[26] Tamada M, Watanabe T, Horie K, Ohno H. Control of ionic conductivity of ionic liquid/photoresponsive poly( amide acid) gels by photoirradiation. Chem Commun. 2007:4050-2.

[27] Akitsu T, Einaga Y. Novel photo-induced aggregation behavior of a supramolecular system containing iron(III) magnetic ionic liquid and azobenzene. Inorg Chem Commun. 2006;9:1108-10.

[28] Xiao S, Lu X, Lu Q. Photosensitive polymer from ionic self-assembly of azobenzene dye and poly (ionic liquid) and its alignment characteristic toward liquid crystal molecules. Macromolecules. 2007;40:794450.

[29] Marcos M, Romero P, Serrano JL. Photosensitive Ionic Nematic Liquid Crystalline Complexes Based on Dendrimers and Hyperbranched Polymers and a Cyanoazobenzene Carboxylic Acidt. Chem Mater. 2008;20:5209-17.

[30] Yan $\mathrm{H}$, Long $\mathrm{Y}$, Song $\mathrm{K}$, Tung $\mathrm{C}-\mathrm{H}$, Zheng L. Photo-induced transformation from wormlike to spherical micelles based on pyrrolidinium ionic liquids. Soft matter. 2014;10:115-21.

[31] Ueki T, Nakamura Y, Lodge TP, Watanabe M. Light-controlled reversible micellization of a diblock copolymer in an ionic liquid. Macromolecules. 2012;45:7566-73.

[32] Ueki T, Yamaguchi A, Watanabe M. Unlocking of interlocked heteropolymer gel by light: photoinduced volume phase transition in an ionic liquid from a metastable state to an equilibrium phase. Chem Commun. 2012;48:5133-5.

[33] Ueki T, Nakamura Y, Usui R, Kitazawa Y, So S, Lodge TP, et al. Photo Reversible Gelation of a Triblock Copolymer in an Ionic Liquid. Angew Chem Int Ed. 2015;54:3018-22.

[34] Zhang S, Liu S, Zhang Y, Deng Y. Photoinduced Isothermal Phase Transition of Ionic Liquid Crystals. Chem Asian J. 2012;7:2004.

[35] Yung KY, Schadock-Hewitt AJ, Hunter NP, Bright FV, Baker GA. 'Liquid litmus': chemosensory pHresponsive photonic ionic liquids. Chem Commun. 2011;47:4775-7.

[36] Zhang QH, Zhang SG, Liu SM, Ma XY, Lu L, Deng YQ. Ionic liquid-modified dyes and their sensing performance toward acids in aqueous and non-aqueous solutions. Analyst. 2011;136:1302-4.

[37] Paul K, áde Rooy SL. Ionic liquid-based fluorescein colorimetric pH nanosensors. RSC Adv. 2013;3:2105461.

[38] Guo J, Qiu L, Deng Z, Yan F. Plastic reusable pH indicator strips: preparation via anion-exchange of poly (ionic liquids) with anionic dyes. Polym Chem. 2013;4:1309-12.

[39] Galpothdeniya WIS, McCarter KS, De Rooy SL, Regmi BP, Das S, Hasan F, et al. lonic liquid-based optoelectronic sensor arrays for chemical detection. RSC Adv. 2014;4:7225-34.

[40] Wang H, Tan B, Wang J, Li Z, Zhang S. Anion-Based pH Responsive lonic Liquids: Design, Synthesis, and Reversible Self-Assembling Structural Changes in Aqueous Solution. Langmuir. 2014;30:3971-8.

[41] Xie ZL, Huang X, Taubert A. Dyelonogels: Proton-Responsive lonogels Based on a Dye-lonic Liquid Exhibiting Reversible Color Change. Adv Funct Mater. 2014;24:2837-43.

[42] Rodríguez H, Williams M, Wilkes JS, Rogers RD. Ionic liquids for liquid-in-glass thermometers. Green Chem. 2008;10:501-7.

[43] Zhang Q, Ma X, Liu S, Yang B, Lu L, He Y, et al. Hydrophobic 1-Allyl-3-alkylimidazolium Dicyanamide lonic Liquids with Low Densities. J Mater Chem. 2011;21:6864-8.

[44] Baker GA, Baker SN, McCleskey TM. Noncontact two-color luminescence thermometry based on intramolecular luminophore cyclization within an ionic liquid. Chem Commun. 2003:2932-3.

[45] Tollan CM, Marcilla R, Pomposo JA, Rodriguez J, Aizpurua J, Molina J, et al. Irreversible Thermochromic Behavior in Gold and Silver Nanorod/Polymeric lonic Liquid Nanocomposite Films. ACS Appl Mater Inter. 2009;1:348-52.

[46] Wei X, Yu L, Wang D, Jin X, Chen GZ. Thermo-solvatochromism of chloro-nickel complexes in 1hydroxyalkyl-3-methyl-imidazolium cation based ionic liquids. Green Chem. 2008;10:296-305.

[47] Wei X, Yu L, Jin X, Wang D, Chen GZ. Solar-thermochromism of Pseudocrystalline Nanodroplets of Ionic Liquid-Nill Complexes Immobilized inside Translucent Microporous PVDF Films. Adv Mater. 2009;21:77680.

[48] Aoyagi N, Shimojo K, Brooks NR, Nagaishi R, Naganawa H, Hecke KV, et al. Thermochromic properties of low-melting ionic uranyl isothiocyanate complexesw. Chem Commun. 2011;47:4490-2. 
[49] Liang C, Yuan C-Y, Warmack RJ, Barnes CE, Dai S. lonic Liquids: A New Class of Sensing Materials for Detection of Organic Vapors Based on the Use of a Quartz Crystal Microbalance. Anal Chem. 2002;74:2172-6.

[50] Yu L, Garcia D, Ren R, Zeng X. Ionic liquid high temperature gas sensors. Chem Commun. 2005:2277-9.

[51] Goubaidoulline I, Vidrich G, Johannsmann D. Organic Vapor Sensing with lonic Liquids Entrapped in Alumina Nanopores on Quartz Crystal Resonators. Anal Chem. 2005;77:615-9.

[52] Jin X, Yu L, Garcia D, Ren RX, Zeng X. Ionic Liquid High-Temperature Gas Sensor Array. Anal Chem. 2006;78:6980-9.

[53] Rehman A, Hamilton A, Chung A, Baker GA, Wang Z, Zeng X. Differential Solute Gas Response in lonicLiquid-Based QCM Arrays: Elucidating Design Factors Responsible for Discriminative Explosive Gas Sensing. Anal Chem. 2011;83:7823-33.

[54] Ji Q, Honma I, Paek S-M, Akada M, Hill JP, Vinu A, et al. Layer-by-Layer Films of Graphene and lonic Liquids for Highly Selective Gas Sensing. Angew Chem Int Ed. 2010;49: 9737 -9.

[55] Hou K-Y, Rehman A, Zeng X. Study of Ionic Liquid Immobilization on Polyvinyl Ferrocene Substrates for Gas Sensor Arrays. Langmuir. 2011;27:5136-46.

[56] Tseng M-C, Chu Y-H. Chemoselective gas sensing ionic liquids. Chem Commun. 2010;46:2983-5.

[57] Buzzeo MC, Hardacre C, Compton RG. Use of room temperature ionic liquids in gas sensor design. Anal Chem. 2004;76:4583-8.

[58] Yu L, Jin X, Zeng X. Methane interactions with polyaniline/butylmethylimidazolium camphorsulfonate ionic liquid composite. Langmuir. 2008;24:11631-6.

[59] Funasako Y, Mochida T, Takahashi K, Sakurai T, Ohta H. Vapochromic lonic Liquids from Metal-Chelate Complexes Exhibiting Reversible Changes in Color, Thermal, and Magnetic Properties. Chem Eur J. 2012;18:11929-36.

[60] Oter O, Ertekin K, Topkaya D, Alp S. Room temperature ionic liquids as optical sensor matrix materials for gaseous and dissolved CO2. Sensor Actuat B-Chem. 2006;117:295-301.

[61] Oter O, Ertekin K, Topkaya D, Alp S. Emission-based optical carbon dioxide sensing with HPTS in green chemistry reagents: room-temperature ionic liquids. Anal Bioanal Chem. 2006;386:1225-34.

[62] Borisov SM, Waldhier MC, Klimant I, Wolfbeis OS. Optical carbon dioxide sensors based on siliconeencapsulated room-temperature ionic liquids. Chem Mater. 2007;19:6187-94.

[63] Chen LC, Huang DJ, Ren SY, Chi YW, Chen GN. Carbon Dioxide Gas Sensor Based on Ionic Liquid-Induced Electrochemiluminescence. Anal Chem. 2011;83:6862-7.

[64] Lee BS, Chi YS, Lee JK, Choi IS, Song CE, Namgoong SK, et al. Imidazolium ion-terminated self-assembled monolayers on Au: Effects of counteranions on surface wettability. J Am Chem Soc. 2004;126:480-1.

[65] Shen YF, Zhang YJ, Kuehner D, Yang GF, Yuan FY, Niu L. Ion-Responsive Behavior of Ionic-Liquid Surfactant Aggregates with Applications in Controlled Release and Emulsification. ChemPhysChem. 2008;9:2198-202.

[66] Vijayakrishna K, Jewrajka SK, Ruiz A, Marcilla R, Pomposo JA, Mecerreyes D, et al. Synthesis by RAFT and ionic responsiveness of double hydrophilic block copolymers based on ionic liquid monomer units. Macromolecules. 2008;41:6299-308.

[67] Vijayakrishna K, Mecerreyes D, Gnanou Y, Taton D. Polymeric vesicles and micelles obtained by selfassembly of ionic liquid-based block copolymers triggered by anion or solvent exchange. Macromolecules. 2009;42:5167-74.

[68] Hu X, Huang J, Zhang W, Li M, Tao C, Li G. Photonic Ionic Liquids Polymer for Naked-Eye Detection of Anions. Adv Mater. 2008;20:4074-8.

[69] Cui J, Zhu W, Gao N, Li J, Yang H, Jiang Y, et al. Inverse Opal Spheres Based on Polyionic Liquids as Functional Microspheres with Tunable Optical Properties and Molecular Recognition Capabilities. Angew Chem Int Ed. 2014;53:3844-8.

[70] Huang J, Tao CA, An Q, Zhang WX, Wu YG, Li XS, et al. 3D-ordered macroporous poly(ionic liquid) films as multifunctional materials. Chem Commun. 2010;46:967-9.

[71] Loe-Mie F, Marchand G, Berthier J, Sarrut N, Pucheault M, Blanchard-Desce M, et al. Towards an Efficient Microsystem for the Real-Time Detection and Quantification of Mercury in Water Based on a Specifically Designed Fluorogenic Binary Task-Specific lonic Liquid. Angew Chem Int Ed. 2010;49:424-7.

[72] Cui K, Lu XM, Cui W, Wu J, Chen XM, Lu QH. Fluorescent nanoparticles assembled from a poly(ionic liquid) for selective sensing of copper ions. Chem Commun. 2010;47:920-2.

[73] Huang J, Tao CA, An Q, Lin CX, Li XS, Xu D, et al. Visual indication of enviromental humidity by using poly(ionic liquid) photonic crystals. Chem Commun. 2010;46:4103-5.

[74] P W, T W. Ionic liquids in synthesis. 2002. p. 348-9. 
[75] Hayashi S, Hamaguchi HO. Discovery of a magnetic ionic liquid [bmim]FeCl4. Chem Lett. 2004;33:1590-1.

[76] Li M, De Rooy SL, Bwambok DK, El-Zahab B, DiTusa JF, Warner IM. Magnetic chiral ionic liquids derived from amino acids. Chem Commun. 2009:6922-4.

[77] Bäcker T, Breunig O, Valldor M, Merz K, Vasylyeva V, Mudring A-V. In-situ crystal growth and properties of the magnetic ionic liquid [C2mim] [FeCl4]. Cryst Growth Des. 2011;11:2564-71.

[78] García-Saiz A, Migowski P, Vallcorba O, Junquera J, Blanco JA, González JA, et al. A Magnetic lonic Liquid Based on Tetrachloroferrate Exhibits Three-Dimensional Magnetic Ordering: A Combined Experimental and Theoretical Study of the Magnetic Interaction Mechanism. Chem Eur J. 2014;20:72-6.

[79] Brown P, Butts CP, Eastoe J, Hernández EP, de Araujo Machado FL, de Oliveira RJ. Dication magnetic ionic liquids with tuneable heteroanions. Chem Commun. 2013;49:2765-7.

[80] Kozlova SA, Verevkin SP, Heintz A, Peppel T, Kockerling M. Paramagnetic lonic Liquid 1-Butyl-3methylimidazolium Tetrabromidocobaltate(II): Activity Coefficients at Infinite Dilution of Organic Solutes and Crystal Structure. J Chem Eng Data. 2009;54:1524-8.

[81] Peppel T, ckerling MK, Geppert-Rybczyn'ska M, Ralys RV, Lehmann JK, Verevkin SP, et al. Low-Viscosity Paramagnetic lonic Liquids with Doubly Charged [Co(NCS)4]2- Ions. Angew Chem Int Ed. 2010;49:7116-9.

[82] Del Sesto RE, McCleskey TM, Burrell AK, Baker GA, Thompson JD, Scott BL, et al. Structure and magnetic behavior of transition metal based ionic liquids. Chem Commun. 2008:447-9.

[83] Mallick B, Balke B, Felser C, Mudring AV. Dysprosium room-temperature ionic liquids with strong luminescence and response to magnetic fields. Angew Chem Int Ed. 2008;47:7635-8.

[84] Getsis A, Balke B, Felser C, Mudring AV. Dysprosium-Based lonic Liquid Crystals: Thermal, Structural, Photo- and Magnetophysical Properties. Cryst Growth Des. 2009;9:4429-37.

[85] Branco A, Branco LsC, Pina F. Electrochromic and magnetic ionic liquids. Chem Commun. 2010;47:2300-2.

[86] Krieger BM, Lee HY, Emge TJ, Wishart JF, Castner EW. Ionic liquids and solids with paramagnetic anions. Phys Chem Chem Phys. 2010;12:8919-25.

[87] Nacham O, Clark KD, Yu H, Anderson JL. Synthetic Strategies for Tailoring the Physicochemical and Magnetic Properties of Hydrophobic Magnetic Ionic Liquids. Chem Mater. 2015;27:923-31.

[88] Yoshida Y, Saito GZ. Influence of structural variations in 1-alkyl-3-methylimidazolium cation and tetrahalogenoferrate(III) anion on the physical properties of the paramagnetic ionic liquids. J Mater Chem. 2006;16:1254-62.

[89] Funasako $\mathrm{Y}$, Mochida $\mathrm{T}$, Inagaki $\mathrm{T}$, Sakurai $\mathrm{T}$, Ohta $\mathrm{H}$, Furukawa $\mathrm{K}$, et al. Magnetic memory based on magnetic alignment of a paramagnetic ionic liquid near room temperature. Chem Commun. 2011;47:4475-7.

[90] Mochida T, Inagaki T. Metallocenium Ionic Liquids. Chem Lett. 2010;39:572-3.

[91] Clark KD, Nacham O, Yu H, Li T, Yamsek MM, Ronning DR, et al. Extraction of DNA by Magnetic lonic Liquids: Tunable Solvents for Rapid and Selective DNA Analysis. Anal Chem. 2015;87:1552-9.

[92] Yoshida Y, Tanaka H, Saito G. Organic paramagnetic ionic liquids based on anion containing 2,2,6,6tetramethyl-1-piperidinyloxyl radical moiety. Chem Lett. 2007;36:1096-7.

[93] Uchida Y, Oki S, Tamura R, Sakaguchi T, Suzuki K, Ishibashi K, et al. Electric, electrochemical and magnetic properties of novel ionic liquid nitroxides, and their use as an EPR spin probe. J Mater Chem. 2009;19:6877.

[94] Yoshida Y, Otsuka A, Saito G, Natsume S, Nishibori E, Takata M, et al. Conducting and magnetic properties of 1-ethyl-3-methylimidazolium (EMI) salts containing paramagnetic irons: Liquids [EMI](MCl4)-Cl-III] (M = Fe and Fe0.5Ga0.5) and solid [EMI](2)[(FeCl4)-Cl-II]. Bull Chem Soc Jpn. 2005;78:1921-8.

[95] Miao C-X, Wang J-Q, Yu B, Cheng W-G, Sun J, Chanfreau S, et al. Synthesis of bimagnetic ionic liquid and application for selective aerobic oxidation of aromatic alcohols under mild conditions. Chem Commun. 2011;47:2697-9.

[96] Kim JY, Kim JT, Song EA, Min YK, Hamaguchi H. Polypyrrole nanostructures self-assembled in magnetic ionic liquid as a template. Macromolecules. 2008;41:2886-9.

[97] Okuno M, Hamaguchi HO, Hayashi S. Magnetic manipulation of materials in a magnetic ionic liquid. Appl Phys Lett. 2006;89:132506.

[98] Brown P, Bushmelev A, Butts CP, Cheng J, Eastoe J, Grillo I, et al. Magnetic Control over Liquid Surface Properties with Responsive Surfactants. Angew Chem Int Ed. 2012;51: 2414-6.

[99] Dobbelin M, Jovanovski V, Llarena I, Marfil LJC, Cabanero G, Rodriguez J, et al. Synthesis of paramagnetic polymers using ionic liquid chemistry. Polym Chem. 2011;2:1275-8.

[100] Carrasco P, Tzounis L, Mompean F, Strati K, Georgopanos P, Garcia-Hernandez M, et al. Thermoset Magnetic Materials Based on Poly (ionic liquid) s Block Copolymers. Macromolecules. 2013;46:1860-7. 
[101] Sun N, Swatloski RP, Maxim ML, Rahman M, Harland AG, Haque A, et al. Magnetite-embedded cellulose fibers prepared from ionic liquid. J Mater Chem. 2008;18:283-90.

[102] Taubert A, Xie ZL, Jelicic A, Wang FP, Rabu P, Friedrich A, et al. Transparent, flexible, and paramagnetic ionogels based on PMMA and the iron-based ionic liquid 1-butyl-3-methylimidazolium tetrachloroferrate(III) [Bmim][FeCl(4)]. J Mater Chem. 2010;20:9543-9.

[103] Altin E, Gradl J, Peukert W. First studies on the rheological behavior of suspensions in ionic liquids. Chem Eng Technol. 2006;29:1347-54.

[104] Guerrero-Sanchez C, Lara-Ceniceros T, Jimenez-Regalado E, Rasa M, Schubert US. Magnetorheological fluids based on ionic liquids. Adv Mater. 2007;19:1740-7.

[105] Oliveira FC, Rossi LM, Jardim RF, Rubim JC. Magnetic fluids based on $\gamma$-Fe2O3 and CoFe2O4 nanoparticles dispersed in ionic liquids. J Phys Chem C. 2009;113:8566-72.

[106] Behrens S, Essig S. A facile procedure for magnetic fluids using room temperature ionic liquids. J Mater Chem. 2012;22:3811-6.

[107] Medeiros AM, Parize AL, Oliveira VM, Neto BA, Bakuzis AF, Sousa MH, et al. Magnetic lonic Liquids Produced by the Dispersion of Magnetic Nanoparticles in 1-n-Butyl-3-methylimidazolium bis (trifluoromethanesulfonyl) imide (BMI. NTf2). ACS Appl Mater Inter. 2012;4:5458-65.

[108] Zhang S, Zhang Y, Wang Y, Liu S, Deng Y. Sonochemical formation of iron oxide nanoparticles in ionic liquids for magnetic liquid marble. Phys Chem Chem Phys. 2012;14:5132-8.

[109] Jain N, Zhang XL, Hawkett BS, Warr GG. Stable and Water-Tolerant Ionic Liquid Ferrofluids. ACS Appl Mater Inter. 2011;3:662-7.

[110] Beaujuge PM, Reynolds JR. Color control in $\pi$-conjugated organic polymers for use in electrochromic devices. Chem Rev. 2010;110:268-320.

[111] Fujimoto T, Matsushita MM, Yoshikawa H, Awaga K. Electrochemical and electrochromic properties of octathio [8] circulene thin films in ionic liquids. J Am Chem Soc. 2008;130:15790-1.

[112] Branco A, Belchior J, Branco LC, Pina F. Intrinsically electrochromic ionic liquids based on vanadium oxides: illustrating liquid electrochromic cells. RSC Adv. 2013;3:25627-30.

[113] Jordão N, Cabrita L, Pina F, Branco LC. Novel Bipyridinium Ionic Liquids as Liquid Electrochromic Devices. Chem Eur J. 2014;20:3982-8.

[114] Jordão N, Cruz H, Branco A, Pina F, Branco LC. Electrochromic Devices Based on Disubstituted OxoBipyridinium Ionic Liquids. ChemPlusChem. 2014;80:202-8.

[115] Kavanagh A, Fraser KJ, Byrne R, Diamond D. An electrochromic ionic liquid: design, characterization, and performance in a solid-state platform. ACS Appl Mater Inter. 2012;5:55-62.

[116] Tanabe K, Yasuda T, Yoshio M, Kato T. Viologen-based redox-active ionic liquid crystals forming columnar phases. Org Lett. 2007;9:4271-4.

[117] Yazaki S, Funahashi M, Kato T. An electrochromic nanostructured liquid crystal consisting of $\pi-$ conjugated and ionic moieties. J Am Chem Soc. 2008;130:13206-7.

[118] Yazaki S, Funahashi M, Kagimoto J, Ohno H, Kato T. Nanostructured liquid crystals combining ionic and electronic functions. J Am Chem Soc. 2010;132:7702-8.

[119] Beneduci A, Cospito S, La Deda M, Veltri L, Chidichimo G. Electrofluorochromism in $\pi$-conjugated ionic liquid crystals. Nat Commun. 2014;5.

[120] Bartolozzi M. Development of redox flow batteries. A historical bibliography. J Power Sources. 1989;27:219-34.

[121] Jessop PG, Heldebrant DJ, Li XW, Eckert CA, Liotta CL. Green chemistry - Reversible nonpolar-to-polar solvent. Nature. 2005;436:1102-.

[122] Yamada T, Lukac PJ, George M, Weiss RG. Reversible, room-temperature ionic liquids. Amidinium carbamates derived from amidines and aliphatic primary amines with carbon dioxide. Chem Mater. 2007;19:967-9.

[123] Yamada T, Lukac PJ, Yu T, Weiss RG. Reversible, Room-Temperature, Chiral lonic Liquids. Amidinium Carbamates Derived from Amidines and Amino-Acid Esters with Carbon Dioxide. Chem Mater. 2007;19:4761-8.

[124] Yu T, Yamada T, Gaviola GC, Weiss RG. Carbon Dioxide and Molecular Nitrogen as Switches between Ionic and Uncharged Room-Temperature Liquids Comprised of Amidines and Chiral Amino Alcohols. Chem Mater. 2008;20:5337-44.

[125] Jessop PG, Phan L, Carrier A, Robinson S, Durr CJ, Harjani JR. A solvent having switchable hydrophilicity. Green Chem. 2010;12:809-14. 
[126] Kohno Y, Arai H, Ohno H. Dual stimuli-responsive phase transition of an ionic liquid/water mixture. Chem Commun. 2011;47:4772-4.

[127] Li W, Zhang Z, Han B, Hu S, Song J, Xie Y, et al. Switching the basicity of ionic liquids by CO 2. Green Chem. 2008;10:1142-5.

[128] Heldebrant DJ, Koech PK, Yonker CR. A reversible zwitterionic SO2-binding organic liquid. Energy Environ Sci. 2010;3:111-3.

[129] Yu T, Yamada T, Weiss RG. In situ Formation of Thermally Stable, Room-Temperature lonic liquids from CS2 and Amidine/Amine Mixtures. Chem Mater. 2010;22:5492-9.

[130] Phan L, Andreatta JR, Horvey LK, Edie CF, Luco AL, Mirchandani A, et al. Switchable-polarity solvents prepared with a single liquid component. J Org Chem. 2008;73:127-32.

[131] Blasucci V, Dilek C, Huttenhower H, John E, Llopis-Mestre V, Pollet P, et al. One-component, switchable ionic liquids derived from siloxylated amines. Chem Commun,. 2009:116-8.

[132] Heldebrant DJ, Koech PK, Ang MTC, Liang C, Rainbolt JE, Yonkera CR, et al. Reversible zwitterionic liquids, the reaction of alkanol guanidines, alkanol amidines, and diamines with CO2. Green Chem. 2010;12:71321.

[133] Xiong D, Li Z, Wang H, Wang J. Selective separation of aliphatic and aromatic amines with CO 2 switchable ionic liquids aqueous two-phase systems. Green Chem. 2013;15:1941-8.

[134] Yang Y, Xie H, Liu E. Acylation of cellulose in reversible ionic liquids. Green Chem. 2014;16:3018-23.

[135] Anugwom I, Eta V, Virtanen P, Mäki-Arvela P, Hedenström M, Hummel M, et al. Switchable lonic Liquids as Delignification Solvents for Lignocellulosic Materials. ChemSusChem. 2014;7:1170-6.

[136] Wang C, Luo H, Luo X, Li H, Dai S. Equimolar CO2 capture by imidazolium-based ionic liquids and superbase systems. Green Chem. 2010;12:2019-23.

[137] Liu Y, Jessop PG, Cunningham M, Eckert CA, Liotta CL. Switchable surfactants. Science. 2006;313:958-60.

[138] Pandey S, Baker SN, Pandey S, Baker GA. Optically responsive switchable ionic liquid for internallyreferenced fluorescence monitoring and visual determination of carbon dioxide. Chem Commun. 2012;48:7043-5.

[139] Brown P, Wasbrough MJ, Gurkan BE, Hatton TA. CO2-responsive microemulsions based on reactive ionic liquids. Langmuir. 2014;30:4267-72.

[140] Paul A, Mandal PK, Samanta A. On the optical properties of the imidazolium ionic liquids. J Phys Chem B. 2005;109:9148-53.

[141] Paul A, Mandal PK, Samanta A. How transparent are the imidazolium ionic liquids? A case study with 1methyl-3-butylimidazolium hexafluorophosphate, [bmim][PF6]. Chem Phys Lett. 2005;402:375-9.

[142] Burrell AK, Del Sesto RE, Baker SN, McCleskey TM, Baker GA. The large scale synthesis of pure imidazolium and pyrrolidinium ionic liquids. Green Chem. 2007;9:449-54.

[143] Chen XW, Liu JW, Wang JH. A Highly Fluorescent Hydrophilic lonic Liquid as a Potential Probe for the Sensing of Biomacromolecules. J Phys Chem B. 2011;115:1524-30.

[144] Zhang J, Zhang QH, Shi F, Zhang SG, Qiao BT, Liu LQ, et al. Greatly enhanced fluorescence of dicyanamide anion based ionic liquids confined into mesoporous silica gel. Chem Phys Lett. 2008;461:229-34.

[145] Huang JF, Luo HM, Liang CD, Sun IW, Baker GA, Dai S. Hydrophobic bronsted acid-base ionic liquids based on PAMAM dendrimers with high proton conductivity and blue photoluminescence. J Am Chem Soc. 2005;127:12784-5.

[146] Boydston AJ, Pecinovsky CS, Chao ST, Bielawski CW. Phase-tunable fluorophores based upon benzobis(imidazolium) salts. J Am Chem Soc. 2007;129:14550-1.

[147] Anderson JL, Armstrong DW, Wei GT. Ionic liquids in analytical chemistry. Anal Chem. 2006;78:2892-902.

[148] Zhang SG, Zhang QH, Ye BX, Li XL, Zhang XP, Deng YQ. Photochromism of spiropyran in ionic liquids: enhanced fluorescence and delayed thermal reversion. J Phys Chem B. 2009;113:6012-9.

[149] Gago S, Cabrita L, Lima JC, Branco LC, Pina F. Synthesis and characterization of luminescent room temperature ionic liquids based on Ru (bpy)(CN) 4 2-. Dalton T. 2013;42:6213-8.

[150] Boydston AJ, Vu PD, Dykhno OL, Chang V, Wyatt AR, Stockett AS, et al. Modular fluorescent benzobis(imidazolium) salts: Syntheses, photophysical analyses, and applications. J Am Chem Soc. 2008;130:3143-56.

[151] Chen ZJ, Zhang SG, Qi XJ, Liu SM, Zhang QH, Deng YQ. Fluorescent quinolizinium ionic liquids (salts) with unexpectedly high quantum yields up to >99\%. J Mater Chem. 2011;21:8979-82.

[152] Fei Z, Zhu DR, Yang X, Meng L, Lu Q, Ang WH, et al. An internal fluorescent probe based on anthracene to evaluate cation-anion interactions in imidazolium salts. Chem Eur J. 2010;16:6473-81. 
[153] Kohmoto S, Tsuyuki R, Hara Y, Kaji A, Takahashi M, Kishikawa K. Dual-mode of assembly of anthracenebased imidazolium salts both in non-polar organic solvents and in aqueous solution. Chem Commun. 2011;47:9158-60.

[154] Wang WH, Fu A, Lan JB, Gao G, You JS, Chen L. Rational Design of Fluorescent Bioimaging Probes by Controlling the Aggregation Behavior of Squaraines: A Special Effect of Ionic Liquid Pendants. Chem Eur J. 2010;16:5129-37.

[155] Zhang QH, Yang BQ, Zhang SG, Liu SM, Deng YQ. Ionic liquidized-naphthalenesulfonamide: successful fabrication of liquid fluorescent materials. J Mater Chem. 2011;21:16335-8.

[156] Fiorani G, Selva M, Perosa A, Benedetti A, Enrichi F, Licence P, et al. Luminescent dansyl-based ionic liquids from amino acids and methylcarbonate onium salt precursors: synthesis and photobehaviour. Green Chem. 2015;17:538-50.

[157] Campbell PS, Yang M, Pitz D, Cybinska J, Mudring AV. Highly Luminescent and Color-Tunable Salicylate Ionic Liquids. Chem Eur J. 2014;20:4704-12.

[158] Siraj N, Hasan F, Das S, Kiruri LW, Steege Gall KE, Baker GA, et al. Carbazole-derived group of uniform materials based on organic salts: Solid state fluorescent analogues of ionic liquids for potential applications in organic-based blue light-emitting diodes. J Phys Chem C. 2014;118:2312-20.

[159] Bwambok DK, El-Zahab B, Challa SK, Li M, Chandler L, Baker GA, et al. Near-Infrared Fluorescent NanoGUMBOS for Biomedical Imaging. ACS Nano. 2009;3:3854-60.

[160] Tang S, Babai A, Mudring AV. Europium-based ionic liquids as luminescent soft materials. Angew Chem Int Ed. 2008;47:7631-4.

[161] Pitula S, Mudring AV. Synthesis, Structure, and Physico-optical Properties of Manganate (II)-Based lonic Liquids. Chem Eur J. 2010;16:3355-65.

[162] Nockemann P, Thijs B, Postelmans N, Van Hecke K, Van Meervelt L, Binnemans K. Anionic rare-earth thiocyanate complexes as building blocks for low-melting metal-containing ionic liquids. J Am Chem Soc. 2006;128:13658-9.

[163] Babai A, Mudring A-V. Anhydrous Praseodymium Salts in the lonic Liquid [bmpyr][Tf2N]: Structural and Optical Properties of [bmpyr]4[Prl6][Tf2N] and [bmyr]2[Pr(Tf2N)5]. Chem Mater. 2005;17:6230-8.

[164] Nockemann P, Beurer E, Driesen K, Van Deun R, Van Hecke K, Van Meervelt L, et al. Photostability of a highly luminescent europium beta-diketonate complex in imidazolium ionic liquids. Chem Commun. 2005:4354-6.

[165] Lunstroot K, Nockemann P, Van Hecke K, Van Meervelt L, Gorller-Walrand C, Binnemans K, et al. Visible and Near-Infrared Emission by Samarium(III)-Containing lonic Liquid Mixtures. Inorg Chem. 2009;48:301826.

[166] Pereira CuC, Dias S, Coutinho I, Leal J, Branco LC, Laia CsA. Europium (III) tetrakis ( $\beta$-diketonate) complex as an ionic liquid: a calorimetric and spectroscopic study. Inorg Chem. 2013;52:3755-64.

[167] Wang D, Wang H, Li H. Novel luminescent soft materials of terpyridine-containing ionic liquids and europium (III). ACS Appl Mater Inter. 2013;5:6268-75.

[168] Ru Q, Xue Z, Wang Y, Liu Y, Li H. Luminescent Materials of Europium (III) Coordinated by a TerpyridineFunctionalized Poly (Ionic Liquid). Eur J Inorg Chem. 2014;2014:469-74.

[169] Tang SF, Mudring AV. Terbium $\beta$-Diketonate Based Highly Luminescent Soft Materials. Eur J Inorg Chem. 2009;2009:2769-75.

[170] Bwambok DK, Challa SK, Lowry M, Warner IM. Amino Acid-Based Fluorescent Chiral lonic Liquid for Enantiomeric Recognition. Anal Chem. 2010;82:5028-37.

[171] Goossens K, Nockemann P, Driesen K, Goderis B, Gorller-Walrand C, Van Hecke K, et al. Imidazolium ionic liquid crystals with pendant mesogenic groups. Chem Mater. 2008;20:157-68.

[172] Getsis A, Tang SF, Mudring AV. A Luminescent lonic Liquid Crystal: [C(12)mim](4)[EuBr(6)]Br. Eur J Inorg Chem. 2010:2172-7.

[173] Dechambenoit P, Ferlay S, Donnio B, Guillon D, Hosseini MW. From tectons to luminescent supramolecular ionic liquid crystals. Chem Commun. 2011;47:734-6.

[174] Tokare A, Larionova J, Guari Y, Guerin C, Lopez-De-Luzuriaga JM, Monge M, et al. Gold- and silver-based ionic liquids: modulation of luminescence depending on the physical state. Dalton T. 2010;39:10574-6.

[175] Tanabe K, Yasuda T, Kato T. Luminescent Ionic Liquid Crystals Based on Tripodal Pyridinium Salts. Chem Lett. 2008;37:1208-9.

[176] Olivier JH, Camerel F, Barbera J, Retailleau P, Ziessel R. Ionic Liquid Crystals Formed by Self-Assembly around an Anionic Anthracene Core. Chem Eur J. 2009;15:8163-74. 
[177] Olivier JH, Camerel F, Ulrich G, Barbera J, Ziessel R. Luminescent lonic Liquid Crystals from SelfAssembled BODIPY Disulfonate and Imidazolium Frameworks. Chem Eur J. 2010;16:7134-42.

[178] Wiggins KM, Kerr RL, Chen Z, Bielawski CW. Design, synthesis, and study of benzobis- and bibenz(imidazolium)-based ionic liquid crystals. J Mater Chem. 2010;20:5709-14.

[179] Giner I, Gascon I, Gimenez R, Cea P, Lopez MC, Lafuente C. Supramolecular Architecture in Langmuir Films of a Luminescent Ionic Liquid Crystal. J Phys Chem C. 2009;113:18827-34.

[180] Getsis A, Mudring AV. Switchable Green and White Luminescence in Terbium-Based lonic Liquid Crystals. Eur J Inorg Chem. 2011:3207-13.

[181] Cardinaels T, Ramaekers J, Driesen K, Nockemann P, Van Hecke K, Van Meervelt L, et al. Thermotropic Ruthenium(II)-Containing Metallomesogens Based on Substituted 1,10-Phenanthroline Ligands. Inorg Chem. 2009;48:2490-9.

[182] Antharjanam PKS, Jaseer M, Ragi KN, Prasad E. Intrinsic luminescence properties of ionic liquid crystals based on PAMAM and PPI dendrimers. J Photoch Photobio A. 2009;203:50-5.

[183] Westphal E, da Silva DH, Molin F, Gallardo H. Pyridinium and imidazolium 1, 3, 4-oxadiazole ionic liquid crystals: a thermal and photophysical systematic investigation. RSC Adv. 2013;3:6442-54.

[184] Driesen K, Nockemann P, Binnemans K. Ionic liquids as solvents for near-infrared emitting lanthanide complexes. Chem Phys Lett. 2004;395:306-10.

[185] Brandner A, Kitahara T, Beare N, Lin CK, Berry MT, May PS. Luminescence Properties and Quenching Mechanisms of $\operatorname{Ln}(\operatorname{Tf}(2) N)(3)$ Complexes in the lonic Liquid bmpyr Tf(2)N. Inorg Chem. 2011;50:6509-20.

[186] Binnemans K. Lanthanides and Actinides in Ionic Liquids. Chem Rev. 2007;107:2592-614.

[187] Guillet E, Imbert D, Scopelliti R, Bunzli JCG. Tuning the emission color of europium-containing ionic liquid-crystalline phases. Chem Mater. 2004;16:4063-70.

[188] Mudring A-V, Tang S. Ionic Liquids for Lanthanide and Actinide Chemistry. Eur J Inorg Chem. 2010:256981.

[189] Nakashima T, Kawai T. Quantum dots-ionic liquid hybrids: efficient extraction of cationic CdTe nanocrystals into an ionic liquid. Chem Commun. 2005:1643-5.

[190] Nakashima T, Sakakibar T, Kawai T. Highly Luminescent CdTe Nanocrystal-Polymer Composites Based on Ionic Liquid. Chem Lett. 2005;34:1410-1.

[191] Hecke K, Meervelt L. Hydrophobic ionic liquids with strongly coordinating anions. Chem Commun. 2010;46:234-6.

[192] Nockemann P, Thijs B, Pittois S, Thoen J, Glorieux C, Van Hecke K, et al. Task-specific ionic liquid for solubilizing metal oxides. J Phys Chem B. 2006;110:20978-92.

[193] Nockemann P, Thijs B, Parac-Vogt TN, Van Hecke K, Van Meervelt L, Tinant B, et al. CarboxylFunctionalized Task-Specific lonic Liquids for Solubilizing Metal Oxides. Inorg Chem. 2008;47:9987-99.

[194] Nockemann P, Thijs B, Lunstroot K, Parac-Vogt TN, Gorller-Walrand C, Binnemans K, et al. Speciation of Rare-Earth Metal Complexes in Ionic Liquids: A Multiple-Technique Approach. Chem Eur J. 2009;15:144961.

[195] Li HR, Shao HF, Wang YG, Qin DS, Liu BY, Zhang WJ, et al. Soft material with intense photoluminescence obtained by dissolving Eu2O3 and organic ligand into a task-specific ionic liquid. Chem Commun. 2008:5209-11.

[196] Li HR, Liu P, Shao HF, Wang YG, Zheng YX, Sun Z, et al. Green synthesis of luminescent soft materials derived from task-specific ionic liquid for solubilizing lanthanide oxides and organic ligand. J Mater Chem. 2009;19:5533-40.

[197] Feng Y, Li H, Gan Q, Wang Y, Liu B, Zhang H. A transparent and luminescent ionogel based on organosilica and ionic liquid coordinating to Eu3+ ions. J Mater Chem. 2010;20:972-5.

[198] Li H, Li D, Wang Y, Ru Q. A Series of Carboxylic-Functionalized Ionic Liquids and their Solubility for Lanthanide Oxides. Chem Asian J. 2011:1443-9.

[199] Wen T, Li H, Wang Y, Wang L, Zhang W, Zhang L. Ln 3+-mediated formation of luminescent ionogels. J Mater Chem C. 2013;1:1607-12.

[200] Wei Y, Liu Y, Li H, He X, Zhang Q, Kang Z, et al. Carbon nanoparticle ionic liquid hybrids and their photoluminescence properties. J Colloid Interface Sci. 2011;358:146-50.

[201] Green M, Rahmana P, Smyth-Boyle D. Ionic liquid passivated CdSe nanocrystals. Chem Commun. 2007:574-6.

[202] Nonoguchi Y, Nakashima T, Kawai T. Size- and Temperature-Dependent Emission Properties of Zincblende CdTe Nanocrystals in Ionic Liquid. J Phys Chem C. 2007;111:11811-5. 
[203] Nakashima T, Nonoguchi $Y$, Kawai T. Ionic liquid-based luminescent composite materials. Polym Adv Technol. 2008;19:1401-5.

[204] Liu DP, Li GD, Su Y, Chen JS. Highly Luminescent ZnO Nanocrystals Stabilized by lonic-Liquid Components. Angew Chem Int Ed. 2006;45:7370-3.

[205] Mei Y, Lu Y, Yan B. Soft materials composed with lanthanide (Eu 3+, Tb 3+) beta-diketonates and $\mathrm{ZnO}$ nanoparticles through ionic liquid linkage to integrate white luminescence. J Photoch Photobio A. 2014;280:1-4.

[206] Lunstroot K, Driesen K, Nockemann P, Gorller-Walrand C, Binnemans K, Bellayer S, et al. Luminescent ionogels based on europium-doped ionic liquids confined within silica-derived networks. Chem Mater. 2006;18:5711-5.

[207] Lunstroot K, Driesen K, Nockemann P, Van Hecke K, Van Meervelt L, Gorller-Walrand C, et al. Lanthanidedoped luminescent ionogels. Dalton T. 2009:298-306.

[208] Ru Q, Wang Y, Zhang W, Yu X, Li H. Thermally reversible, flexible, transparent, and luminescent ionic organosilica gels. Eur J Inorg Chem. 2013;2013:2342-9.

[209] Lunstroot K, Driesen K, Nockemann P, Viau L, Mutin PH, Vioux A, et al. Ionic liquid as plasticizer for europium(III)-doped luminescent poly(methyl methacrylate) films. Phys Chem Chem Phys. 2010;12:187985.

[210] Xie Z-L, Xu H-B, Geßner A, Kumke MU, Priebe M, Fromm KM, et al. A transparent, flexible, ion conductive, and luminescent PMMA ionogel based on a Pt/Eu bimetallic complex and the ionic liquid [Bmim][N (Tf) 2]. J Mater Chem. 2012;22:8110-6.

[211] Wang H, Wang Y, Zhang L, Li H. Transparent and luminescent ionogels based on lanthanide-containing ionic liquids and poly (methyl methacrylate) prepared through an environmentally friendly method. RSC Adv. 2013;3:8535-40.

[212] Wakizono S, Yamamoto K, Kadokawa J-i. FRET function of polymeric ionic liquid film containing rhodamine moieties for exhibiting emissions by excitation at wide wavelength areas. J Photoch Photobio A. 2011;222:283-7.

[213] Campbell PS, Lorbeer C, Cybinska J, Mudring AV. One-Pot Synthesis of Luminescent PolymerNanoparticle Composites from Task-Specific lonic Liquids. Adv Funct Mater. 2013;23:2924-31.

[214] Cuan J, Yan B. Luminescent lanthanide-polyoxometalates assembling zirconia-alumina-titania hybrid xerogels through task-specified ionic liquid linkage. RSC Adv. 2014;4:1735-43.

[215] Mei Y, Lu Y, Yan B. Soft hybrids of Eu 3+ beta-diketonates and MS ( $M=Z n, C d$ ) nanoparticles using mercapto-ionic liquid linkage for white luminescence integration. New J Chem. 2013;37:2619-23.

[216] Mei Y, Yan B. White luminescent hybrid soft materials of lanthanide (Eu 3+, Sm 3+) beta-diketonates and $\mathrm{Ag} / \mathrm{Ag} 2 \mathrm{~S}$ nanoparticles based with thiol-functionalized ionic liquid bridge. Inorg Chem Commun. 2014;40:39-42.

[217] Marder SR, Beratan DN, Cheng LT. Approaches for optimizing the first electronic hyperpolarizability of conjugated organic molecules. Science. 1991;252:103-6.

[218] Diemer V, Chaumeil H, Defoin A, Fort A, Boeglin A, Carre C. Syntheses of sterically hindered pyridinium phenoxides as model compounds in nonlinear optics. Eur J Org Chem. 2006:2727-38.

[219] Wustenberg B, Branda NR. A photoswitchable donor-pi-linker-acceptor system based on a modified hexatriene backbone. Adv Mater. 2005;17:2134-+.

[220] Delaire JA, Nakatani K. Linear and nonlinear optical properties of photochromic molecules and materials. Chem Rev. 2000;100:1817-45.

[221] Evans OR, Lin WB. Crystal engineering of NLO materials based on metal-organic coordination networks. Acc Chem Res. 2002;35:511-22.

[222] Del Sesto RE, Dudis DS, Ghebremichael F, Heimer NE, Low TKC, Wilkes JS, et al. Modeling, synthesis and characterization of third-order nonlinear optical salts. P Soc Photo-Opt Ins. 2003;5212:292-8.

[223] Souza RF, Alencar MARC, Meneghetti MR, Dupont J, Hickmann JM. Nonlocal optical nonlinearity of ionic liquids. J Phys-Condens Mat. 2008;20:155102.

[224] Loredo CV, Barrera-Rivera K, Trejo-Durán M, Alvarado-Méndez E, Martínez-Richa A, Andrade-Lucio J. Nonlinear optical characterization of ionics liquids. Photonics North 2009: International Society for Optics and Photonics; 2009. p. 738610-4.

[225] Santos CE, Alencar MA, Migowski P, Dupont J, Hickmann JM. Anionic and cationic influence on the nonlocal nonlinear optical response of ionic liquids. Chem Phys. 2012;403:33-6.

[226] Zhu ZQ, Xiang SJ, Chen QY, Chen CS, Zeng Z, Cui YP, et al. Novel low-melting salts with donor-acceptor substituents as targets for second-order nonlinear optical applications. Chem Commun. 2008:5016-8. 
[227] von Freymann G, Kitaev V, Lotsch BV, Ozin GA. Bottom-up assembly of photonic crystals. Chem Soc Rev. 2013;42:2528-54.

[228] Kanai T, Yamamoto S, Sawada T. Swelling of gel-immobilized colloidal photonic crystals in ionic liquids. Macromolecules. 2011;44:5865-7.

[229] Ueno K, Inaba A, Sano Y, Kondoh M, Watanabe M. A soft glassy colloidal array in ionic liquid, which exhibits homogeneous, non-brilliant and angle-independent structural colours. Chem Commun. 2009:3603-5.

[230] Ueno K, Inaba A, Ueki T, Kondoh M, Watanabe M. Thermosensitive, Soft Glassy and Structural Colored Colloidal Array in Ionic Liquid: Colloidal Glass to Gel Transition. Langmuir. 2010;26:18031-8.

[231] Ueno K, Watanabe M. From colloidal stability in ionic liquids to advanced soft materials using unique media. Langmuir. 2011;27:9105-15.

[232] Ueno K, Sano Y, Inaba A, Kondoh M, Watanabe M. Soft glassy colloidal arrays in an ionic liquid: Colloidal glass transition, ionic transport, and structural color in relation to microstructure. J Phys Chem B. 2010;114:13095-103.

[233] Gao H, Shreeve JnM. Azole-based energetic salts. Chem Rev. 2011;111:7377-436.

[234] Steinhauser G, Klapötke TM. “Green" Pyrotechnics: A Chemists' Challenge. Angew Chem Int Ed. 2008;47:3330-47.

[235] Singh RP, Verma RD, Meshri DT, Shreeve JnM. Energetic Nitrogen-Rich Salts and lonic Liquids. Angew Chem Int Ed. 2006;45:3584-601.

[236] Zhang Q, Shreeve JnM. Energetic lonic Liquids as Explosives and Propellant Fuels: A New Journey of lonic Liquid Chemistry. Chem Rev. 2014;114:10527-74.

[237] Zhang Y, Gao H, Joo YH, Shreeve JnM. Ionic liquids as hypergolic fuels. Angew Chem Int Ed. 2011;50:9554-62.

[238] Curtius T. Ueber stickstoffwasserstoffsäure (azoimid) N3H. Ber Dtsch Chem Ges. 1890;23:3023-33.

[239] Walden P. Bull Acad Imper Sci (St Petersburg). 1914;8:405-22.

[240] Drake G, Hawkins T, Brand A, Hall L, Mckay M, Vij A, et al. Energetic, Low-Melting Salts of Simple Heterocycles. Propell Explos Pyrot. 2003;28:174-80.

[241] Zhang Q, Shreeve JnM. Ionic Liquid Propellants: Future Fuels for Space Propulsion. Chem Eur J. 2013;19:15446-51.

[242] Sebastiao E, Cook C, Hu A, Murugesu M. Recent developments in the field of energetic ionic liquids. J Mater Chem A. 2014;2:8153-73.

[243] Katritzky AR, Singh S, Kirichenko K, Holbrey JD, Smiglak M, Reichert WM, et al. 1-Butyl-3methylimidazolium 3, 5-dinitro-1, 2, 4-triazolate: a novel ionic liquid containing a rigid, planar energetic anion. Chem Commun. 2005:868-70.

[244] Ye C, Xiao J-C, Twamley B, Jean'ne MS. Energetic salts of azotetrazolate, iminobis (5-tetrazolate) and 5, 5 -bis (tetrazolate). Chem Commun. 2005:2750-2.

[245] Darwich C, Klapötke TM, Sabaté CM. 1, 2, 4-Triazolium-Cation-Based Energetic Salts. Chem Eur J. 2008;14:5756-71.

[246] Xue H, Arritt SW, Twamley B, Shreeve JnM. Energetic salts from N-aminoazoles. Inorg Chem. 2004;43:7972-7.

[247] Xue H, Gao Y, Twamley B, Shreeve JnM. New energetic salts based on nitrogen-containing heterocycles. Chem Mater. 2005;17:191-8.

[248] Klapötke TM, Mayer P, Schulz A, Weigand JJ. 1, 5-Diamino-4-methyltetrazolium Dinitramide. J Am Chem Soc. 2005;127:2032-3.

[249] Klapötke TM, Stierstorfer J. Azidoformamidinium and 5-aminotetrazolium dinitramide-two highly energetic isomers with a balanced oxygen content. Dalton T. 2009:643-53.

[250] Schneider S, Hawkins T, Rosander M, Vaghjiani G, Chambreau S, Drake G. Ionic liquids as hypergolic fuels. Energy Fuels. 2008;22:2871-2.

[251] Chambreau SD, Schneider S, Rosander M, Hawkins T, Gallegos CJ, Pastewait MF, et al. Fourier transform infrared studies in hypergolic ignition of ionic liquids. J Phys Chem A. 2008;112:7816-24.

[252] Zhang Y, Shreeve JnM. Dicyanoborate-Based Ionic Liquids as Hypergolic Fluids. Angew Chem Int Ed. 2011;50:935-7.

[253] Li S, Gao H, Shreeve JnM. Borohydride Ionic Liquids and Borane/lonic-Liquid Solutions as Hypergolic Fuels with Superior Low Ignition-Delay Times. Angew Chem Int Ed. 2014;53:2969-72.

[254] Zhang $Q$, Yin P, Zhang J, Shreeve JnM. Cyanoborohydride-Based lonic Liquids as Green Aerospace Bipropellant Fuels. Chem Eur J. 2014;20:6909-14. 
[255] Schneider S, Hawkins T, Ahmed Y, Rosander M, Hudgens L, Mills J. Green Bipropellants: Hydrogen-Rich Ionic Liquids that Are Hypergolic with Hydrogen Peroxide. Angew Chem Int Ed. 2011;50:5886-8.

[256] Jones CB, Haiges R, Schroer T, Christe KO. Oxygen-Balanced Energetic lonic Liquid. Angew Chem. 2006;118:5103-6.

[257] Durbin D, Malardier-Jugroot C. Review of hydrogen storage techniques for on board vehicle applications. Int J Hydrogen Energy. 2013;38:14595-617.

[258] Bluhm ME, Bradley MG, Butterick R, Kusari U, Sneddon LG. Amineborane-based chemical hydrogen storage: enhanced ammonia borane dehydrogenation in ionic liquids. J Am Chem Soc. 2006;128:7748-9.

[259] Himmelberger DW, Alden LR, Bluhm ME, Sneddon LG. Ammonia borane hydrogen release in ionic liquids. Inorg Chem. 2009;48:9883-9.

[260] Wright WR, Berkeley ER, Alden L, Baker RT, Sneddon LG. Transition metal catalysed ammonia-borane dehydrogenation in ionic liquids. Chem Commun. 2011;47:3177-9.

[261] Nakagawa T, Burrell AK, Del Sesto RE, Janicke MT, Nekimken AL, Purdy GM, et al. Physical, structural, and dehydrogenation properties of ammonia borane in ionic liquids. RSC Adv. 2014;4:21681-7.

[262] Sahler S, Konnerth H, Knoblauch N, Prechtl MH. Hydrogen storage in amine boranes: lonic liquid supported thermal dehydrogenation of ethylene diamine bisborane. Int J Hydrogen Energy. 2013;38:3283-90.

[263] Sahler S, Sturm S, Kessler MT, Prechtl MH. The Role of Ionic Liquids in Hydrogen Storage. Chem Eur J. 2014;20:8934-41.

[264] Doroodian A, Dengler JE, Genest A, Rösch N, Rieger B. Methylguanidinium Borohydride: An lonic-LiquidBased Hydrogen-Storage Material. Angew Chem Int Ed. 2010;49:1871-3.

[265] Rekken B, Carre-Burritt A, Scott B, Davis B. N-substituted amine-borane ionic liquids as fluid phase, hydrogen storage materials. J Mater Chem A. 2014;2:16507-15.

[266] Stracke MP, Ebeling G, Cataluña R, Dupont J. Hydrogen-storage materials based on imidazolium ionic liquids. Energy Fuels. 2007;21:1695-8.

[267] Fukushima T, Kosaka A, Ishimura Y, Yamamoto T, Takigawa T, Ishii N, et al. Molecular ordering of organic molten salts triggered by single-walled carbon nanotubes. Science. 2003;300:2072-4.

[268] McCrary PD, Beasley PA, Alaniz SA, Griggs CS, Frazier RM, Rogers RD. Graphene and Graphene Oxide Can "Lubricate" Ionic Liquids based on Specific Surface Interactions Leading to Improved Low-Temperature Hypergolic Performance. Angew Chem Int Ed. 2012;51:9784-7.

[269] Ding Y, Sun X, Zhang L, Mao S, Xie Z, Liu ZW, et al. Entrapping an lonic Liquid with Nanocarbon: The Formation of a Tailorable and Functional Surface. Angew Chem Int Ed. 2015;54:231-5.

[270] Tunckol M, Durand J, Serp P. Carbon nanomaterial-ionic liquid hybrids. Carbon. 2012;50:4303-34.

[271] Zhao F, Wu X, Wang M, Liu Y, Gao L, Dong S. Electrochemical and bioelectrochemistry properties of room-temperature ionic liquids and carbon composite materials. Anal Chem. 2004;76:4960-7.

[272] Fukushima T, Aida T. Ionic liquids for soft functional materials with carbon nanotubes. Chem Eur J. 2007;13:5048-58.

[273] Lee J, Aida T. "Bucky gels" for tailoring electroactive materials and devices: the composites of carbon materials with ionic liquids. Chem Commun. 2011;47:6757-62.

[274] Sekitani T, Noguchi Y, Hata K, Fukushima T, Aida T, Someya T. A rubberlike stretchable active matrix using elastic conductors. Science. 2008;321:1468-72.

[275] Bellayer S, Gilman JW, Eidelman N, Bourbigot S, Flambard X, Fox DM, et al. Preparation of homogeneously dispersed multiwalled carbon nanotube/polystyrene nanocomposites via melt extrusion using trialkyl imidazolium compatibilizer. Adv Funct Mater. 2005;15:910-6.

[276] Whitten PG, Spinks GM, Wallace GG. Mechanical properties of carbon nanotube paper in ionic liquid and aqueous electrolytes. Carbon. 2005;43:1891-6.

[277] Wang J, Chu H, Li Y. Why single-walled carbon nanotubes can be dispersed in imidazolium-based ionic liquids. ACS Nano. 2008;2:2540-6.

[278] Shim Y, Kim HJ. Solvation of carbon nanotubes in a room-temperature ionic liquid. ACS Nano. 2009;3:1693-702.

[279] Zhao Y, Gao Y, Zhan D, Liu H, Zhao Q, Kou Y, et al. Selective detection of dopamine in the presence of ascorbic acid and uric acid by a carbon nanotubes-ionic liquid gel modified electrode. Talanta. 2005;66:517.

[280] Fukushima T, Kosaka A, Yamamoto Y, Aimiya T, Notazawa S, Takigawa T, et al. Dramatic effect of dispersed carbon nanotubes on the mechanical and electroconductive properties of polymers derived from ionic liquids. Small. 2006;2:554-60. 
[281] Tunckol M, Fantini S, Malbosc F, Durand J, Serp P. Effect of the synthetic strategy on the non-covalent functionalization of multi-walled carbon nanotubes with polymerized ionic liquids. Carbon. 2013;57:20916.

[282] Fukushima T, Asaka K, Kosaka A, Aida T. Fully Plastic Actuator through Layer-by-Layer Casting with lonicLiquid-Based Bucky Gel. Angew Chem Int Ed. 2005;44:2410-3.

[283] Mukai K, Asaka K, Sugino T, Kiyohara K, Takeuchi I, Terasawa N, et al. Highly Conductive Sheets from Millimeter-Long Single-Walled Carbon Nanotubes and lonic Liquids: Application to Fast-Moving, LowVoltage Electromechanical Actuators Operable in Air. Adv Mater. 2009;21:1582-5.

[284] Kachoosangi RT, Musameh MM, Abu-Yousef I, Yousef JM, Kanan SM, Xiao L, et al. Carbon nanotubeionic liquid composite sensors and biosensors. Anal Chem. 2008;81:435-42.

[285] Katakabe T, Kaneko T, Watanabe M, Fukushima T, Aida T. Electric double-layer capacitors using "bucky gels" consisting of an ionic liquid and carbon nanotubes. J Electrochem Soc. 2005;152:A1913-A6.

[286] Tamailarasan P, Ramaprabhu S. Carbon nanotubes-graphene-solidlike ionic liquid layer-based hybrid electrode material for high performance supercapacitor. J Phys Chem C. 2012;116:14179-87.

[287] Zhang T, Zhou H. From Li-O2 to Li-air batteries: Carbon nanotubes/ionic liquid gels with a tricontinuous passage of electrons, ions, and oxygen. Angew Chem. 2012;124:11224-9.

[288] Zhao L, Li Y, Liu Z, Shimizu H. Carbon nanotube-conducting polymer core- shell hybrid using an imidazolium-salt-based ionic liquid as a linker: designed as a potential platinum electrode alternative material for large-scale solution processing. Chem Mater. 2010;22:5949-56.

[289] Polo-Luque ML, Simonet BM, Valcárcel M. Ionic liquid combined with carbon nanotubes: A soft material for the preconcentration of PAHs. Talanta. 2013;104:169-72.

[290] Polo-Luque M, Simonet B, Valcárcel M. Effect of carbon nanotubes on properties of soft materials based on carbon nanotubes-ionic liquid combinations. Talanta. 2013;110:160-3.

[291] Price BK, Hudson JL, Tour JM. Green chemical functionalization of single-walled carbon nanotubes in ionic liquids. J Am Chem Soc. 2005;127:14867-70.

[292] Guryanov I, Toma FM, Montellano López A, Carraro M, Da Ros T, Angelini G, et al. Microwave-Assisted Functionalization of Carbon Nanostructures in Ionic Liquids. Chem Eur J. 2009;15:12837-45.

[293] Zhang B, Ning W, Zhang J, Qiao X, Zhang J, He J, et al. Stable dispersions of reduced graphene oxide in ionic liquids. J Mater Chem. 2010;20:5401-3.

[294] Srinivasan S, Shin WH, Choi JW, Coskun A. A bifunctional approach for the preparation of graphene and ionic liquid-based hybrid gels. J Mater Chem A. 2013;1:43-8.

[295] Khare V, Pham M-Q, Kumari N, Yoon H-S, Kim C-S, Park J-I, et al. Graphene - Ionic Liquid Based Hybrid Nanomaterials as Novel Lubricant for Low Friction and Wear. ACS Appl Mater Inter. 2013;5:4063-75.

[296] Zhang Y, Shen Y, Yuan J, Han D, Wang Z, Zhang Q, et al. Design and Synthesis of Multifunctional Materials Based on an lonic-Liquid Backbone. Angew Chem Int Ed. 2006;45:5867-70.

[297] Park MJ, Lee JK, Lee BS, Lee Y-W, Choi IS, Lee S-g. Covalent modification of multiwalled carbon nanotubes with imidazolium-based ionic liquids: effect of anions on solubility. Chem Mater. 2006;18:1546-51.

[298] Wilhelm T. The electrolyte switchable solubility of multi-walled carbon nanotube/ionic liquid (MWCNT/IL) hybrids. Chem Commun. 2006:2356-8.

[299] Zhang Y, Shen Y, Han D, Wang Z, Song J, Li F, et al. Carbon nanotubes and glucose oxidase bionanocomposite bridged by ionic liquid-like unit: preparation and electrochemical properties. Biosens Bioelectron. 2007;23:438-43.

[300] Lei Y, Xiong C, Dong L, Guo H, Su X, Yao J, et al. Ionic liquid of ultralong carbon nanotubes. Small. 2007;3:1889-93.

[301] Wang Z, Zhang Q, Kuehner D, Xu X, Ivaska A, Niu L. The synthesis of ionic-liquid-functionalized multiwalled carbon nanotubes decorated with highly dispersed Au nanoparticles and their use in oxygen reduction by electrocatalysis. Carbon. 2008;46:1687-92.

[302] Guo S, Dong S, Wang E. Constructing Carbon Nanotube/Pt Nanoparticle Hybrids Using an ImidazoliumSalt-Based lonic Liquid as a Linker. Adv Mater. 2010;22:1269-72.

[303] Li S, Dong Z, Yang H, Guo S, Gou G, Ren R, et al. Microenvironment Effects in Electrocatalysis: IonicLiquid-Like Coating on Carbon Nanotubes Enhances the Pd-Electrocatalytic Alcohol Oxidation. Chem Eur J. 2013;19:2384-91.

[304] Rodríguez-Pérez L, García R, Herranz MÁ, Martín N. Modified SWCNTs with Amphoteric Redox and Solubilizing Properties. Chem Eur J. 2014;20:7278-86. 
[305] Karousis N, Economopoulos SP, Sarantopoulou E, Tagmatarchis N. Porphyrin counter anion in imidazolium-modified graphene-oxide. Carbon. 2010;48:854-60.

[306] Yu B, Liu Z, Ma C, Sun J, Liu W, Zhou F. Ionic liquid modified multi-walled carbon nanotubes as lubricant additive. Tribol Int. 2015;81:38-42.

[307] Han L, Li H, Choi S-J, Park M-S, Lee S-M, Kim Y-J, et al. lonic liquids grafted on carbon nanotubes as highly efficient heterogeneous catalysts for the synthesis of cyclic carbonates. Applied Catalysis A: General. 2012;429:67-72.

[308] Rodríguez-Pérez L, Teuma E, Falqui A, Gómez M, Serp P. Supported ionic liquid phase catalysis on functionalized carbon nanotubes. Chem Commun. 2008:4201-3.

[309] Karousis N, Ichihashi T, Chen S, Shinohara H, Yudasaka M, lijima S, et al. Imidazolium modified carbon nanohorns: switchable solubility and stabilization of metal nanoparticles. J Mater Chem. 2010;20:295964.

[310] Campisciano V, Parola VL, Liotta LF, Giacalone F, Gruttadauria M. Fullerene-lonic-Liquid Conjugates: A New Class of Hybrid Materials with Unprecedented Properties. Chem Eur J. 2015.

[311] Yang H, Shan C, Li F, Han D, Zhang Q, Niu L. Covalent functionalization of polydisperse chemicallyconverted graphene sheets with amine-terminated ionic liquid. Chem Commun. 2009:3880-2.

[312] Bhunia P, Hwang E, Min M, Lee J, Seo S, Some S, et al. A non-volatile memory device consisting of graphene oxide covalently functionalized with ionic liquid. Chem Commun. 2012;48:913-5.

[313] Kerscher B, Appel A-K, Thomann R, Mülhaupt R. Treelike polymeric ionic liquids grafted onto graphene nanosheets. Macromolecules. 2013;46:4395-402.

[314] Zhu C, Zhai J, Dong S. Ionic liquid-induced three-dimensional macroassembly of graphene and its applications in electrochemical energy storage. Nanoscale. 2014;6:10077-83.

[315] Zeng C, Tang Z, Guo B, Zhang L. Supramolecular ionic liquid based on graphene oxide. Phys Chem Chem Phys. 2012;14:9838-45.

[316] Bhunia P, Hwang E, Yoon Y, Lee E, Seo S, Lee H. Synthesis of Highly n-Type Graphene by Using an lonic Liquid. Chem Eur J. 2012;18:12207-12.

[317] DucáTruong Q. Synthesis of nitrogen-doped graphene by pyrolysis of ionic-liquid-functionalized graphene. J Mater Chem C. 2013;1:1713-6.

[318] Borra EF, Seddiki O, Angel R, Eisenstein D, Hickson P, Seddon KR, et al. Deposition of metal films on an ionic liquid as a basis for a lunar telescope. Nature. 2007;447:979-81.

[319] Rogers RD. Materials science: Reflections on ionic liquids. Nature. 2007;447:917-8. 


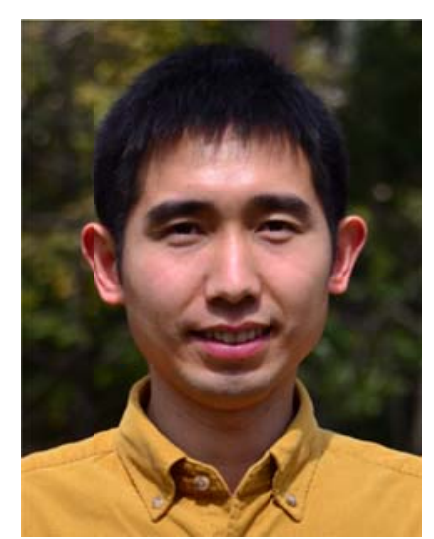

Shiguo Zhang received his $\mathrm{PhD}$ degree in 2011, supervised by Prof. Youquan Deng, from the Lanzhou Institute of Chemical Physics (LICP), Chinese Academy of Sciences (CAS), and worked as an assistant researcher in the LICP from 2011 to 2012. In April 2012, he joined Prof. Masayoshi Watanabe's group as a postdoctoral researcher at Yokohama National University. His research interests include ionic liquids, soft functional materials, carbon materials and energy conversion/storage.

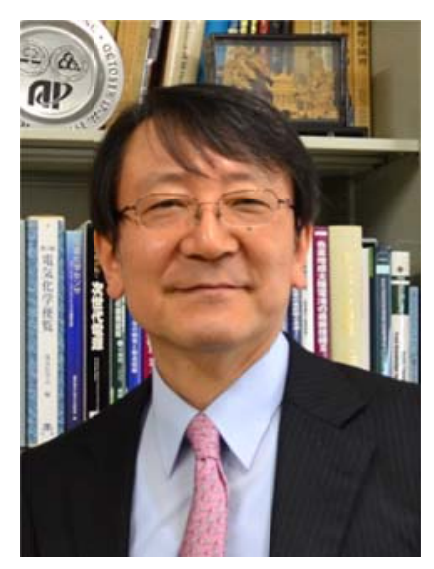

Masayoshi Watanabe is a professor at Yokohama National University. He received his $\mathrm{PhD}$ degree from Waseda University in 1983. After being a visiting scientist with Prof. Royce W. Murray at the University of North Carolina (1988-1990), he joined Yokohama National University in 1992 and was promoted to full professor in 1998. His main research interests are ionic and nano-structured materials for chemical energy production using fuel cells, and Li-ion and $\mathrm{Li}$-sulfur batteries. He has published more than 300 original research papers and 150 books and reviews, and he has more than 18000 citations (H-index: 67).

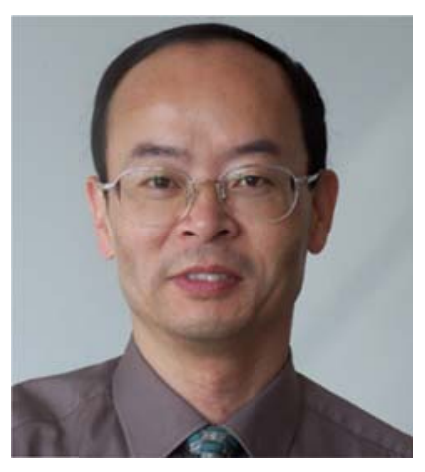

Youquan Deng is a professor of physics chemistry and head of the Centre for Green Chemistry and Catalysis, Lanzhou Institute of Chemical Physics (LICP), Chinese Academy of Sciences (CAS). He received a BS degree at Lanzhou University and got his $\mathrm{PhD}$ at the University of Portsmouth (UK, with Dr T. G. Nevell). He has been engaging in the $\mathrm{R} \& \mathrm{D}$ of ionic liquids, green chemistry, non-phosgene processes and nano-catalysis for many years. He has authored 40 patents and more than 180 scientific papers in international journals. 


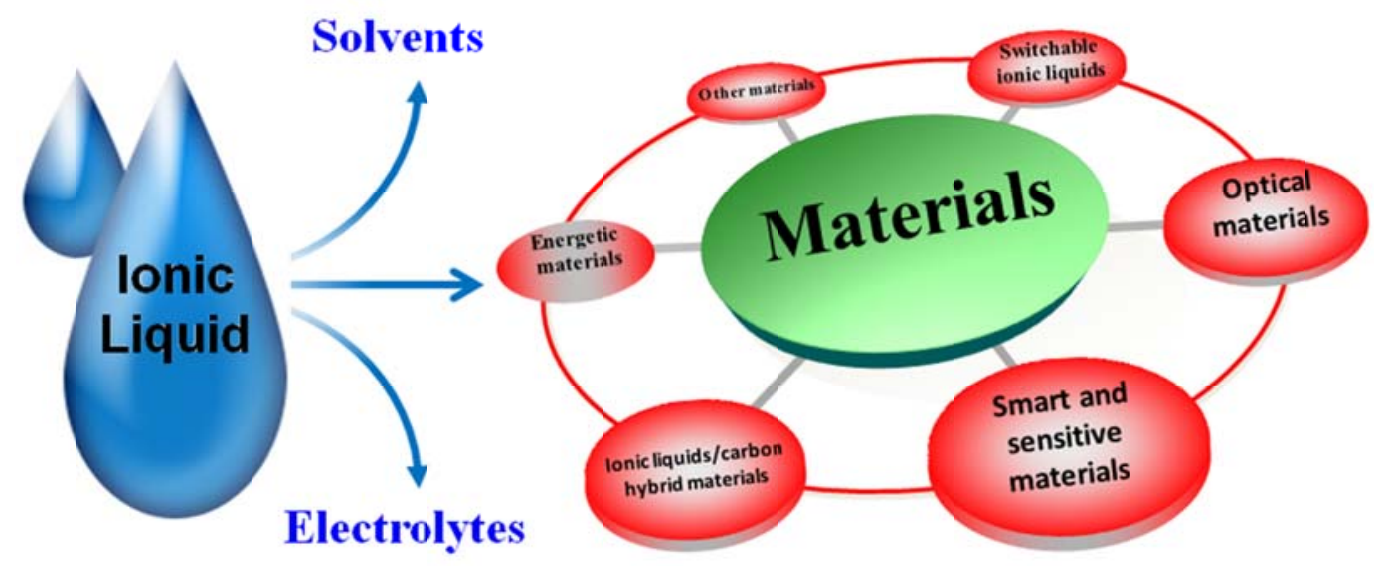

Figure 1. Evolution of ionic liquids from solvents and electrolytes to advanced functional materials. 

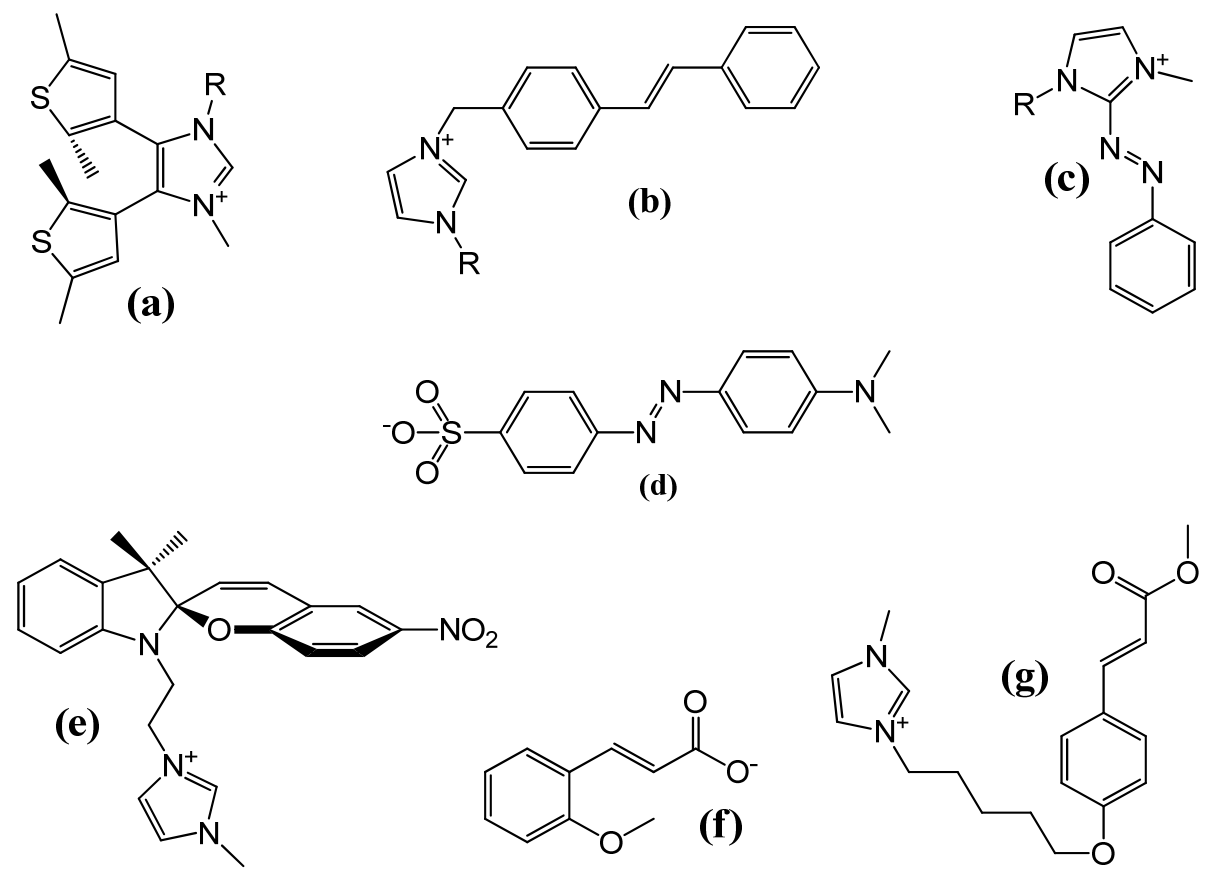

Figure 2. Molecular structures of typical cationic or anionic moieties used for photoresponsive ILs (a: diarylethene, b: stilbene, c: phenylazo-substituted imidazolium, d: azobenzene, e: spiropyran, $\mathrm{f}$ and $\mathrm{g}$ : cinnamate). 


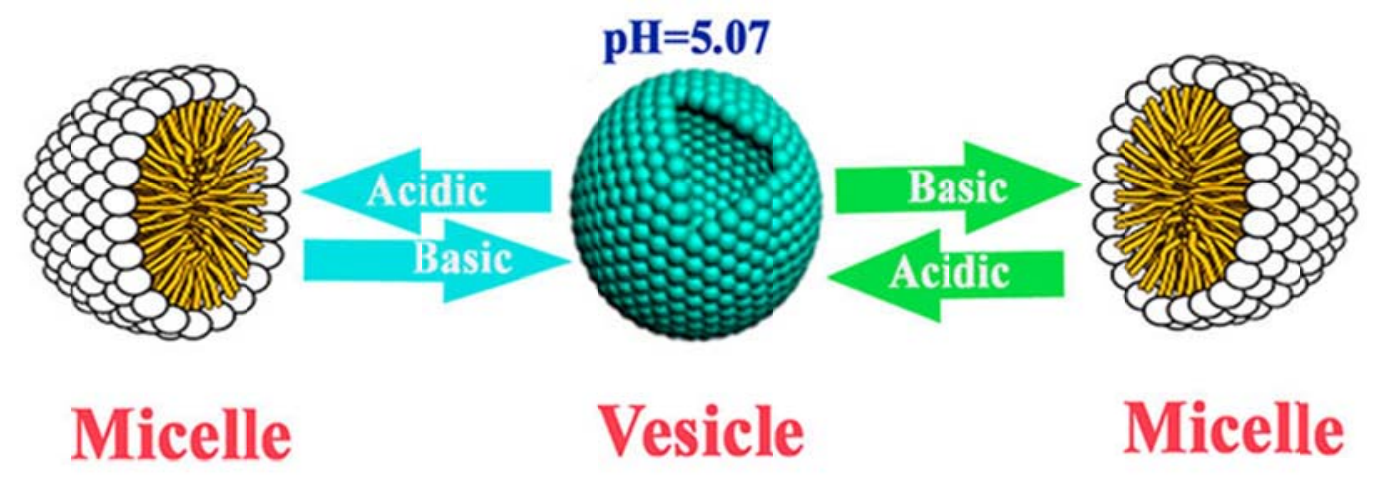

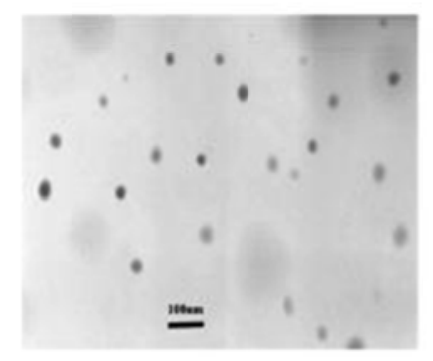

(a)

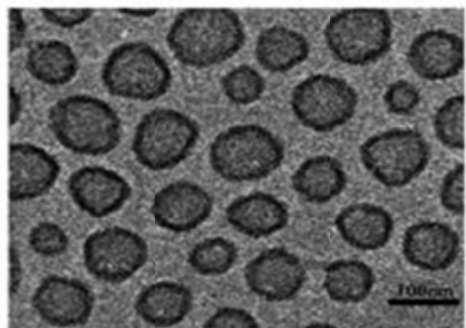

(b)

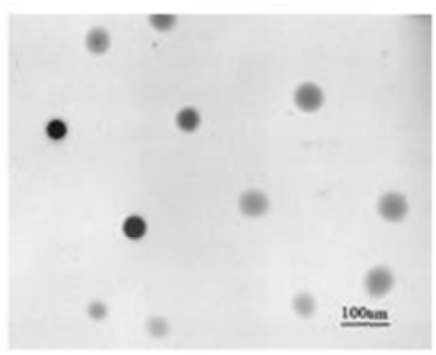

(c)

Figure 3. Schematic representations and TEM images of $\mathrm{pH}$-induced reversible transition between vesicle and micelle for $\left[\mathrm{C}_{14} \mathrm{MIm}\right]\left[\mathrm{C}_{6} \mathrm{H}_{4} \mathrm{COOKCOO}\right]$-containing aqueous solution. Reproduced with permission.[40] Copyright 2014, American Chemical Society. 

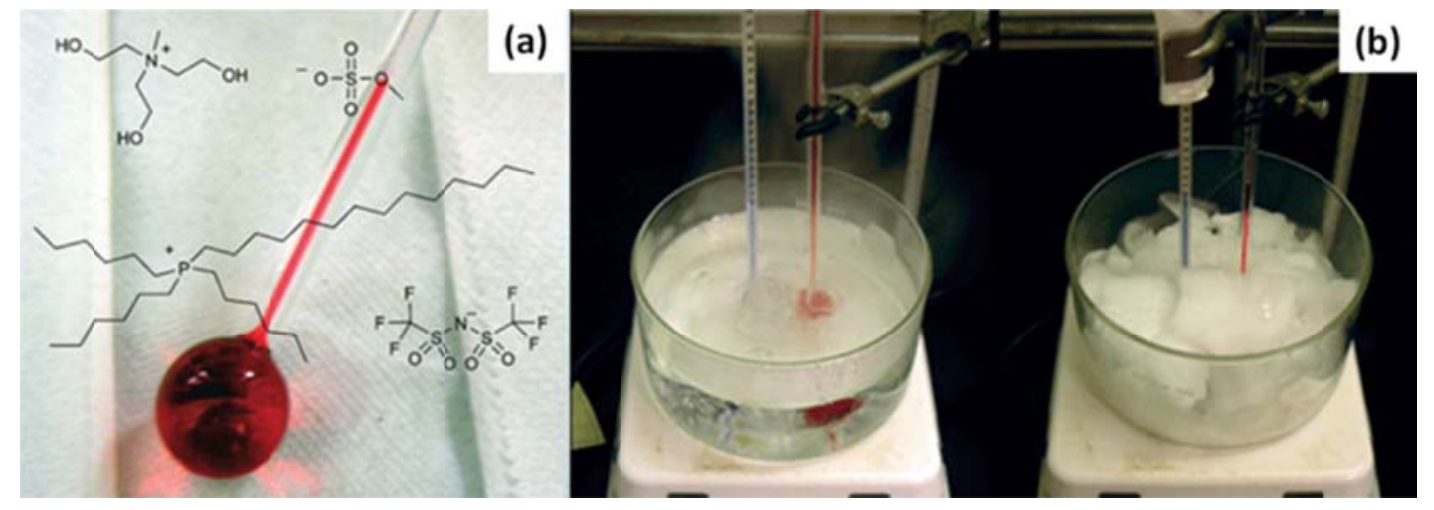

Figure 4. (a) Colored [TEMA] $\left[\mathrm{MeSO}_{4}\right]$-based IL thermometer and (b) its temperaturedependent volume change between $100{ }^{\circ} \mathrm{C}$ (left) and $0{ }^{\circ} \mathrm{C}$ (right). Reproduced with permission.[42] Copyright 2008, Royal Society of Chemistry. 


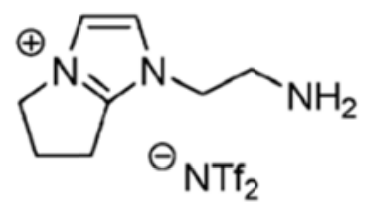

SIL 1

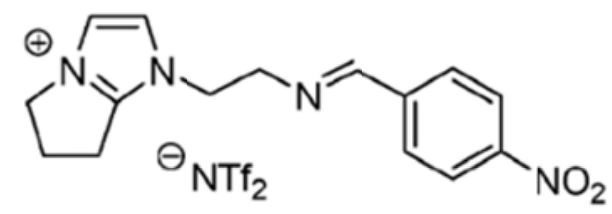

SIL 2

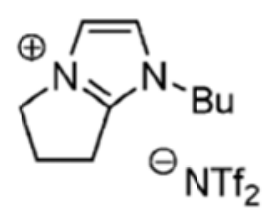

[b-3C-im] [NTf 2$]$

Figure 5. Chemical structures of chemoselective gas-sensing ILs (SILs 1 and 2) and the control IL [b-3C-im][NTf $\left.{ }_{2}\right]$. Reproduced with permission.[56] Copyright 2010, Royal Society of Chemistry. 


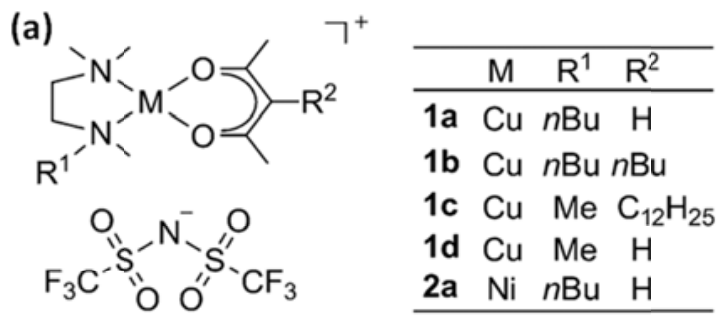

(b)
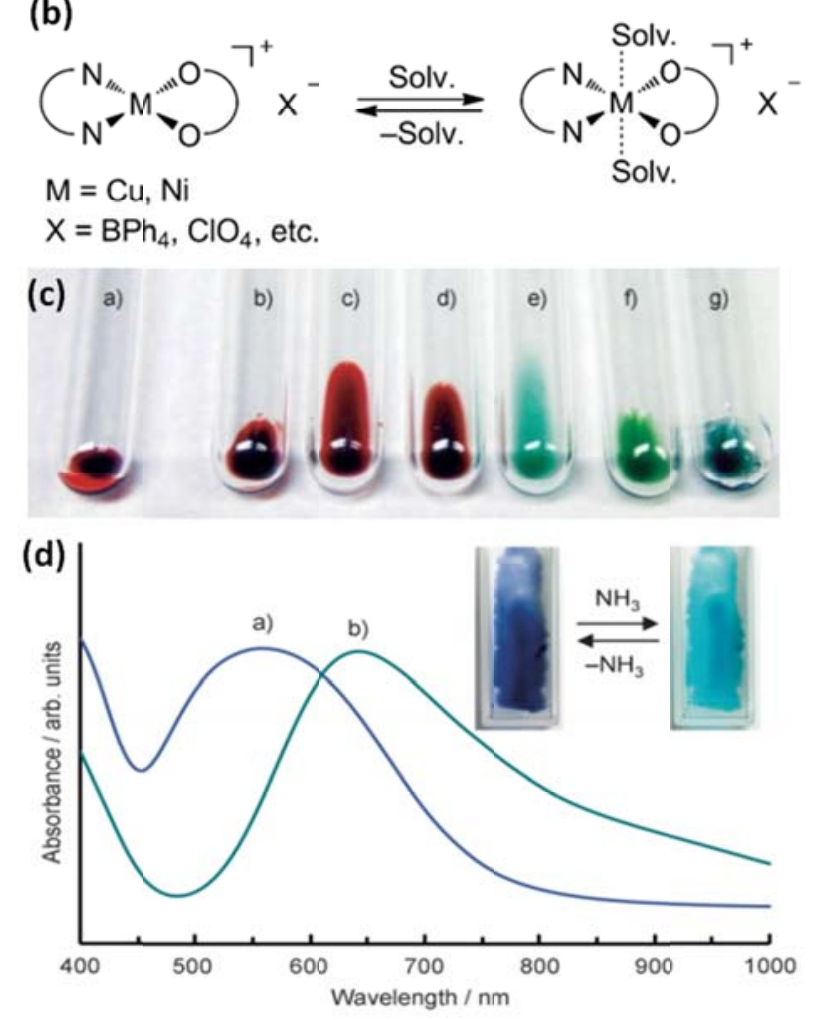

Figure 6. (a) Molecular structure of vapochromic ILs. (b) Coordination changes in solvatochromic complexes. (c) Photographs of $[2 \mathrm{a}]\left[\mathrm{NTf}_{2}\right]$ a) before exposure to vapor, and after absorption of two equivalent amounts of b) acetonitrile, c) acetone, d) methanol, e) DMF, f) DMSO, and g) pyridine. (d) Vapochromism and UV/vis absorption spectra of $[1 \mathrm{a}]\left[\mathrm{NTf}_{2}\right]$ a) before and b) after exposure to an ammonia gas. Inset shows photographs of the liquids. Reproduced with permission.[59] Copyright 2012, Wiley. 
(a)<smiles>CN(Cc1ccc(C(=O)Oc2cccc3cccnc23)cc1)C(C)(C)C</smiles>

L1

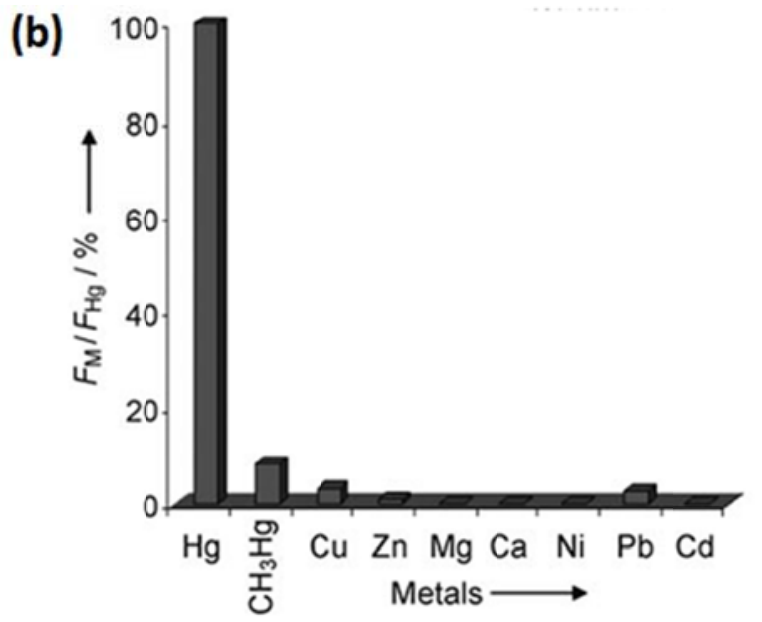

(c)

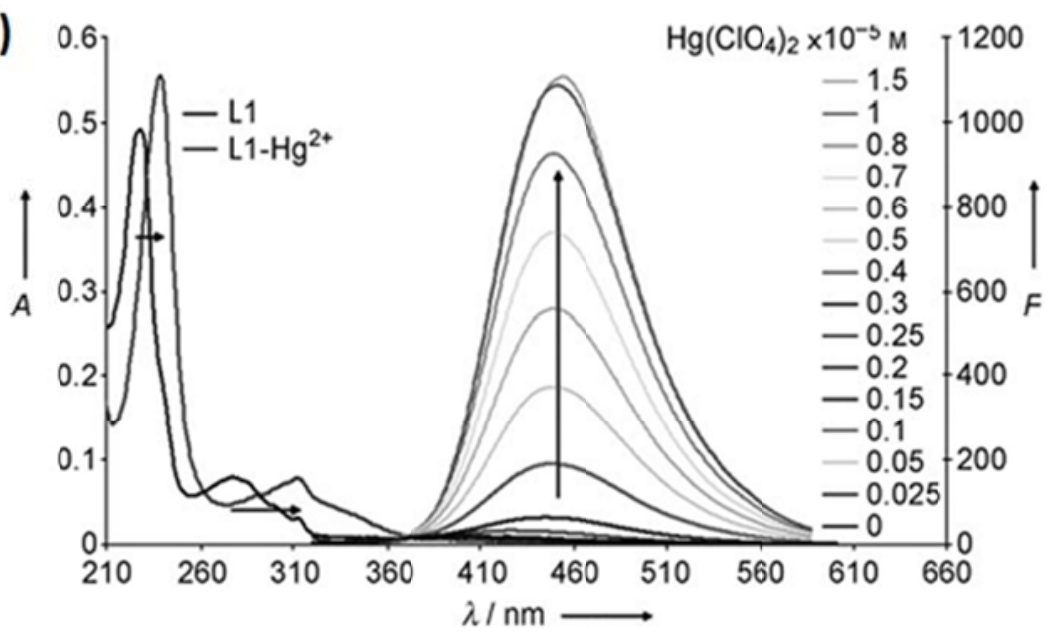

Figure 7. (a) Molecular structure of fluorogenic IL L1. (b) Selectivity of $\mathrm{Hg}^{2+}$ for L1 over other metal ions. (c) Absorption and emission spectra of L1 in the absence and presence of increasing concentrations of $\mathrm{Hg}\left(\mathrm{ClO}_{4}\right)_{2}$ in butylmethylpyrrolidinium bis(trifluoromethylsulfonyl)imide. Reproduced with permission.[71] Copyright 2009, Wiley. 

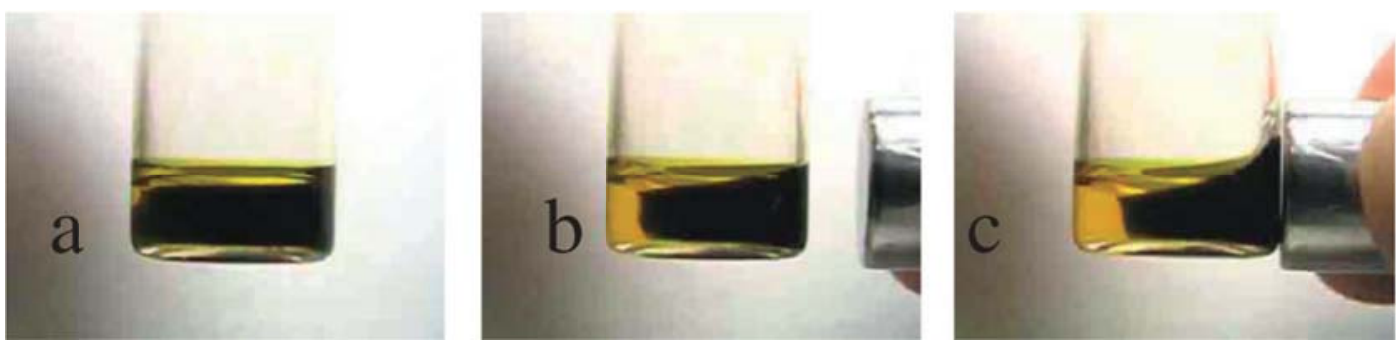

Figure 8. Magnetic response of $[\mathrm{BMIm}]\left[\mathrm{FeCl}_{4}\right]$ under applied magnetic field. Reproduced with permission.[75] Copyright 2004, Chemical Society of Japan. 


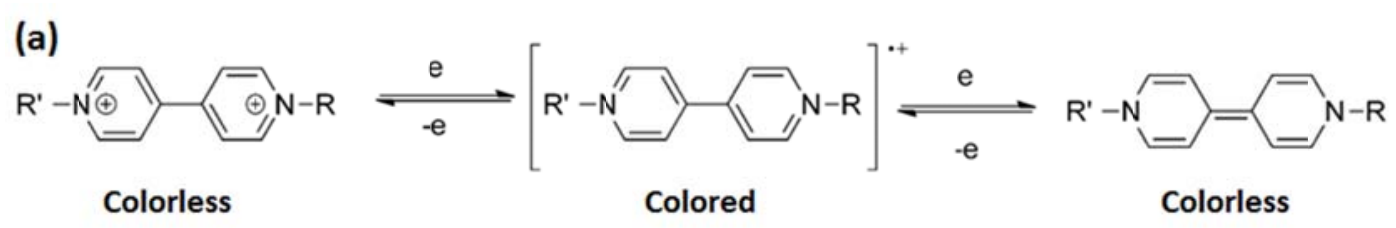

(b)

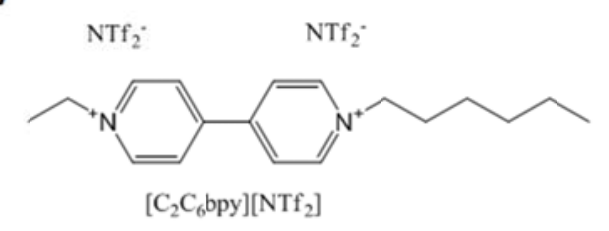

(c)

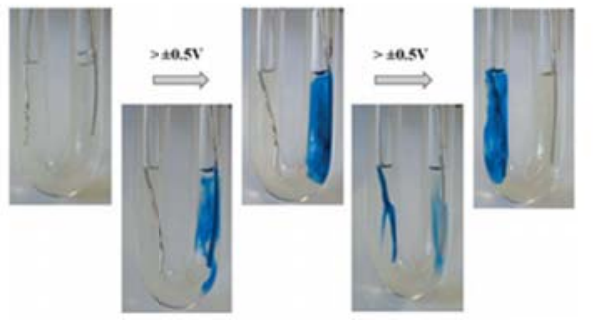

Figure 9. (a) Three common redox states for viologen-based moieties. (b) Molecular structure of $\left[\mathrm{C}_{2} \mathrm{C}_{6}\right.$ bpy $]\left[\mathrm{NTf}_{2}\right]$ and its reversible electrochromism in a conventional RTIL, [EMIm][NTf 2 . Reproduced with permission.[113] Copyright 2014, Wiley. 

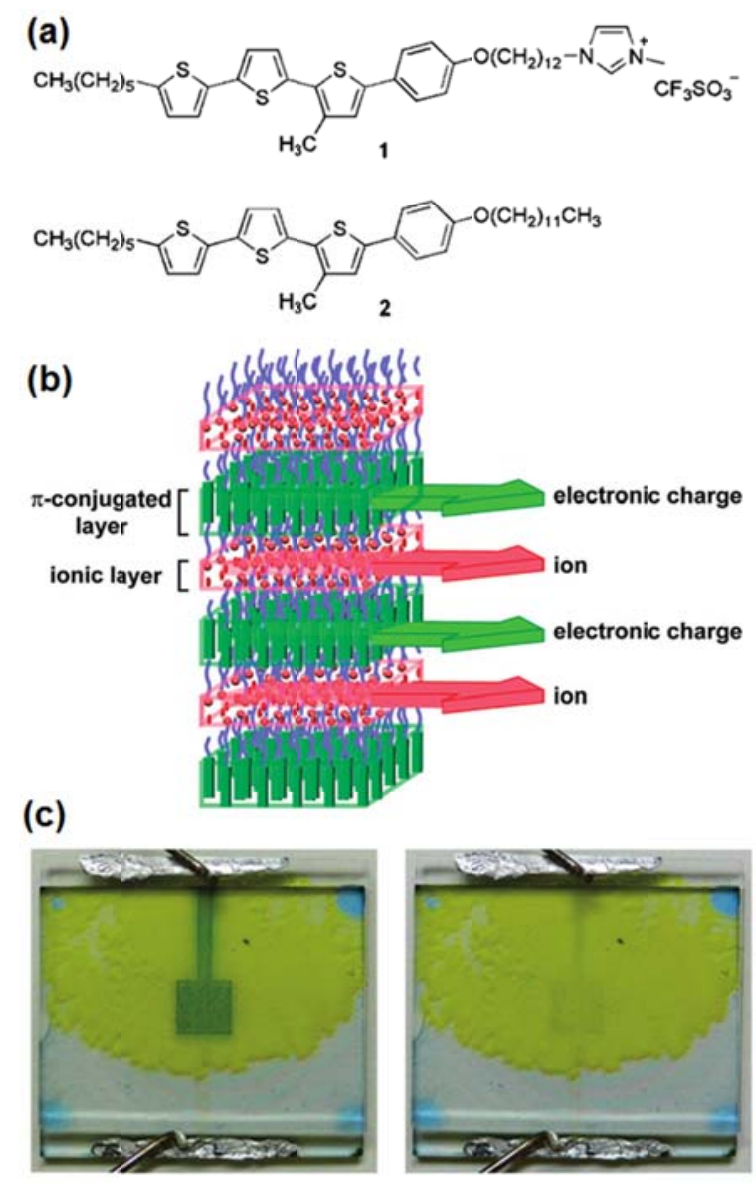

Figure 10. (a) Molecular structures of terthiophene-based electrochromic ILC 1 consisting of ionic and $\pi$-conjugated moieties and reference compound without an ionic moiety 2. Reproduced with permission.[117] Copyright 2008, American Chemical Society. (b) Schematic illustration of a nanostructured smectic liquid crystal phase for coupling of the ionic and electronic functions. (c) Photographs of the cell for compound 1 in the smectic A phase at $120^{\circ} \mathrm{C}$ at an applied potential of $2 \mathrm{~V}$ (left) and $0 \mathrm{~V}$ (right); a poly(3,4-ethylenedioxythiophene)-polystyrene sulfonate layer was chosen as an electron acceptor on the cathode. Reproduced with permission.[118] Copyright 2010, American Chemical Society. 


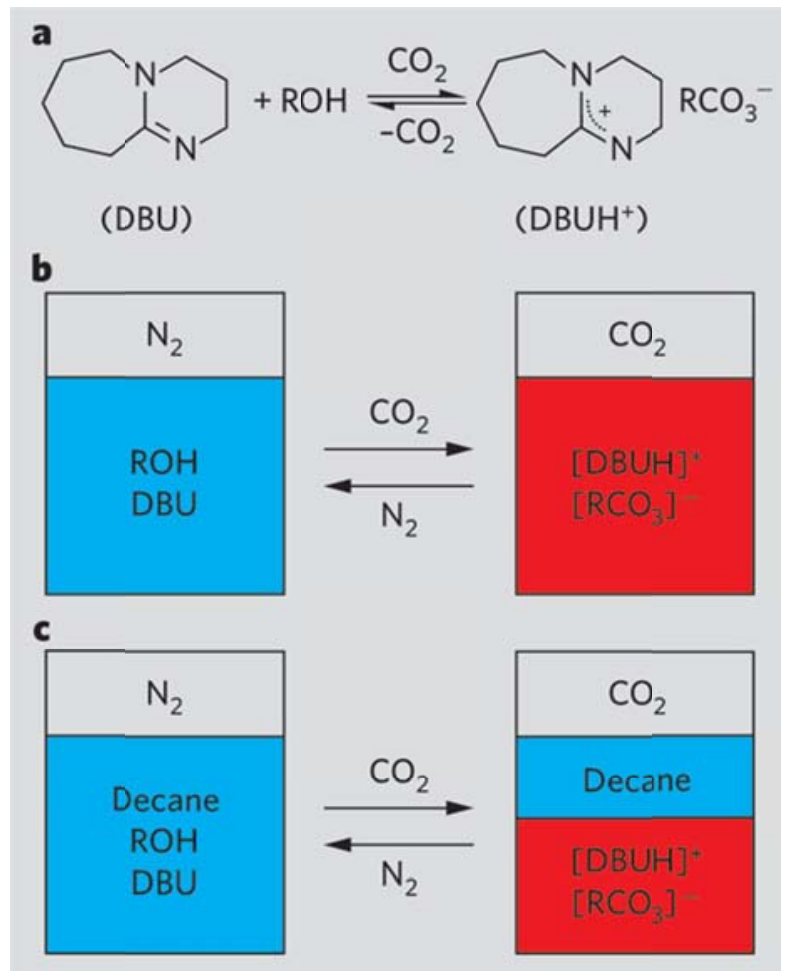

Figure 11. (a) Switching of a switchable IL system by bubbling $\mathrm{CO}_{2}$ or $\mathrm{N}_{2}$ and (b, c) its polarity change illustrated by the miscibility of decane. Reproduced with permission.[121] Copyright 2005, Nature Publishing Group. 
(a)
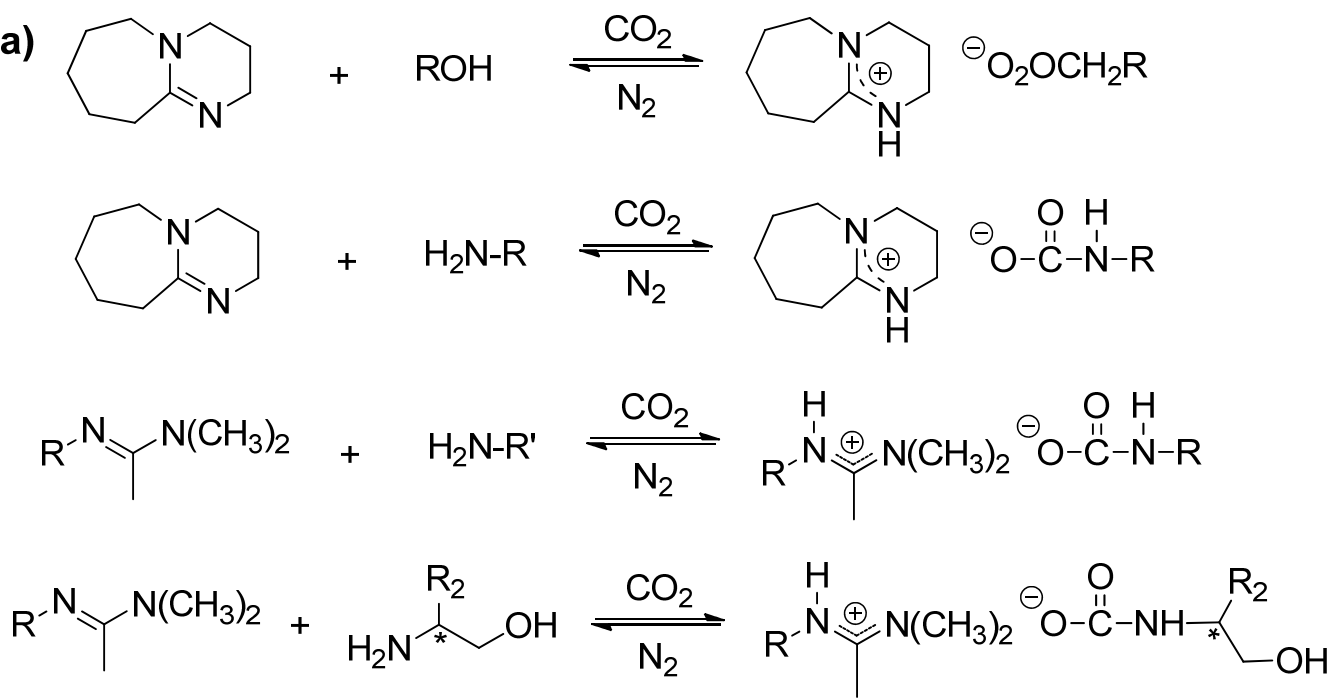

(b)

$$
\mathrm{NHR}_{2} \quad \frac{\mathrm{CO}_{2}}{\mathrm{~N}_{2}} \quad \mathrm{R}_{2} \mathrm{NH}_{2}^{\oplus} \ominus^{\ominus} \mathrm{O}_{2} \mathrm{NR}_{2}
$$
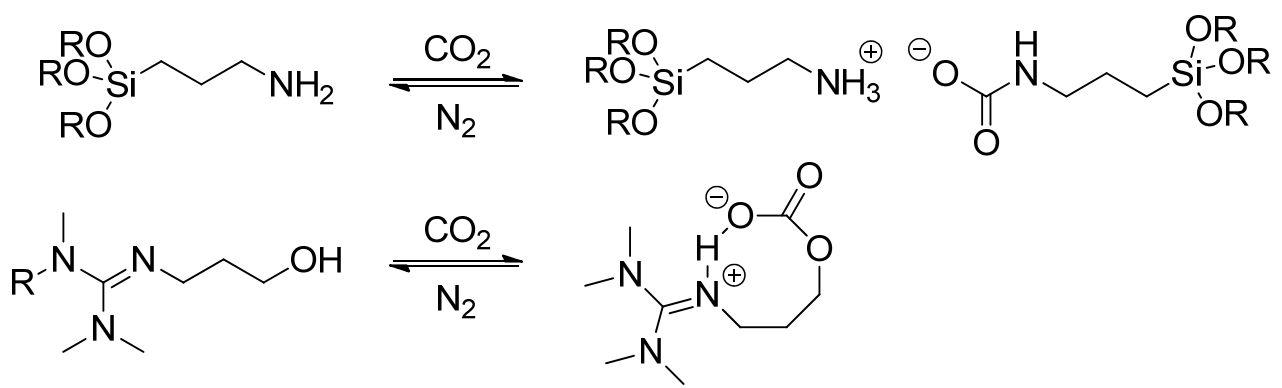

Figure 12. Switchable ILs based on (d) two-component or (e) one-component systems. 

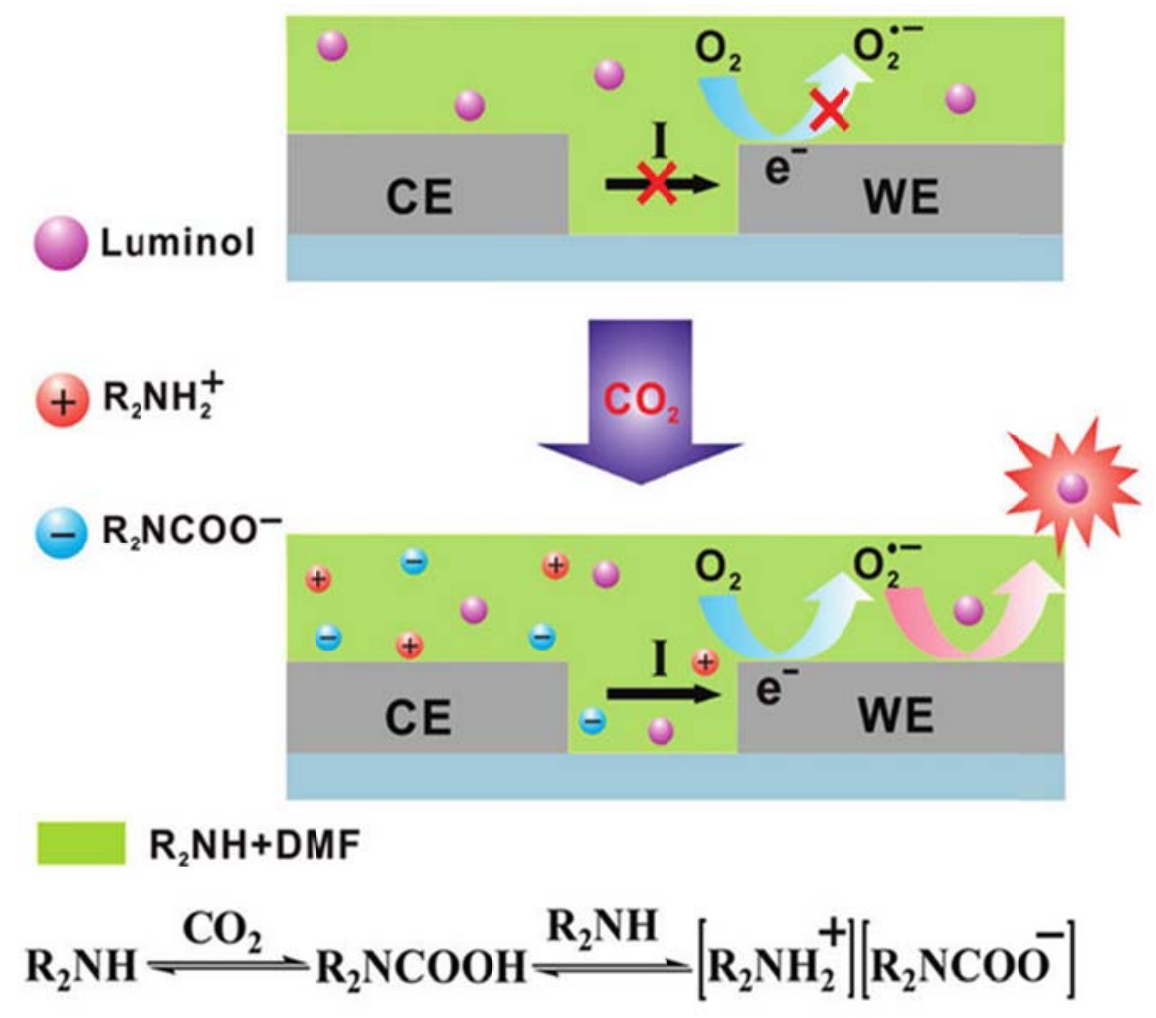

CIL

Figure 13. Principle of $\mathrm{CO}_{2}$ sensor based on switchable IL-induced ECL. Reproduced with permission.[63] Copyright 2011, American Chemical Society. 


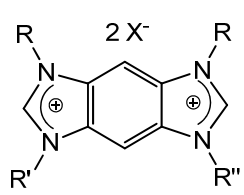

(a)

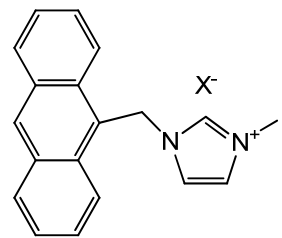

(b)

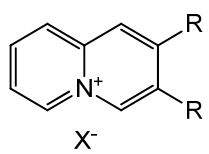

(c)

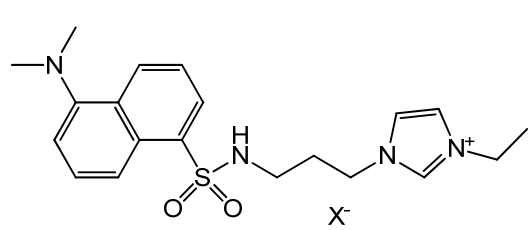

(d)

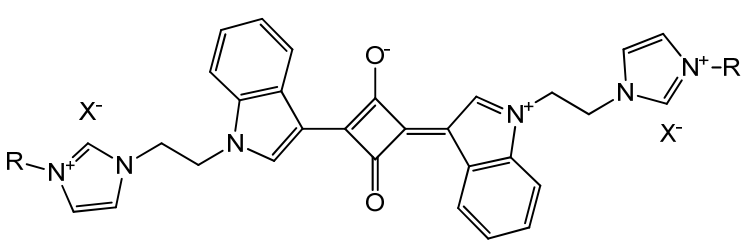

(f)

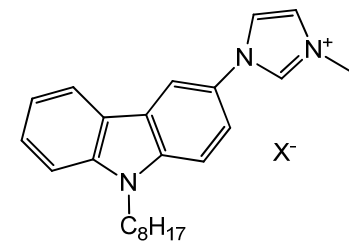

(e)

Figure 14. Structures of typical luminescent ILs bearing organic chromophores [a: benzobis(imidazolium), b: anthracene, c: dansyl, d: quinolizinium, e: carbazole, f: squaraine, and g: salicylate]. 

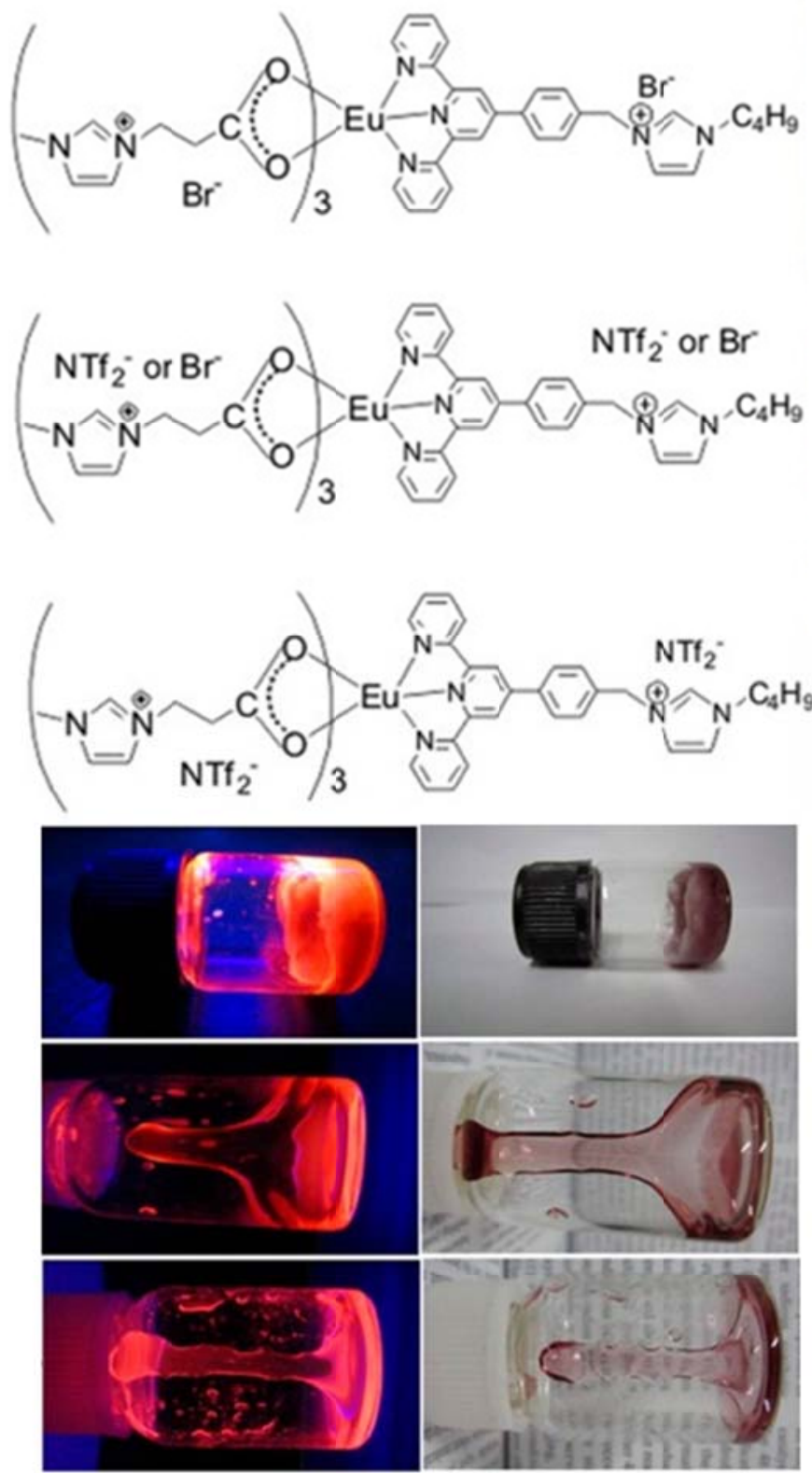

Figure 15. Molecular structures and bright red emission of ILs containing $\mathrm{Eu}^{3+}$ complex. Reproduced with permission.[167] Copyright 2013, American Chemical Society. 

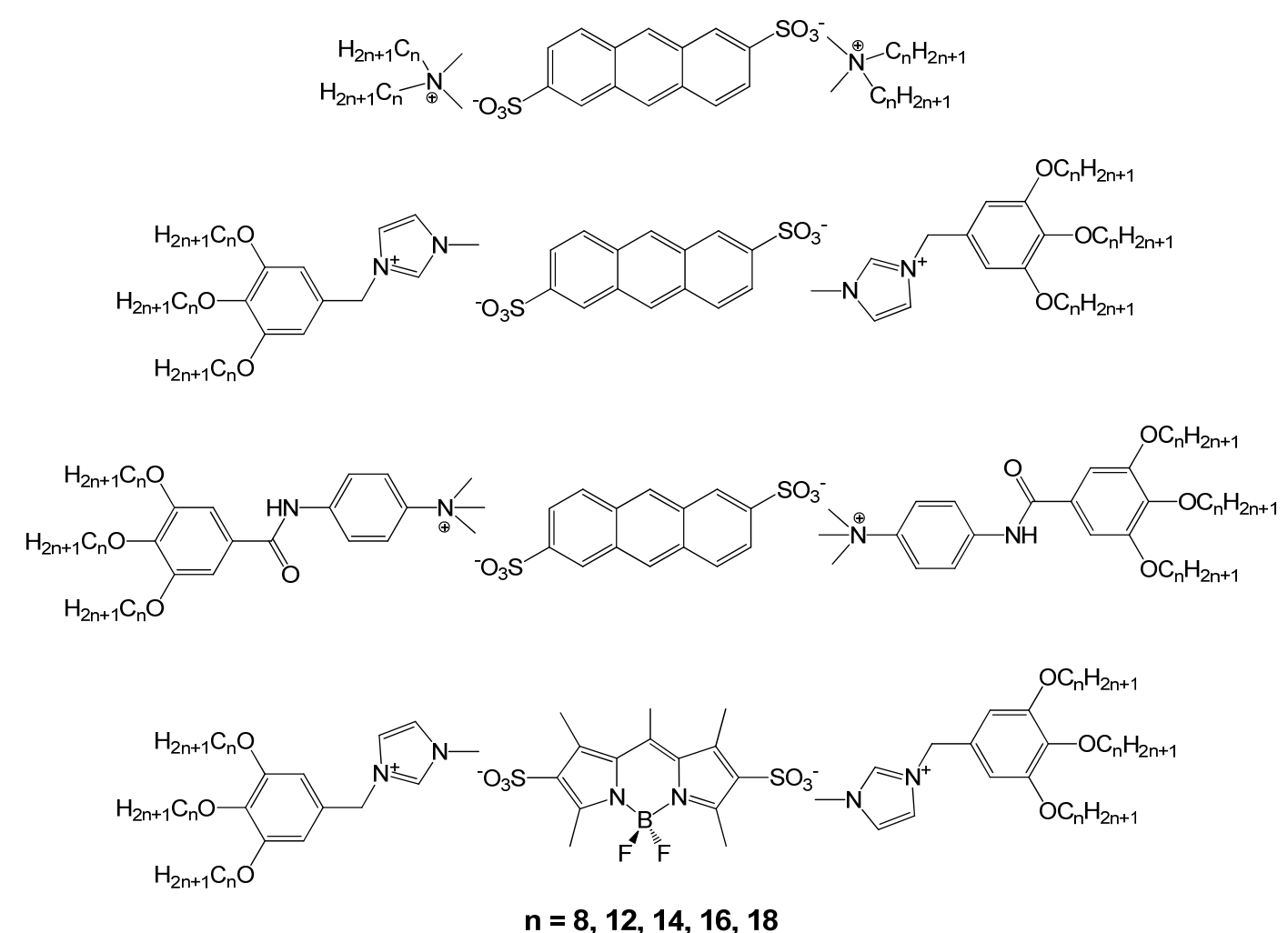

Figure 16. Structure of luminescent ILCs obtained by the ionic self-assembly process. 


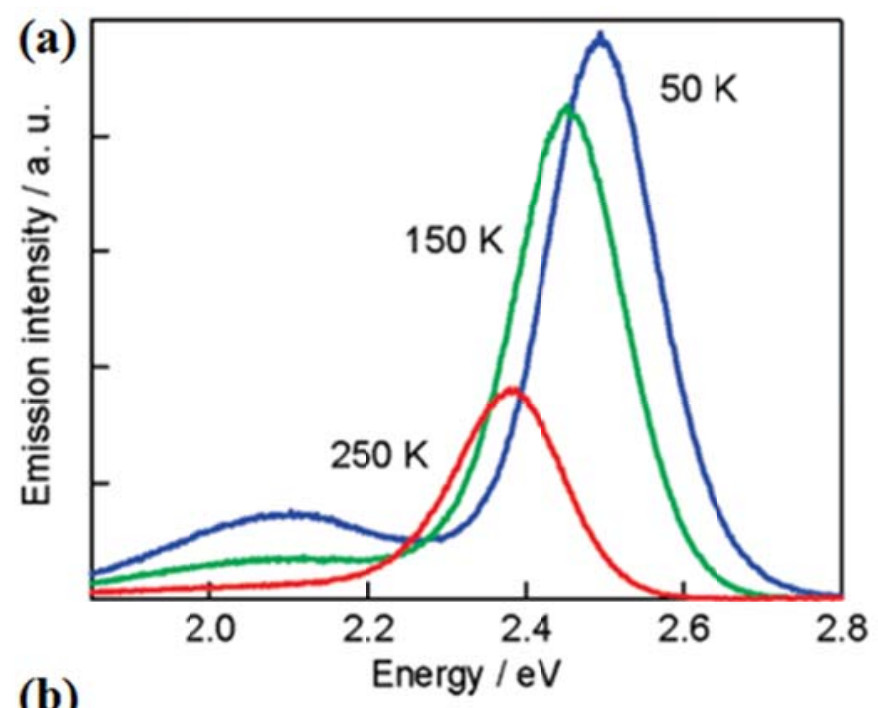

(b)

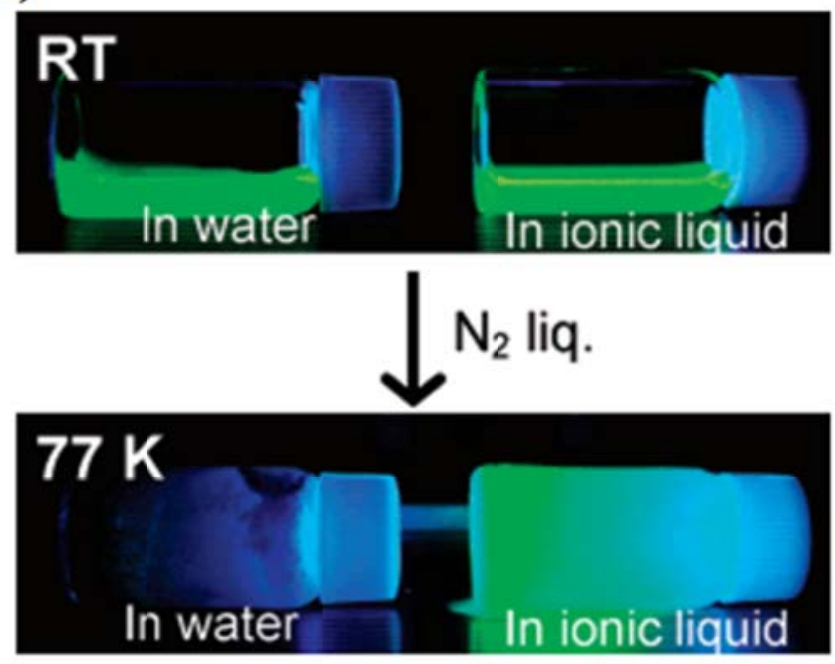

Figure 17. (a) Temperature-dependent emission spectra of CdTe in $[\mathrm{BMIm}]\left[\mathrm{NTf}_{2}\right]$ and (b) cooling effect on the emission of CdTe in water and $[\mathrm{BMIm}]\left[\mathrm{NTf}_{2}\right]$. Reproduced with permission.[202] Copyright 2007, American Chemical Society. 


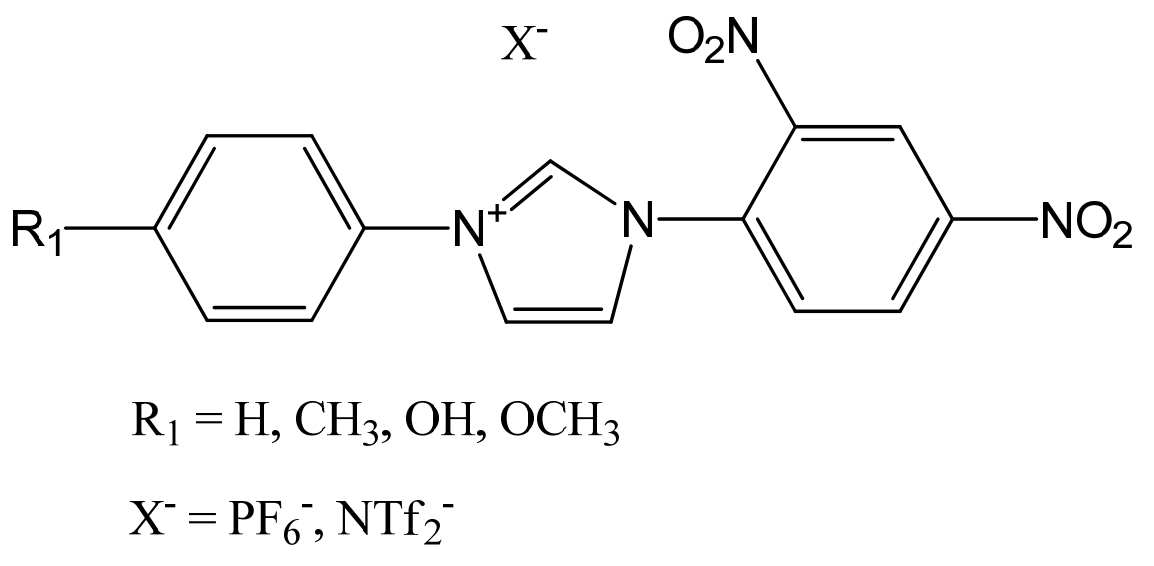

Figure 18. Molecular structures of ILs with second-order NLO response. 


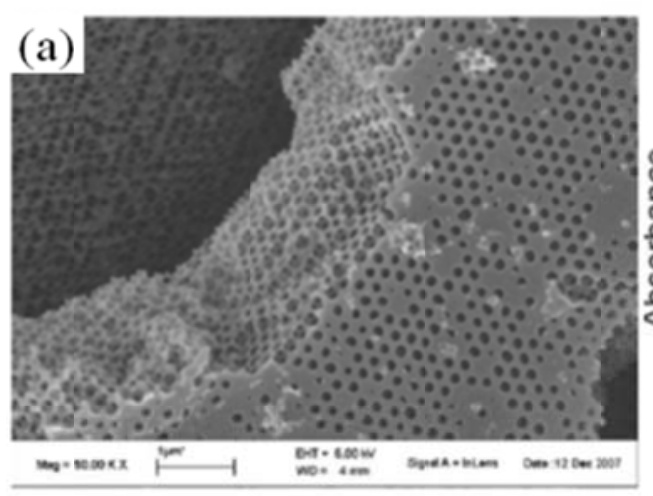

(b)

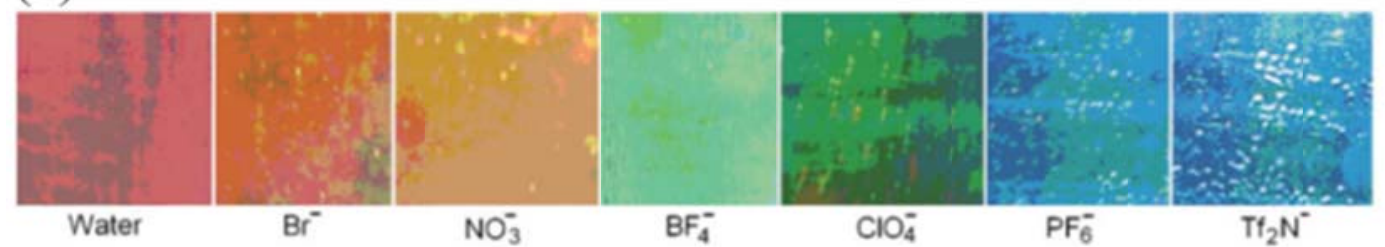

Figure 19. (a) Scanning electron microscopy images of PIL film prepared using ordered silica colloidal crystal template. (b) Stop-band shifts and (c) induced color changes of the PIL film upon soaking in various $0.02 \mathrm{M}$ anion aqueous solutions. Reproduced with permission.[68] Copyright 2008, Wiley. 
(a)

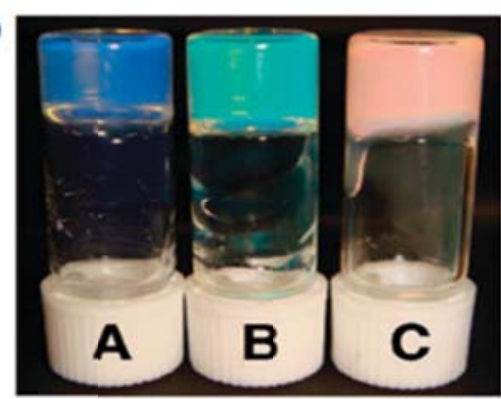

(b)

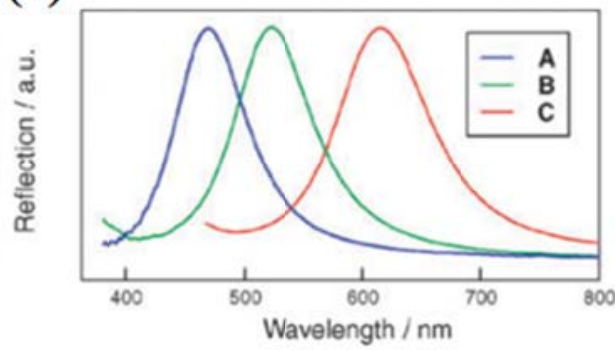

(c)
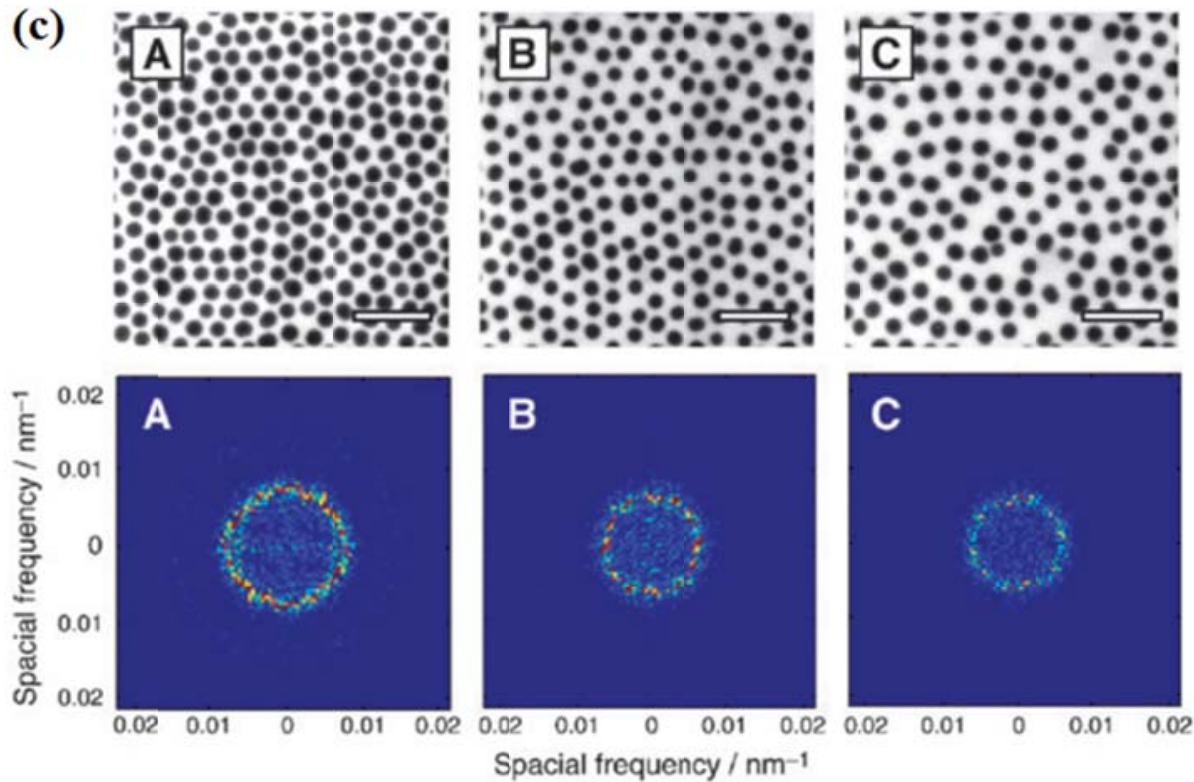

Figure 20. (a) Photograph and (b) reflection spectra of [EMIm][NTf 2$]$-based SGCAs with different particle concentrations $(\mathrm{A}=33.3, \mathrm{~B}=25.0, \mathrm{C}=14.3)$. (c) TEM images (top) and corresponding 2D Fourier power spectra (bottom) of SGCAs. Scale bar is 500 nm. Reproduced with permission.[229] Copyright 2009, Royal Society of Chemistry. 
(a)
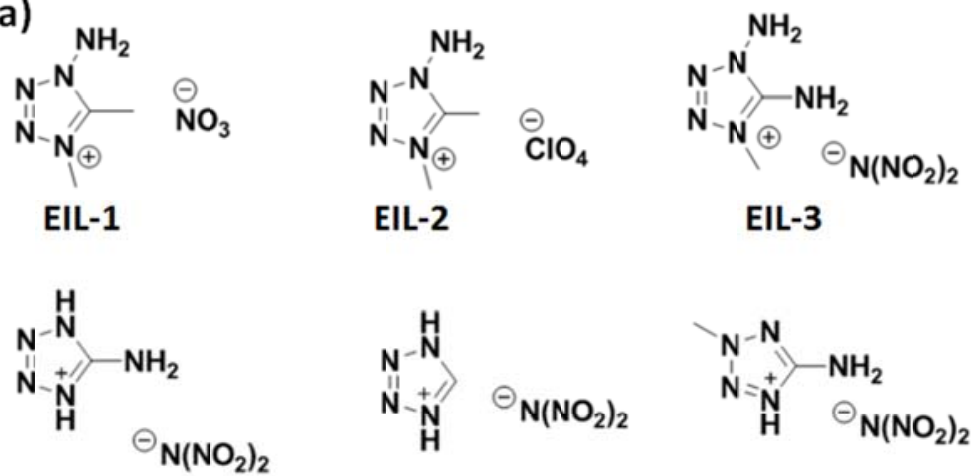

\section{EIL-4 EIL-5 EIL-6}

(b)
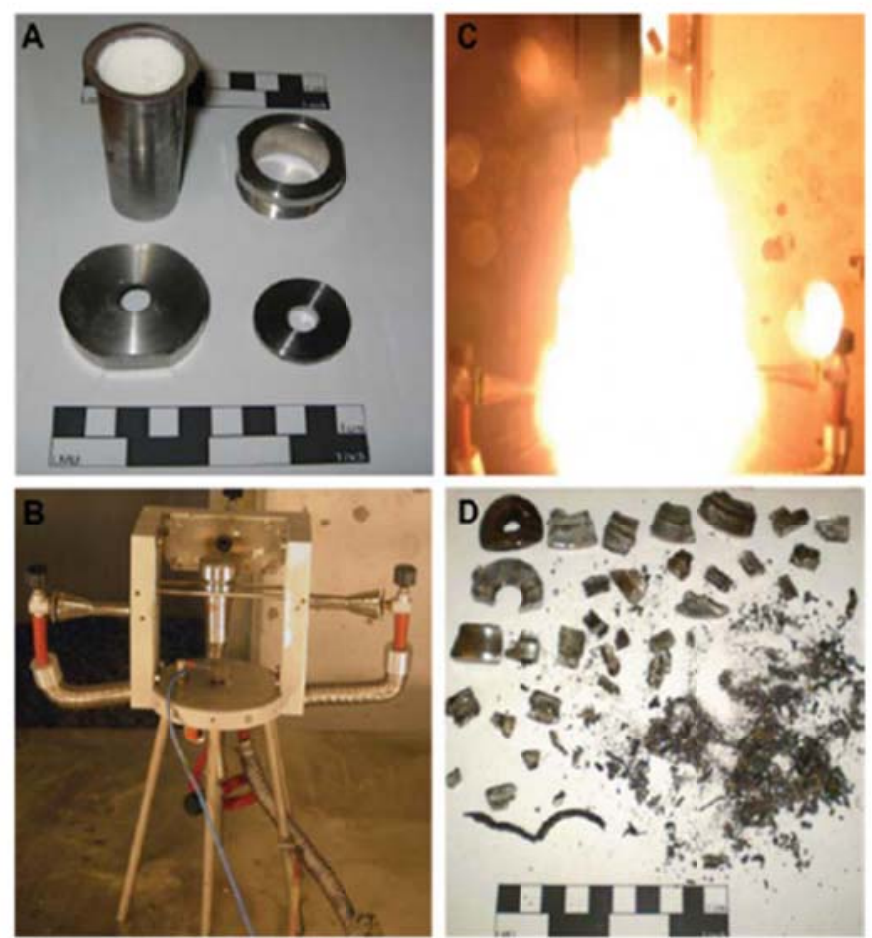

Figure 21. (a) Six typical tetrazolium-based EILs. b) Pictures of EIL-4 in the Koenen test: (A) steel sleeve loaded with $25 \mathrm{~mL}$ of explosive; (B) Koenen test setup showing the four Bunsen burners; (C) moment of explosion (0.25 ms) of EIL-4; (D) collected fragments. 


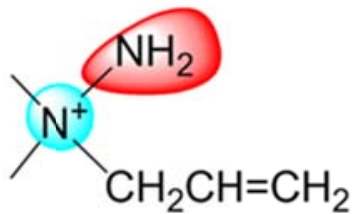

$-\mathrm{BH}_{2}(\mathrm{CN})_{2}$

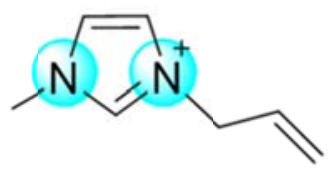

$$
\mathrm{BH}_{4}{ }^{-}
$$

EIL-8

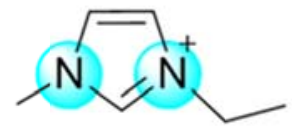

$\mathrm{BH}_{3} \mathrm{CN}^{-}$

EIL-9

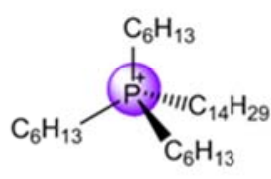

\section{EIL-10}

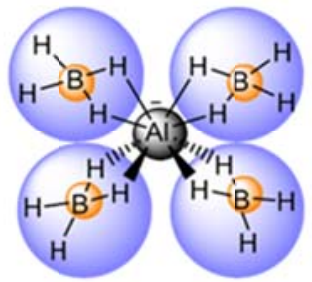

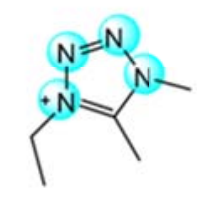

EIL-11

Figure 22. Structures of EILs based on B-H-bond-rich anions (EIL-7, 8, 9) and aluminum complex anions (EIL-10: trihexyltetradecylphosphonium tetraborohydroaluminate;

EIL-11: 1-ethyl-4,5-dimethyltetrazolium tetranitratoaluminate). 

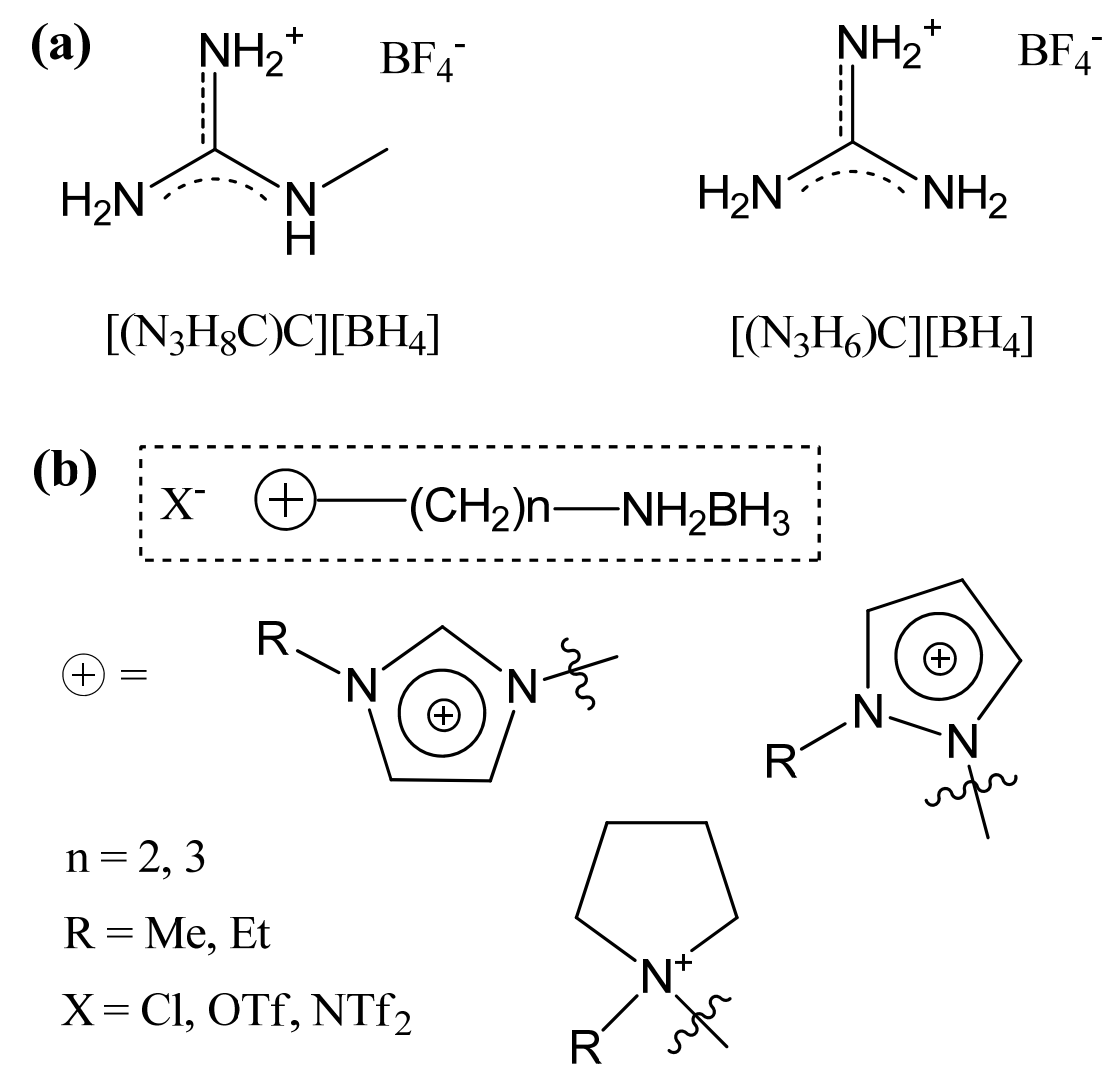

Figure 23. Molecular structures of hydrogen-storage ILs. 


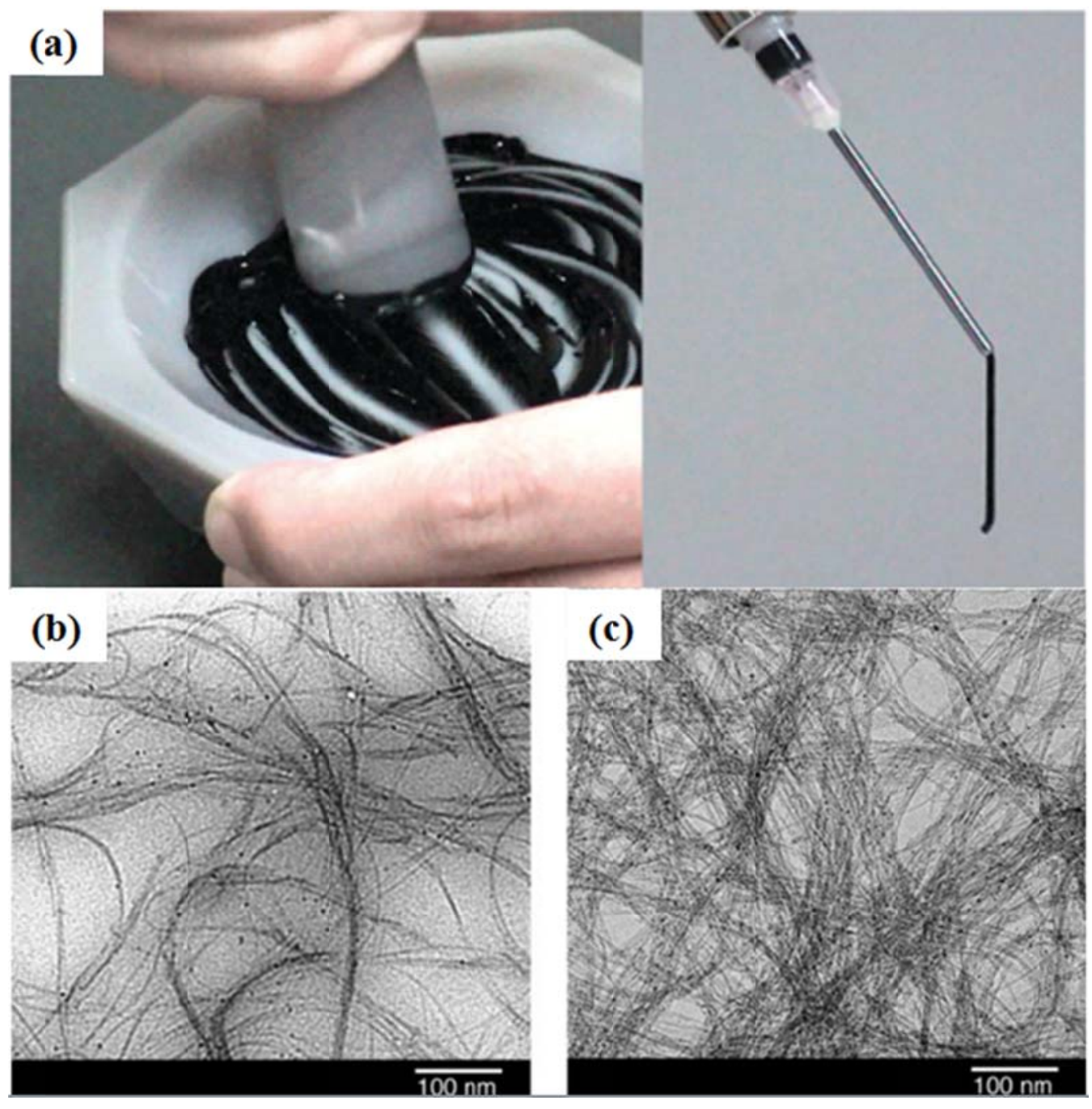

Figure 24. (a) Pictures of a bucky gel prepared by grinding a suspension of SWCNTs in [BMIm] $\left[\mathrm{BF}_{4}\right]$. TEM image of (b) SWCNTs obtained by dispersing bucky gel in deionized water and (c) as-received SWCNTs as a reference, after sonication in ethanol. Reproduced with permission.[267] Copyright 2003, AAAS. 

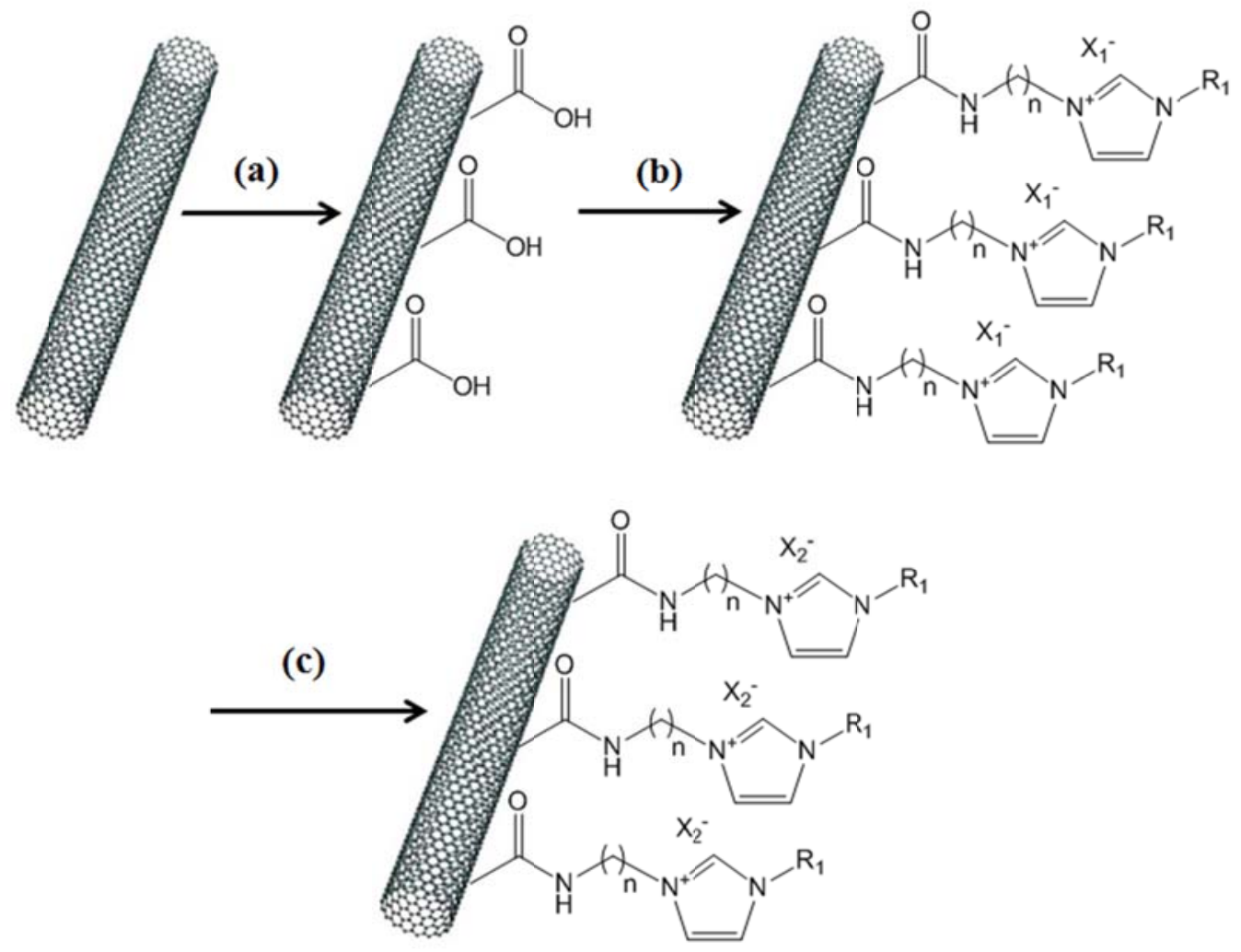

Figure 25. Schematic depiction of chemical modification of CNTs by ILs: (a) Chemical oxidation of CNTs. (b) Covalent modification of CNTs using an IL backbone. (c) Anionic exchange. 